Victor Barros Couri

\title{
Análises e perspectivas de estudos empíricos em Collaborative Planning, Forecasting and Replenishment (CPFR)
}

Dissertação de Mestrado

Dissertação apresentada ao Programa de Pós-graduação em Engenharia de Produção da PUC-Rio como requisito parcial para obtenção do grau de Mestre em Engenharia de Produção.

Orientador: Prof. Luiz Felipe Roris Rodriguez Scavarda do Carmo Coorientador: Prof. Ing. Bernd Hellingrath 


\title{
Victor Barros Couri
}

\section{Análises e perspectivas de estudos empíricos em Collaborative Planning, Forecasting and Replenishment (CPFR)}

Dissertação apresentada como requisito parcial para obtenção do grau de Mestre pelo Programa de Pós-Graduação em Engenharia de Produção da PUC-Rio. Aprovada pela Comissão Examinadora abaixo assinada.

\author{
Prof. Luiz Felipe Roris Rodriguez Scavarda do Carmo \\ Orientador \\ Departamento de Engenharia Industrial - PUC-Rio
}

Prof. Antonio Márcio Tavares Thomé

Departamento de Engenharia Industrial - PUC-Rio

Prof. Fernando Luiz Cyrino Oliveira

Departamento de Engenharia Industrial - PUC-Rio

\section{Prof. Márcio da Silveira Carvalho \\ Coordenador Setorial do Centro \\ Técnico Científico - PUC-Rio}

Rio de Janeiro, 06 de setembro de 2017 
Todos os direitos reservados. É proibida a reprodução total ou parcial do trabalho sem autorização da universidade, da autora e do orientador.

\section{Victor Barros Couri}

Graduou-se em Engenharia de Produção na Faculdade Machado Sobrinho (FMS) em Juiz de Fora-MG no ano de 2014. Participou ativamente de projetos de extensão em diversas organizações industriais, tais como: Mercedes Benz do Brasil, Malharia Pinguim, Fábrica de Tecidos São João Evangelista e ArcelorMittal.

Ficha Catalográfica

Couri, Victor Barros

Análises e perspectivas de estudos empíricos em Collaborative Planning, Forecasting and Replenishment (CPFR) / Victor Barros Couri; orientador: Luiz Felipe Roris Rodriguez Scavarda do Carmo; co-orientador: Bernd Hellingrath. - 2017.

93 f.: il. (color) ; $30 \mathrm{~cm}$

Dissertação (mestrado) - Pontifícia Universidade Católica do Rio de Janeiro, Departamento de Engenharia Industrial, 2017.

Inclui bibliografia

1. Engenharia industrial - Teses. 2. Revisão Sistemática da Literatura 3. Colaboração 4. Cadeia de suprimentos 5. Integração 6. Logística. I, Carmo, Luiz Felipe Roris Rodriguez Scavarda do. II. Hellingrath, Bernd. III. Pontifícia Universidade Católica do Rio de Janeiro. Departamento de Engenharia Industrial. IV. Título. 
Dedico este trabalho aos meus pais, principais responsáveis pela minha educação e sempre incentivadores nos momentos difíceis. 


\section{Agradecimentos}

Ao meu orientador Luiz Felipe Roris Rodriguez Scavarda do Carmo pelo apoio e confiança depositada. Gostaria de expressar minha gratidão ao meu coorientador Bernd Hellingrath por suas ideias e tempo valioso para me auxiliar neste trabalho. E também, gostaria de agradecer os ensinamentos e suporte por parte dos professores Márcio Thomé e Fernando Luiz Cyrino Oliveira.

A todos os professores, funcionários e colegas do Departamento que me acrescentaram conhecimento e vivência, me proporcionando momentos muito importantes para a minha formação intelectual e profissional.

Gostaria de agradecer a PUC e a CAPES por toda ajuda para a realização deste trabalho.

A minha namorada Alice, ao meu irmão Igor e a todos os meus amigos e familiares, por tudo que representam na minha vida que, de uma forma ou de outra, me estimularam ou me ajudaram. 


\section{Resumo}

Couri, Victor Barros; Carmo, Luiz Felipe Roris Rodriguez Scavarda do; Hellingrath, Bernd. Análises e perspectivas de estudos empíricos em Collaborative Planning, Forecasting and Replenishment (CPFR). Rio de Janeiro, 2017. 93p. Dissertação de Mestrado - Departamento de Engenharia Industrial, Pontifícia Universidade Católica do Rio de Janeiro.

A prática do Planejamento, Previsão e Reabastecimento Colaborativo (em inglês, Collaborative Planning, Forecasting and Replenishment - CPFR) é um tema recente de integração de cadeias de suprimento que tem sido amplamente abordado na literatura acadêmica. O CPFR é considerado, para muitos pesquisadores, uma iniciativa mais completa e avançada que outros métodos de colaboração na cadeia, sendo, em alguns casos, uma extensão ou aprimoramento dos mesmos. O amadurecimento do tema é representado pela existência de revisões sistemáticas na literatura. Contudo, por ser o CPFR ainda um tema recente com acentuado crescimento de estudos na literatura, esta dissertação tem como objetivo realizar uma atualização destas revisões sistemáticas para verificar novos avanços no assunto, se lacunas ressaltadas já foram pelo menos parcialmente endereçadas e se tendências estão se consolidando. Mais ainda, em função da dificuldade de se implementar o CPFR na prática, um enfoque maior na análise dos estudos empíricos existentes com o objetivo de ir além de resultados parciais e particulares oferecidos na literatura é contemplado nesta dissertação, expandindo assim o escopo das revisões existentes com o foco específico em estudos empíricos. A dissertação apresenta seus resultados guiados em um framework de síntese para integração de cadeias focado em CPFR, tendo como base os passos para a condução de uma pesquisa empírica em gerência de operações, os blocos conceituais do CPFR e a contribuição dos estudos empíricos. Uma agenda para pesquisas futuras finaliza a dissertação.

\section{Palavras-chave}

Revisão Sistemática da Literatura; colaboração; cadeia de suprimentos; integração; logística; gerência de operações 


\section{Abstract}

Couri, Victor Barros; Carmo, Luiz Felipe Roris Rodriguez Scavarda do (advisor); Hellingrath, Bernd. Analysis and perspectives from empirical studies in Collaborative Planning, Forecasting and Replenishment (CPFR). Rio de Janeiro, 2017. 93p. Dissertação de Mestrado Acadêmico Departamento de Engenharia Industrial, Pontifícia Universidade Católica do Rio de Janeiro.

The practice of Collaborative Planning, Forecasting and Replenishment (CPFR) is a recent topic of supply chain integration that has been extensively covered in academic literature. The CPFR is considered by several researchers a more complete and advanced initiative than other methods of collaboration in the chain, being in some cases an extension or improvement of them. The maturation of the theme is represented by the existence of systematic reviews in the literature. However, since CPFR is still a recent topic with a strong growth of studies in the literature, this dissertation aims to carry out an update of these systematic reviews in order to verify new advances in the subject, if highlighted gaps have been at least partially addressed, and also if trends have been consolidating. Moreover, due to the difficulty of implementing CPFR in practice, a greater focus on the analysis of existing empirical studies with the objective of going beyond partial and particular results offered in the literature is contemplated in this dissertation, thus expanding the scope of the existing reviews with specific focus on empirical studies. The dissertation presents its results guided by a synthesis framework for supply chain integration focused on CPFR, based on the steps for conducting an empirical research in operations management, the conceptual building blocks for CPFR and the contribution of the empirical studies. An agenda for future research concludes the dissertation.

\section{Keywords}

Systematic literature review; collaboration; supply chain; integration; logistics; operations management 


\section{Sumário}

1 . Introdução

2. Referencial Teórico 15

2.1.Introdução ao CPFR 15

2.2. CPFR e outras iniciativas de práticas de integração da SC 18

2.3. A prática do CPFR na indústria 21

3 . Método de Pesquisa 24

3.1. O planejamento e formulação do problema 24

3.2. Pesquisar a literatura $\quad 25$

3.3. Coleta de Dados e avaliação da qualidade 27

3.4. Análise, síntese e interpretação dos dados 28

3.5. Apresentação dos resultados e atualização da revisão 30

4. Análise descritiva, metodológica e da contribuição dos estudos 32

4.1. Análise descritiva 32

4.1.1. Comparação entre as revisões sistemáticas da literatura em CPFR 32

4.1.2. Análise descritiva dos estudos empíricos selecionados $\quad 36$

4.2. Passos para condução das pesquisas empíricas 37

4.3. Contribuição dos estudos 40

5. Análise dos blocos conceituais do CPFR 46

5.1. Contexto 46

5.2. Inputs 49

5.3. Reuniões e colaboração 52

5.4. Organização 55

5.5. Tecnologia da informação e comunicação 57

5.6. Métricas 58

5.7. Outcomes e Resultados 62

6. Conclusões 68

7. Referências Bibliográficas $\quad 72$ 


\section{Lista de Figuras}

Figura 1 - Diagrama de fluxo do PRISMA 27

Figura 2 - Framework para o CPFR 29

Figura 3 - Framework de síntese para integração de SC focados em CPFR 30

Figura 4 - Linha do Tempo das publicações de estudos em CPFR 35 Figura 5 - Estudos empíricos em CPFR 36

Figura 6 - Estudos empíricos sobre total em CPFR 37

Figura 7 - Métodos de pesquisa aplicados nos estudos empíricos em CPFR 


\section{Lista de Tabelas}

Tabela 1 - Resultados das Revisões Sistemáticas da Literatura em CPFR

Tabela 2 - Fundamentos teóricos e metodologia de pesquisa aplicados

Tabela 3 - Regiões e países de implementações em CPFR

Tabela 4 - Inputs em CPFR

Tabela 5 - Participantes entre empresas do projeto CPFR

Tabela 6 - Métricas em CPFR

60

Tabela 7 - Outcomes em CPFR

64

Tabela 8 - Resultados em CPFR

66

Tabela 9 - Estudos empíricos em CPFR

80 


\section{Lista de Abreviaturas e Siglas}

CPFR - Collaborative Planning, Forecasting and Replenishment

$\mathrm{CR}$ - Continuous Replenishment

ECR - Efficient Consumer Response

EDI - Electronic Data Interchange

IBP - Integrated Business Planning

ID \& SS - Industry Directions \& Syncra Systems

MRT - Middle Range Theories

MTO - Make-to-Order

MTS - Make-to-Stock

POS - Point of Sales

QR - Quick Response

RBV - Resource based view

RDT - Resource dependent theory

RR - Regular Replenishment

S\&OP - Sales and Operations Planning

SC - Supply Chain

SCM - Supply Chain Management

SCC - Supply Chain Collaboration

SKU - Stock Keeping Unit

TI - Tecnologia da Informação

TIC - Tecnologia da informação e comunicação

VICS - Voluntary Interindustry Commerce Standard

VMI - Vendor-Managed Inventory 


\section{Introdução}

Nas últimas décadas tem se observado um aumento da competitividade não apenas em empresas isoladamente, mas também em um contexto caracterizado por competição baseado em cadeia de suprimentos (em inglês, Supply Chain $\mathrm{SC}$ ), onde a forma com que estas empresas se relacionam com os fornecedores e clientes de suas cadeias vai gerar (ou não) vantagem competitiva (Pires, 2009). Como um reflexo a esta nova realidade de competição, a colaboração na gestão da cadeia de suprimentos (em inglês, Supply Chain Management - SCM) vem sendo perseguida por organizações de forma a melhorar o desempenho de toda a cadeia (Gomes e Kliemann Neto, 2015). Na literatura, a colaboração na SC é descrita como um processo que promove cooperação interorganizacional, trabalho conjunto, abertura, criação de rotinas de tomada de decisão entre empresas, compartilhamento de informações, conhecimento e maior intimidade entre clientefornecedor (Mentzer et al., 2001; Danese, 2011). Alguns autores associam este conceito com o termo integração na SC, que significa o controle unificado de uma série de processos sucessivos anteriormente exercida de modo independente (Flynn et al., 2010). Isto significa dizer que as empresas devem se comportar como parte de um sistema unificado e coordenar-se umas com as outras em direção a objetivos comuns (Mentzer et al., 2001; Danese, 2011).

Iniciativas colaborativas na cadeia de suprimentos têm sido criadas com o objetivo de melhorar o desempenho da SC para obter vantagens competitivas. Entre essas iniciativas, destaca-se o Planejamento, Previsão e Reabastecimento Colaborativo (em inglês, Collaborative Planning, Forecasting and Replenishment CPFR), que para muitos pesquisadores, é identificado como o método colaborativo mais completo e avançado, sendo uma extensão de outras iniciativas colaborativas na SC (Barrat e Oliveira, 2001; Skjoett-Larsen et al., 2003; Du et al., 2009; VICS, 2010; Danese, 2011; Ramanathan e Gunasekaran, 2014).

CPFR é definido como uma prática de negócios entre membros da SC que combina a inteligência colaborativa de múltiplos parceiros comerciais no planejamento e no atendimento da demanda do cliente, de acordo com uma estrutura 
pré-especificada (VICS, 2010; Panahifar et al., 2015b). O CPFR aumenta a visibilidade da demanda do cliente e combina a oferta e a demanda com um fluxo sincronizado de bens da produção e entrega de matérias-primas para a produção e entrega do produto final ao consumidor final. O modelo abrange diferentes processos de negócio que são subdivididos em etapas ou tarefas específicas (ECR Europe, 2001; Skjoett-Larsen et al., 2003; Seifert, 2003; Simatupang e Sridharan, 2005; D’Aubeterre et al., 2008; Chang e Wang, 2008; Danese, 2011; Hollmann et al., 2015).

A literatura acadêmica sobre CPFR cresceu significativamente. Contudo, os esforços para sintetizar o estado da arte da investigação são recentes. Quatro revisões sistemáticas da literatura em CPFR buscaram integrar resultados de estudos e pesquisas relacionados ao tema. Kubde e Bansod (2010) focam nas atividades de planejamento colaborativo e introduzem o CPFR como uma técnica que pode cobrir todas as áreas funcionais das empresas. Thomé et al. (2014) fornecem uma síntese da literatura com o objetivo de reunir os achados de CPFR como um processo de negócios e como uma prática de gestão, além de integrar evidências quantitativas de seu impacto no desempenho da cadeia de suprimentos. Hollmann et al. (2015) enfatizam os fatores de implementação e modelos de CPFR, bem como o impacto do CPFR e de outras iniciativas de colaboração sobre o desempenho da cadeia de suprimentos. Panahifar et al. (2015a) propõem uma estrutura para conduzir uma revisão abrangente da literatura em CPFR de forma a revisar o posicionamento atual do CPFR em uma perspectiva de escopo e valor, além de identificar áreas de preocupação para o CPFR no futuro e propor diretrizes para pesquisas e práticas futuras. Apesar de recentes, estas revisões se basearam em artigos publicados até março de 2014 e, por ser o CPFR ainda um tema jovem com acentuado crescimento recente de estudos na literatura, o oitavo passo de Thomé et al. (2016a) de atualização da revisão pode ser aplicado para verificar novos avanços no assunto, se lacunas ressaltadas em revisões anteriores já foram pelo menos parcialmente endereçadas e se tendências estão se consolidando. Mais ainda, em função das dificuldades de implementar o CPFR na indústria e de obtenção dos benefícios previstos na prática (Småros, 2003; Småros, 2007; Büyüközkan and Vardaloglu, 2012; Hollmann et al., 2015; Panahifar et al., 2015a), um enfoque maior na análise dos estudos empíricos existentes com o objetivo de ir além de resultados parciais e particulares oferecidos na literatura faz- 
se necessária. Nenhuma das revisões anteriormente mencionadas se concentra exclusivamente na condução de estudos empíricos em CPFR, como o escopo desta dissertação. A dissertação segue Flynn et al. (1990), definindo estudo empírico como conhecimento obtido em observações ou experiência do mundo real e é usado para descrever a pesquisa de campo que utiliza dados coletados de situações ou experiências naturais.

Com base neste contexto e com o intuito de fornecer informações importantes relacionadas ao uso do CPFR na indústria, três grupos de perguntas de pesquisa são feitas para guiar o presente estudo:

1) O ritmo de crescimento da literatura sobre CPFR tem sido constante, reforçando o fato de ser um tópico com forte apelo para estudos por parte de acadêmicos e praticantes da indústria?

2) Quais são os fundamentos teóricos e métodos de pesquisa mais comuns nesses estudos empíricos? Qual a força da evidência desses estudos?

3) Quais aspectos do CPFR foram examinados nos estudos empíricos? Quais são as principais barreiras e facilitadores para sua implementação? Onde estão as lacunas atuais associadas a implementação do CPFR, bem como as tendências?

Neste contexto, essa dissertação tem como objetivo atualizar as recentes revisões sistemáticas na literatura realizadas em CPFR, focando em estudos empíricos. Além de buscar uma atualização, a abrangência das bases de dados utilizadas nesta pesquisa é maior, buscando assim um maior alcance de estudos publicados em CPFR.

Esta dissertação está estruturada em cinco capítulos, sendo esse primeiro o introdutório. O segundo capítulo apresenta os fundamentos teóricos associados à pesquisa. Em seguida, o estudo descreve o método de pesquisa utilizado tendo como base os oitos passos fornecido em Thomé et al. (2016a). O Capítulo 4 apresenta as análises dos resultados obtidos com a revisão sistemática da literatura. Por fim, o último capítulo oferece as conclusões do autor referente a pesquisa, assim como suas sugestões para pesquisas futuras. 


\section{Referencial Teórico}

Este capítulo apresenta o referencial teórico para a condução da pesquisa focando inicialmente em uma introdução ao conceito de CPFR para depois discursar sobre sua relação com outras práticas de integração na SC e finalmente apresentar a visão da literatura sobre o seu uso na indústria.

\subsection{Introdução ao CPFR}

CPFR é um processo de colaboração em que duas ou mais partes na cadeia de suprimentos planejam, em conjunto, uma série de atividades promocionais e elaboram previsões sincronizadas, com base nas quais são determinados os processos de produção e reabastecimento (Skjoett-Larsen et al., 2003; Danese, 2006; Wang e Xu, 2014). É uma iniciativa colaborativa que permite aos parceiros de negócios da SC compartilhar informações, previsões sincronizadas, riscos, custos e benefícios com a intenção de melhorar o desempenho global da SC por meio do planejamento e tomada de decisões conjuntas (Thomé et al., 2014; Hollmann et $a l ., 2015)$. A ideia do CPFR é que os parceiros da SC compartilhem informações como histórico de vendas, disponibilidade de produtos e prazos de entrega, a fim de melhorar a coordenação das atividades e eliminar o excesso de inventário (Lehoux et al., 2011).

O CPFR compreende os processos de planejamento, previsão e reposição colaborativos, que, por sua vez, são subdivididos em etapas ou tarefas específicas (VICS, 1998). O mesmo é estabelecido por um acordo entre parceiros de negócios para cooperar na estratégia, tática e execução por uma resolução de exceções (Derrouiche et al., 2008), eliminando assim a incerteza de oferta/demanda por meio de melhores comunicações/colaborações (Attaran e Attaran, 2007). O objetivo do CPFR é converter a cadeia de suprimentos de um sistema "puxado" desajustado, ineficaz e ineficiente para um sistema "puxado" coordenado, baseado na 
demanda do consumidor final (VICS, 2010). Portanto, o CPFR é um processo pelo qual os parceiros comerciais da SC trocam as previsões de vendas e ordens e depois corrigem, ajustam e propõem preços e quantidades para desenvolver uma previsão única (Caridi et al., 2005; 2006).

A importância do CPFR é equilibrar a oferta e a demanda entre os parceiros de negócios da SC, podendo resultar em: (i) melhoria no nível de serviço ao mesmo tempo em que reduz o inventário e os custos, (ii) estabelecer promoções de maior integração, visibilidade e cooperação entre os parceiros, (iii) e uma abordagem holística da SCM (Hollmann et al., 2015). Uma abordagem de gestão cooperativa que ajuda a melhorar as habilidades dos membros da cadeia de suprimentos a aumentar sua receita e lucro (Chang et al., 2007; Lin e Ho, 2014).

A introdução do modelo de CPFR pode aumentar a vantagem competitiva de uma empresa, reduzindo custos da falta de estoque, aumentar a precisão das previsões e melhorar a movimentação do estoque (Fu, 2016). Também permite obter ganhos potenciais que incluem tempos de ciclo de reposição reduzidos, taxas de preenchimento de pedidos mais elevadas, melhor atendimento ao cliente e menores custos de planejamento e implantação de produção para os fornecedores (Andraski e Haedicke, 2003). O CPFR pode ajudar a reduzir o "efeito chicote", onde oscilações da demanda cometidas no varejo da SC são amplificadas e os fornecedores observam uma demanda cada vez mais volátil, mais a montante da cadeia. Essa volatilidade faz com que os fornecedores que operam a montante da cadeia de suprimento mantenham níveis mais altos de estoque de segurança (Ji e Yang, 2005).

O CPFR ainda é um conceito novo com sua primeira aparição sendo atribuída ao ano de 1995 a partir de um projeto piloto entre o Wal-Mart e um de seus fornecedores, a Warner-Lambert, com o apoio da Benchmarking Partes, SAP e Manugistcs (Demiray et al., 2016). A iniciativa teve como principal objetivo a previsão de vendas e o reabastecimento dos estoques dos produtos da marca Listerine de maneira colaborativa. Os resultados apresentados em 1996 foram satisfatórios e o piloto foi um sucesso, contando com a redução de lead times, aumento de vendas e diminuição nos índices de ruptura dos produtos (Gomes e Kliemann Neto, 2015). Uma vez que a sua aplicação original foi iniciada, a prática do CPFR teve muitas aplicações bem-sucedidas na América do Norte, Europa e China (Wang e Xu, 2014). Alguns anos mais tarde, em 1998, o VICS desenvolveu um 
modelo de processo de nove passos como guia para implementação do CPFR (VICS, 1998).

O método foi denominado inicialmente de Collaborative Forecasting and Replenishment (CFAR), mas posteriormente foi renomeado como CPFR para enfatizar o papel do planejamento (Burnette, 2010). O modelo passou por atualizações em 2001, por meio do VICS, e, em 2004, o mesmo desenvolveu uma revisão mais abrangente, visando integrar inovações e superar os problemas identificados no projeto inicial.

Grande parte da pesquisa sobre CPFR é baseada no modelo de processo VICS (Barratt e Oliveira, 2001; Seifert, 2003; Danese, 2007; Hollmann et al., 2015). No entanto, apesar da existência de um modelo tão detalhado e abrangente, alguns autores afirmam que o CPFR pode assumir um número variado de formas por meio da SC (ECR Europa, 2001; Skjoett-Larsen et al., 2003; Danese, 2007; Panahifar et al., 2015a). Na literatura sobre colaboração na SC, o CPFR é classificado em três níveis. O primeiro nível é classificado como CPFR básico, o segundo nível é denominado de CPFR em desenvolvimento, e o último nível, CPFR avançado (ECR e Europa, 2002; Skjoett-Larsen et al., 2003; Danese, 2007; Ramanathan et al., 2012). Skjoett-Larsen et al. (2003) sustentam que o CPFR básico é frequentemente o ponto de partida para as outras iniciativas de colaboração. No nível CPFR básico, apenas uma relação de troca de dados simples entre os parceiros de negócios da cadeia é estabelecida. Já o CPFR em desenvolvimento, a demanda, o planejamento de ordem de compra, os dados promocionais e os dados de produção devem ser compartilhados. Já no nível mais avançado, parceiros da SC devem ter um compartilhamento das principais informações totalmente transparentes (Ramanathan et al., 2012).

Nos anos seguintes a 1998, vários autores colocaram suas próprias definições em CPFR, mas quase todos podem ser rastreados até derivações do original. O que é claro a partir das definições é que CPFR destina-se como uma plataforma comum, é multipartidário e é uma tentativa de coordenar em direção ao nível mais avançado de colaboração. O que é essencial para cada uma dessas atividades é o compartilhamento de informações e se executado adequadamente tem o potencial de permitir benefícios de desempenho significativo em toda a SC (Aviv, 2002; Hollmann, 2014; Panahifar et al., 2015b). 
Além do CPFR, outras formas específicas de implementação de parcerias emergiram como iniciativas de colaboração na cadeia de suprimentos nas últimas décadas, como exemplo: Estoque Gerenciado pelo Fornecedor (em inglês, Vendor-Managed Inventory - VMI), Resposta Eficiente ao Consumidor (em inglês, Efficient Consumer Response - ECR), Reabastecimento Contínuo (em inglês, Continuous Replenishment - CR), entre outras (Mentzer et al., 2001; Barratt e Oliveira, 2001; Danese, 2006; Småros, 2007; Ramanathan e Gunasekaran, 2014; Holmann et al., 2015; Panahifar et al., 2015b). Estas práticas se caracterizam pela colaboração e pela troca intensiva de informações, baseando-se no pressuposto de que, por meio da visibilidade da demanda de clientes e fornecedores, é possível obter, de forma simultânea, reduções de estoque e melhorias dos níveis de serviço (Gomes, 2014). Estas práticas não são independentes, estando relacionadas e podendo ser utilizadas em conjunto. A próxima seção deste capítulo apresenta o CPFR visto em associação com outras práticas de integração da SC.

\subsection{CPFR e outras iniciativas de práticas de integração da SC}

Originalmente construído como um padrão interindustrial, o CPFR foi projetado para ir além das deficiências de outras iniciativas da SC, como Intercâmbio Eletrônico de Dados (em inglês, Electronic Data Interchange - EDI) e do ECR, incorporando a maioria das técnicas utilizadas para integrar parceiros SC sob as iniciativas do VMI e do CR (Stank et al., 1999; Barratt e Oliveira, 2001; SkjoettLarsen et al., 2003; Seifert, 2003; Cassivi et al., 2006; Attaran e Attaran, 2007; Danese, 2007; Danese, 2011; Panahifar et al., 2015b). O CPFR é visto por muitos acadêmicos como uma segunda geração do ECR (Stank et al., 1999; SkjoettLarsen et al., 2003; Ramanathan, 2014; Holmann et al., 2015). Muitos autores referem-se ao CPFR como uma evolução do VMI e CR (Barratt e Oliveira, 2001; Cassivi, 2006; Attaran e Attaran, 2007; Danese, 2011; Holmann et al., 2015).

O CPFR tem um enfoque mais abrangente do que as iniciativas anteriores da SC em relação ao planejamento de promoções, vendas e ordens de previsão; sincronização de planos entre parceiros de negócios; tomada de decisões conjuntas e gestão de exceções (Danese, 2011). CPFR capta as vantagens de tais iniciativas, adicionando o mecanismo de colaboração para facilitar o intercâmbio de informações em um SC de múltiplos níveis (Cassivi, 2006). A prática do CPFR 
combina a inteligência de múltiplos parceiros comerciais no planejamento e cumprimento da demanda do cliente e geralmente é reconhecido como a prática de colaboração na SC mais poderosa (Panahifar et al., 2015b). O CPFR é apontado por vários autores como uma abordagem mais holística, estruturada e colaborativa (Barratt e Oliveira, 2001; Seifert, 2003; Attaran e Attaran, 2007; Du et al., 2009; VICS, 2010; Danese, 2011; Gomes e Kliemann Neto, 2015).

O VMI é uma iniciativa de colaboração na SC que permite ao fornecedor assumir a responsabilidade de acompanhar e reabastecer o inventário de seu cliente com o intuito de melhorar o atendimento e reduzir o custo de estoque (Kuk, 2004). O método enfrenta problemas devido ao fato de varejistas paralisarem seu projeto de implementação por não estarem satisfeitos com os resultados, principalmente devido à falta de colaboração, à capacidade de previsão dos fornecedores e à incapacidade dos fornecedores de lidar com promoções de produtos resultando na paralização de projetos de implementação (Sari, 2008; Yuan et al., 2010). Dessa forma, o CPFR pode solucionar muitos dos problemas encontrados na implementação do VMI porque permite que os integrantes de uma SC desenvolvam conjuntamente previsões de demanda, promoções, planos de produção e de compra e reabastecimento de estoque (Aviv, 2002; Sari, 2008; Panahifar et al., 2015b). Sari (2008) comparou os benefícios obtidos com CPFR e VMI e concluiu que o CPFR é mais benéfico uma vez que apresenta um menor custo total da SC e também, níveis mais elevados de atendimento ao cliente. Cigolini e Rossi (2006) demonstraram que a iniciativa CPFR pode ser mais eficiente para a SC do que o VMI, especialmente quando a demanda é variável.

Outra iniciativa colaborativa citada na literatura é o ECR, um método estruturado em quatro pilares: reposição, seleção, promoção e introdução de novos produtos. O ECR é caracterizado como reativo à demanda e estabelece como processo chave o gerenciamento por categorias e a reposição contínua de produtos. Seu objetivo é buscar padrões comuns, eficiência em toda a SC e melhorar o serviço ao consumidor (Bailey e Francis, 2008). A implementação da prática do CPFR baseia-se no princípio do ECR (Lin e Ho, 2014). Embora a ECR crie uma vantagem significativa para os parceiros da SC em processos de logística e marketing, o CPFR foi criado para ser o método ECR de segunda geração, representando um salto qualitativo na organização dos processos de negócios nas cadeias de suprimentos (Seifert, 2003; Demiray et al., 2016). Gomes e Kliemann Neto 
(2015) descrevem o CPFR como uma extensão de métodos como o ECR devido seu foco ser mais abrangente e proativo em termos de previsão de demanda e tomada de decisões estratégicas conjuntas sobre as variações de demanda existentes.

No início dos anos 90 foi desenvolvido o CR, um método criado com o objetivo de melhorar as quatros estratégias principais do ECR e representar uma inovação em relação as práticas do VMI, por considerar a previsão de vendas e a demanda histórica. O CR é um processo na SC em que a reposição frequente ocorre do fornecedor para o varejista ou distribuidor, aumentando a frequência de reabastecimento, de modo a manter um maior fluxo na cadeia de suprimentos e minimizar o efeito chicote (Barratt, 2001). Audy et al. (2012) compararam o CR, o VMI e o CPFR e seu impacto no desempenho da SC: seus resultados apontam que o CPFR gera o maior lucro do sistema, seguido por VMI e CR. No entanto, analisando o lucro separadamente para o fabricante e atacadista, o CR apresenta o maior lucro para o atacadista, enquanto o CPFR ainda produz o maior lucro para o fabricante. Quando o fabricante compartilhou parte da economia de transporte com o varejista, o CPFR tornou-se a melhor opção para ambos os parceiros de negócios.

O método colaborativo que mais se assemelha com o CPFR é o Planejamento de Vendas e Operações (em inglês, Sales and Operations Planning - S\&OP), uma ferramenta que une diferentes processos em um conjunto integrado de planos. Seus principais objetivos são equilibrar a oferta e demanda, e construir pontes entre o plano de negócios ou plano estratégico e os planos operacionais da empresa visando o aumento da lucratividade (Thomé et al., 2012). O S\&OP é um processo com o intuito de criar um plano integrado operacional e financeiro por meio de uma série de avaliações coordenadas pela alta gerência para integrar planos estratégicos, operacionais e financeiros em um horizonte maior (VICS, 2010). Enquanto o S\&OP é considerado o modelo de melhor prática para a colaboração interna de uma entidade empresarial, o CPFR para muitos casos, é considerado o melhor modelo para a colaboração externa entre entidades empresariais. O S\&OP é um processo de gerenciamento de negócios que alinha centros de excelência funcional em um processo colaborativo interno coordenado. O CPFR é um processo de gerenciamento de negócios que alinha as capacidades complementares dos parceiros comerciais em um processo colaborativo externo coordenado. A oportunidade inexplorada está ligando o S\&OP e o CPFR para desenvolver um 
plano de negócios integrado que é coordenado entre parceiros comerciais para gerenciar toda a SC e criar vantagem competitiva para cada participante da cadeia (VICS, 2010).

\subsection{A prática do CPFR na indústria}

No final do Século XX e início do Século XXI, o modelo CPFR ganhou força e esteve em alta no setor industrial. Em uma pesquisa realizada no ano de 1999 com 120 empresas pela Industry Directions \& Syncra Systems (ID \& SS, 2000), descobriu-se que $26 \%$ estavam implementando planos relacionados ao CPFR (destes 23\% ainda se encontravam na fase experimental, $3 \%$ trabalhando em planos para além de seis meses) e que $42 \%$ estavam buscando pesquisas relacionadas (Schachtman, 2000; Chang, 2007). Progressive Grocer's Annual Report da indústria de supermercado no mesmo ano indicou que $33 \%$ de todos os executivos planejavam implementar programas CPFR com parceiros de negócios ao longo do ano seguinte (Lewis, 2000). O mesmo autor cita que esse número aumentou para $37 \%$ para os varejistas e $45 \%$ para os executivos do atacado. De acordo com $V o$ luntary Interindustry Commerce Standard (VICS) em 2004, desde a primeira aparição do CPFR até aquele ano, mais de 300 empresas aderiram às práticas do CPFR, resultando em benefícios substanciais para os participantes (VICS, 2004). Além disso, esse crescimento foi sustentado pelo fato de expressivos resultados terem sido alcançados na implementação do programa em redes de suprimento coordenadas por grandes empresas de alto desempenho como Wal-Mart, Nabisco \& Wegmans, Procter \& Gamble e Kmart (Danese, 2006).

Contudo, apesar de resultados promissores apresentados em relação às práticas do CPFR, vários desafios significativos de implementação ainda existem, o que tem levado a taxas de absorção mais lentas do que o esperado (Småros et al., 2003; Danese, 2007; Büyüközkan e Vardaloğlu, 2012; Panahifar et al., 2015a). A principal razão para essa lenta aceitação é o reconhecimento geral de que o sucesso da implementação do CPFR não é uma tarefa trivial e que sua prática inflige mudanças significantes na maneira "usual" de fazer negócios (Panahifar et al., 2015b). Embora conceitualmente simples, as implementações do CPFR são complexas na prática, pois exigem trocas de grande quantidade de dados, levando um longo tempo para se consolidar, além de envolver diversas áreas funcionais de vá- 
rias empresas (Nagashima et al., 2015). O CPFR possui complexidade na implementação por envolver fatores técnicos e fatores não técnicos e, ainda, por ser um processo em que a implementação passa por vários ciclos de funcionamento até estabilizar o sistema (Gomes e Kliemann Neto, 2015; Panahifar et al., 2015a).

Desde o início, diversos pesquisadores já alertavam para a escassez de implementação do CPFR em grande escala e que o uso das práticas desse método na SC é limitado (Småros et al., 2003; Småros, 2007; Büyüközkan e Vardaloğlu, 2012; Hollmann et al., 2015). Algumas empresas questionam os benefícios do CPFR e mesmo as empresas que abraçam este modelo muitas vezes limitam a escala de sua implementação, principalmente porque não podem avaliar seus benefícios (Panahifar et al., 2015c). A falta de informação adequada e detalhada sobre os fatores críticos de sucesso na implementação do CPFR é considerado uma importante razão para este lento progresso. Ainda que esses fatores na implementação do CPFR variem devido as características das diferentes cadeias, é vital que os gestores das empresas conheçam e compreendam estes fatores antes de começarem a adaptar o CPFR aos seus parceiros comerciais (Panahifar et al., 2015d).

Uma expectativa abaixo do esperado em relação ao CPFR tem sido observada no mundo industrial, e o mesmo decorre na literatura, em que a falta de pesquisa enfocando os inibidores de CPFR e/ou barreiras da implementação da prática tem ocorrido (Hollmann, 2014; Panahifar et al., 2015a; Panahifar et al., 2016). A maioria dos estudos simplesmente se concentra em uma análise do próprio sucesso (Panahifar et al., 2015b). Vários estudos abordando os benefícios da implementação do CPFR foram discutidos na literatura, mas há uma necessidade de estudos que empiricamente examinem como alguns dos benefícios citados em CPFR têm ocorrido na prática (Panahifar et al., 2015a). Não é possível encontrar muitos estudos e pesquisas na literatura que lidam com todo o conceito CPFR e suas aplicações em tempo real. A maioria das publicações apresenta aplicações parciais de CPFR como resultados de surveys, revisões de literatura ou teoria (Demiray et al., 2016). Muitos estudos se concentram em apresentar o método de forma analiticamente ou por esquemas, poucos estudos forneceram validações empíricas dos resultados analíticos (Yao et al., 2013; Nagashima et al., 2015). Além disso, a obtenção de dados relacionados a cadeias de suprimentos é particularmente difícil, o que torna ainda mais árduo a ocorrência de estudos empíricos relacionados ao tema (Nagashima et al., 2015). 
O contexto apresentado neste capítulo de fundamentação teórica reforça a importância das três perguntas de pesquisa introduzidas no primeiro capítulo desta dissertação. Estas perguntas de pesquisa são respondidas com base na revisão sistemática da literatura em CPFR proposta como objetivo desta dissertação, cujas etapas de condução estão descritas no próximo capítulo com base nas recomendações de Thomé et al. (2016a) para a revisão sistemática da literatura em gerências de operações. 


\section{Método de Pesquisa}

A literatura acadêmica em CPFR oferece vários métodos para se conduzir uma revisão sistemática da literatura (e.g., Cooper, 2010). Por exemplo, apenas para administração pode-se citar a existência de detalhados guidelines como os de Tranfield et al. (2003), Rousseau et al. (2008) e Denyer e Tranfield (2009). Contudo, dado que o CPFR é um conceito associado a SCM, esta pesquisa adota a abordagem de oitos passos propostos em Thomé et al. (2016a) para uma revisão sistemática da literatura, pois o mesmo é focado em gerência de operações. Os oitos passos são: (i) o planejamento e formulação do problema; (ii) pesquisar a literatura; (iii) coleta de dados; (iv) avaliação da qualidade; (v) síntese e análise dos dados; (vi) interpretação; (vii) apresentação de resultados; e (viii) atualização da revisão.

\subsection{O planejamento e formulação do problema}

Um dos primeiros passos foi a constituição do time de pesquisa. Este foi estabelecido com a presença de três membros, o autor dessa dissertação de mestrado e seus dois orientadores. Para determinar a realização de uma revisão sistemática na literatura a respeito do tema CPFR, foram identificadas quatro recentes revisões sistemática na literatura em Collaborative Planning, Forecasting and Replenishment (Kubdge e Bansod, 2010; Thomé et al., 2014; Hollmann et al., 2015; Panahifar et al., 2015a). Como se trata de um tema novo com crescente e recente publicação associada, entende-se que após mais de três anos após a última revisão da literatura, devido ao fato desta cobrir publicações até março de 2014, exista a necessidade de realizar uma atualização desses estudos, seguindo o passo oito de Thomé et al. (2016a). Além da atualização, o foco desta revisão concentra-se nos estudos empíricos, conforme exposto na contextualização oferecido, nas perguntas de pesquisa e nos objetivos da pesquisa apresentados nos dois primeiros capítulos desta dissertação. 
Com a realização de uma revisão sistemática da literatura em CPFR, buscase reunir detalhadamente pesquisas empíricas realizadas em CPFR de forma a integrar os diferentes resultados em um único estudo. Além disso, apresentar a importância dessa prática de gestão ao longo da cadeia de suprimentos no cenário atual e contribuir para que pesquisadores e praticantes tenham uma maior compreensão dos resultados já alcançados na prática.

\subsection{Pesquisar a literatura}

Para a etapa de seleção de estudos na literatura, utilizou-se a recomendação de sete passos oferecidos em Vom Brocke et al. (2009), Thomé et al. (2012), Thomé et al. (2014) e Thomé et al. (2016a). Estes passos são: 1) Seleção de artigos ou base bibliográfica; 2) pesquisa de palavras-chaves; 3) revisão dos resumos selecionados; 4) aplicação de critério para inclusão/exclusão dos estudos; 5) revisão completa dos textos dos artigos selecionados; 6) revisão de referências citadas nos artigos selecionados; 7) busca de citações feitas aos artigos selecionados (tanto nas buscas backward quanto nas buscas forward), busca essa também chamada de snowball.

Três bases de dados foram selecionadas para a pesquisa. Estas três bases de dados consistem em artigos publicados na maioria em revistas científicas de gestão de operações e gestão organizacional. São elas: Scopus, EBSCO, e ISI Web of Science. A não inclusão de outras bases de dados é considerado como uma limitação de pesquisa, que é minimizado com o uso do "snowball search".

As palavras-chaves selecionadas foram suficientemente amplas para evitar limitar os resultados de pesquisa, mas específicas o suficiente para trazer apenas os estudos relacionados ao tema. Foram utilizadas as seguintes palavras-chaves na pesquisa: "Collaborative Planning, Forecasting, and Replenishment". A mesma foi aplicada para títulos, resumos e palavras-chaves com limitação até agosto de 2017 em relação às datas de suas publicações. O total de artigos selecionados foi de 200. Excluindo os duplicados (18), o número caiu para 182. Também foram adicionados a esta lista os estudos adicionais incluídos nas revisões de Thomé et al. (2014), Hollmann et al. (2015) e Panahifar et al. (2015a), acrescentando assim 34 estudos, chegando a um total de 216 estudos. 
Os resumos dos artigos encontrados foram revisados para confirmar a inclusão de estudos que atendam os critérios de pesquisa. Os critérios aplicados para processo de exclusão de artigos foram os mesmos de Thomé et al. (2014) e Hollmann et al. (2015): (i) falta de relevância sobre o tema CPFR ou construções mal definidas de CPFR, (ii) CPFR sendo usado apenas como um exemplo e não como um tópico de pesquisa, (iii) artigos tratando elementos de CPFR isoladamente, tais como gestão de estoque, reposição ou previsão de demanda, (iv) artigos baseados apenas em opiniões de autores, (v) artigos que muito brevemente mencionaram CPFR mas não eram relevantes para o tópico geral, (vi) artigos de revistas comerciais e industriais e (vii) artigos que mostram relações causais que não apresentavam evidências empíricas claramente definidas baseadas em modelagem matemática explícita, simulações, pesquisa ou estudos de caso. Neste momento a pesquisa excluiu 78 artigos, selecionando apenas 138 estudos.

Adiante, aplicou-se o critério de exclusão para selecionar apenas estudos empíricos. Neste momento a pesquisa excluiu 98 estudos, selecionando assim apenas 40 estudos para a leitura do artigo de forma completa. Seguindo a metodologia de pesquisa, uma revisão dos textos de forma integral foi realizada, cinco artigos foram excluídos com base nos critérios anteriormente descritos, selecionando assim 35 estudos.

Para aumentar o alcance da pesquisa e reduzir sua limitação frente a amostra selecionada, as referências de cada um desses 35 artigos foram rastreadas como fonte secundárias (backward search), assim como os estudos que citam os estudos selecionados (forward search) usando a base do google scholar, para depois aplicar os critérios anteriores (e.g., exclusão) e selecionar novos artigos na amostra. Este processo de "snowball" não identificou mais artigos.

A Figura 1 apresenta os resultados associados aos sete passos adotados para selecionar estudos com base no diagrama de fluxo de PRISMA (Moher et al., 2009). 


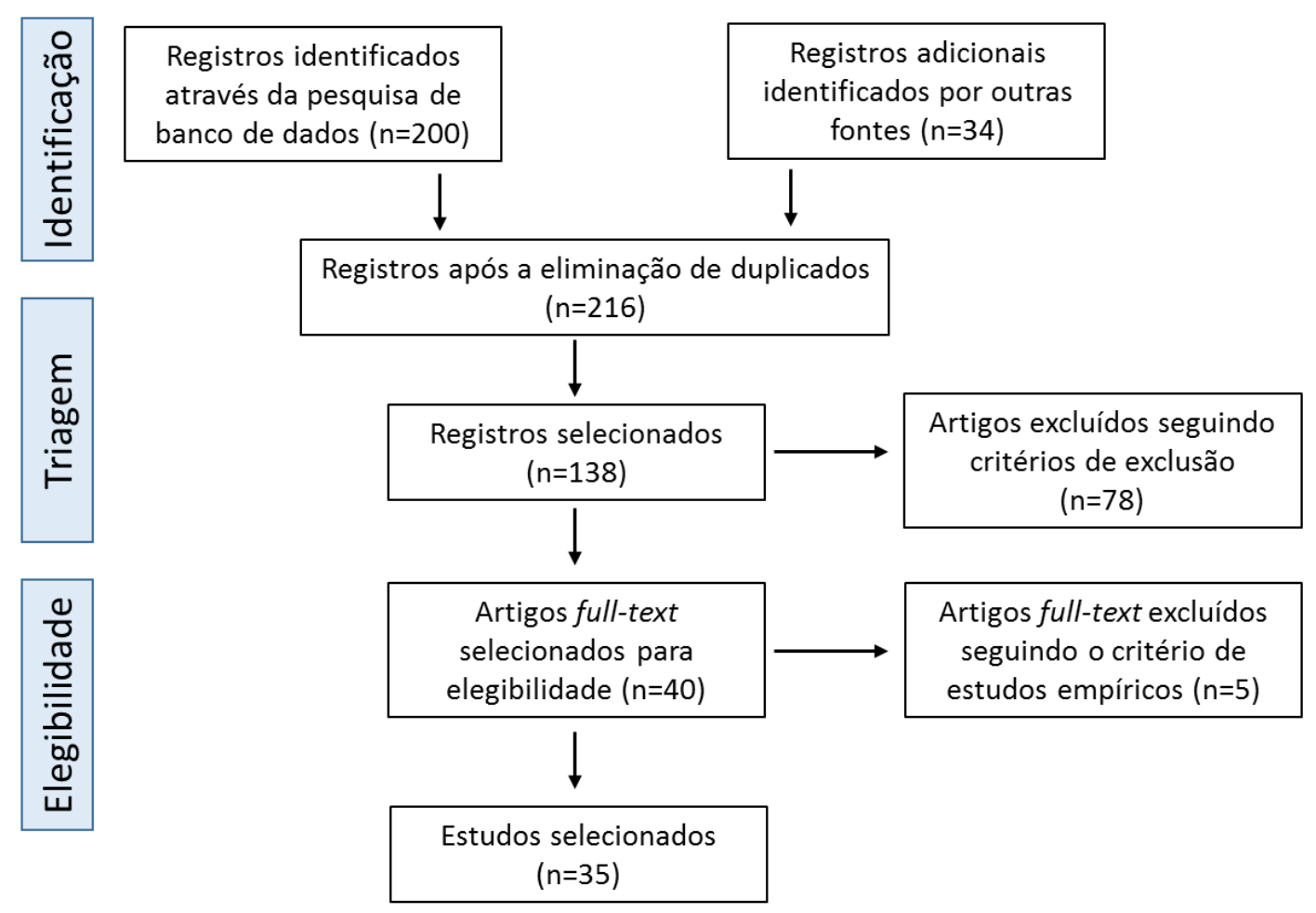

Fonte: adaptado de Moher et al. (2009)

Figura 1 - Diagrama de fluxo do PRISMA

\subsection{Coleta de Dados e avaliação da qualidade}

Um template específico para a coleta de dados foi criado para facilitar esta etapa. A sua criação foi amplamente discutida entre o mestrando e seus orientadores durante o treinamento inicial do seu preenchimento. O template usado seguiu os formatos utilizados em Thomé et al. (2014) e Hollmann et al. (2015) e foram preenchidos pelo time de pesquisa. Uma amostra inicial de cinco artigos foi usada como uma etapa de treinamento dos pesquisadores na população do template e para verificação da adequação do mesmo para a obtenção dos objetivos da pesquisa. As discrepâncias entre os resultados foram amplamente discutidas até que se chegasse ao consenso, conforme sugerido em Thomé et al. (2016a). A avaliação da qualidade dos trabalhos seguiu a definição de qualidade dada em Valentine (2009), sendo qualidade definida como o alinhamento entre os objetivos da pesquisa e suas características de implementação e métodos aplicados, levando assim a validação dos achados e resultados. As discrepâncias também foram amplamente debatidas pelos pesquisadores até se chegar a um consenso. 


\subsection{Análise, síntese e interpretação dos dados}

De forma a apoiar a análise e síntese de pesquisa dos resultados empíricos em CPFR, esta dissertação baseia-se no framework para CPFR, representado na Figura 2, proposta em Thomé et al. (2014). O modelo engloba todos os elementos necessários para descrever as características individuais do CPFR, como sua relação com outras práticas colaborativas, o contexto em que está inserido, entrada de dados, o relacionamento e o nível de colaboração entre os parceiros da SC. Assim como, os facilitadores e os inibidores da implementação do CPFR, a prontidão organizacional, os sistemas de informação utilizados e os benefícios esperados com a aplicação desta prática colaborativa também são definidos. O framework de Thomé et al. (2014) foi utilizado em Hollmann et al. (2015) e teve sua origem no framework para S\&OP de Thomé et al. (2012), este tendo grande influência na literatura de S\&OP em trabalhos como os de Tuomikangas e Kaipia (2014), Ivert et al. (2015a; 2015b), Norozzi e Wikner (2017) e Scavarda et al. (2017). 


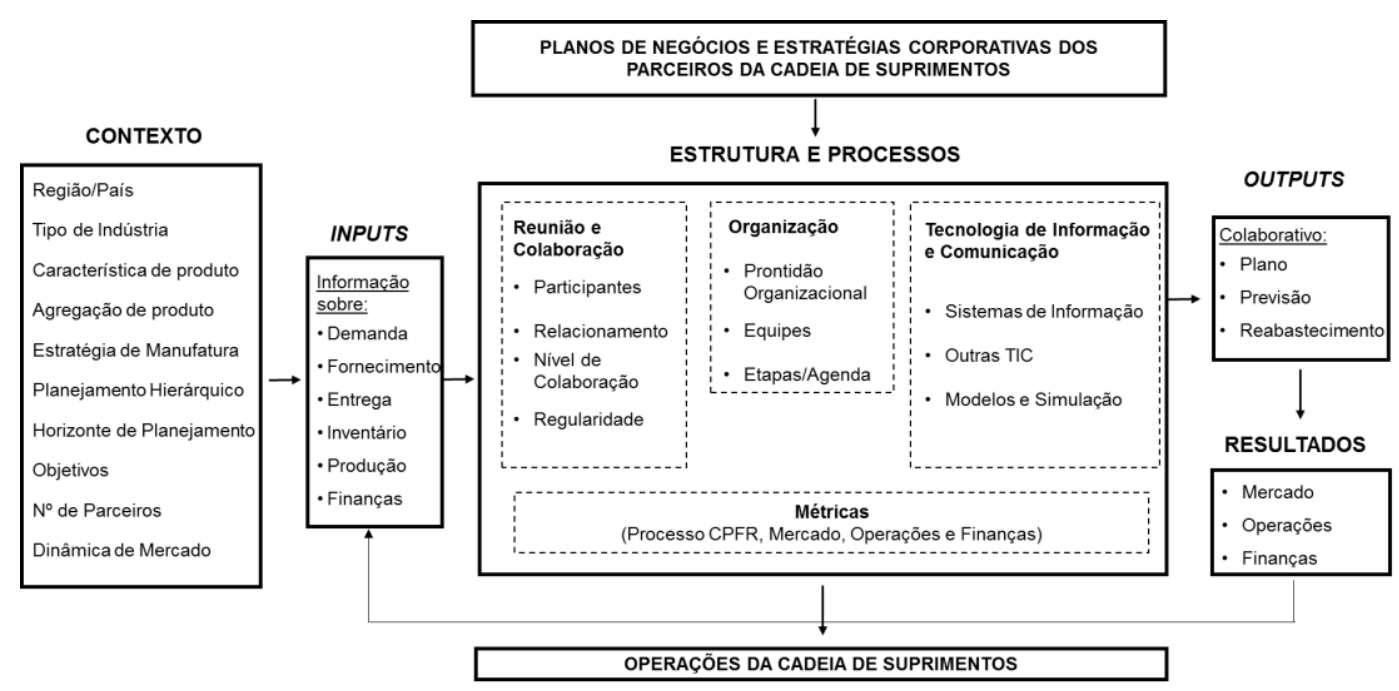

Fonte - Thomé et al. (2014): tradução livre

Figura 2 - Framework para o CPFR

De forma a responder as perguntas de pesquisa, 2 e 3 desta pesquisa (vide o capítulo de introdução), o framework de síntese proposto em Thomé et al. (2017) para auxiliar a revisão das contribuições de estudos empíricos em S\&OP com o viés de teorias de médio alcance (em inglês, Middle Range Theories - MRT) foi utilizado. Para tal, o mesmo foi adaptado de forma a contemplar a dimensão dos blocos conceituais de construção do CPFR no lugar da dimensão destinada ao S\&OP. A base para tal foi o framework para CPFR de Thomé et al. (2014) - vide Figura 2, resultando nas categorias de planos de negócios e estratégias corporativas dos membros da SC, contexto e abordagem de processos (entradas, estrutura \& processos, saídas e resultados). As demais dimensões contemplam os passos para a condução de pesquisa empírica em gerência de operações, contemplando as categorias de fundamentos teóricos, método de pesquisa, método de coleta de dados, implementação e análise dos dados e avaliação da qualidade da pesquisa primária e força da evidência, e as contribuições dos estudos, contemplando as categorias de objetivo e perguntas de pesquisa, premissas, proposições e hipóteses, e conclusão e pesquisas futuras. A Figura 3 apresenta este framework de síntese para a integração de cadeias utilizado nesta pesquisa, adaptando os blocos conceituais utilizados em S\&OP para CPFR. 


\begin{tabular}{|c|c|}
\hline \multirow{4}{*}{ 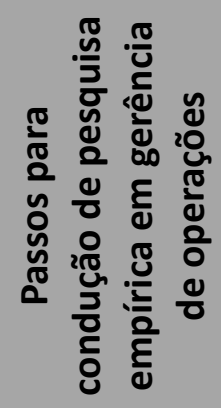 } & Fundamentos teóricos \\
\hline & Método de pesquisa \\
\hline & $\begin{array}{l}\text { Método de coleta de dados, implementação e análise dos da- } \\
\text { dos }\end{array}$ \\
\hline & $\begin{array}{l}\text { Avaliação da qualidade da pesquisa primária e força da evidên- } \\
\text { cia }\end{array}$ \\
\hline \multirow{3}{*}{ 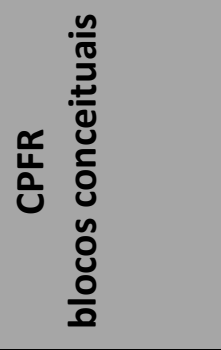 } & $\begin{array}{l}\text { Planos de negócios e estratégias corporativas dos membros da } \\
\text { SC }\end{array}$ \\
\hline & Contexto \\
\hline & Entradas, estrutura \& processos, Saídas e resultados \\
\hline \multirow{3}{*}{ 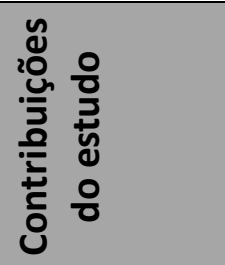 } & Objetivo e perguntas de pesquisa \\
\hline & Premissas, proposições e hipóteses \\
\hline & Conclusão e Pesquisas Futuras \\
\hline
\end{tabular}

Fonte: adaptado de Thomé et al. (2017)

Figura 3 - Framework de síntese para integração de SC focados em CPFR

A análise dos fundamentos teóricos teve como base a lista de teorias oferecidas em Defee et al. (2010), Boer et al. (2015) e Thomé et al. (2017). A análise da força de evidência foi feita com base nas escalas de Reay et al. (2009) e Thomé et al. (2016b), com o ordenamento de forma decrescente de força: (i) ensaios controlados randomizados; (ii) revisões sistemáticas da literatura ou revisões narrativas de alta qualidade ou experimentos e modelos matemáticos e de simulação aplicados em estudos buscando generalizações; (iii) estudos de caso múltiplos ou surveys de amostras grandes; (iv) estudos de caso simples ou surveys de amostras pequenas ou experimentos e modelos matemáticos e de simulação aplicados em estudos buscando generalizações aplicados a problemas e estudos específicos; (v) pesquisa ação e estudos descritivos e (vi) estudos baseados na opinião dos autores ou painel de experts.

\subsection{Apresentação dos resultados e atualização da revisão}

Esta dissertação de mestrado apresenta de forma integrada os resultados da aplicação dos passos de Thomé et al. (2016a) para a condução de uma revisão bi- 
bliográfica em CPFR. Sendo assim, os resultados são apresentados e analisados ao longo da própria dissertação. Este formato de dissertação contém as etapas de resumo, introdução, métodos de pesquisa, discussão dos resultados e conclusão, cumprindo assim as recomendações para apresentação de resultados de revisões sistemáticas sugeridas em PRISMA (Moher et al., 2009) e Thomé et al. (2016a). Vale ressaltar que esta pesquisa se inicia com o oitavo passo de Thomé et al. (2016a), considerando-se o fato de buscar ser uma atualização das demais revisões da literatura em CPFR (i.e., Kubde e Bansod, 2010; Thomé et al., 2014; Hollmann et al., 2015; Panahifar et al., 2015a), mesmo tendo diferenças metodológicas (e.g., bases de dados usadas e escopo específico de atuação). Entretanto, recomenda-se que no futuro este citado passo seja retomado em uma nova revisão para atualizar os achados em CPFR. 


\section{Análise descritiva, metodológica e da contribuição dos estudos}

Este capítulo apresenta discussões dos resultados desta pesquisa com base em uma análise descritiva dos estudos selecionados, os passos para a condução destes estudos e de suas respectivas contribuições, sendo estes dois últimos associados a duas das três dimensões do framework de síntese para a integração de cadeias focados em CPFR (Figura 3). A terceira dimensão deste framework relacionada aos blocos conceituais do CPFR é tratada no Capítulo 5.

\subsection{Análise descritiva}

Esta seção apresenta inicialmente uma análise comparativa dos resultados encontrados em todas as revisões sistemáticas da literatura em CPFR. Em seguida, são abordados os resultados encontrados de estudos empíricos relacionados ao CPFR contemplados nesta dissertação.

\subsubsection{Comparação entre as revisões sistemáticas da literatura em CPFR}

Apesar de sua recente origem, o CPFR tem se difundido pelos acadêmicos e já conta com um número expressivo de trabalhos publicados. A Tabela 1 apresenta uma síntese das revisões realizadas sobre CPFR e um comparativo com questões metodológicas adotadas em relação à presente dissertação como as bases, palavras-chave e campo de pesquisa utilizadas, incluindo o período da amostra e os resultados do número de artigos selecionados com o ápice de publicação anual. 
Tabela 1 - Resultados das Revisões Sistemáticas da Literatura em CPFR

\begin{tabular}{|c|c|c|c|c|c|c|}
\hline Autores & Bases Utilizadas & Palavras-chave & $\begin{array}{l}\text { Campo de } \\
\text { Pesquisa }\end{array}$ & $\begin{array}{c}\text { Período da } \\
\text { amostra }\end{array}$ & $\begin{array}{l}\text { Artigos } \\
\text { Selecio- } \\
\text { nados }\end{array}$ & $\begin{array}{l}\text { Pico de } \\
\text { Publica- } \\
\text { ção }\end{array}$ \\
\hline $\begin{array}{c}\text { Kubde e } \\
\text { Bansod } \\
(2010)\end{array}$ & n.m. & n.m. & n.m. & n.m. & n.m & n.m. \\
\hline $\begin{array}{l}\text { Thomé } \\
\text { et al. } \\
\text { (2014) }\end{array}$ & $\begin{array}{c}\text { Emerald; EBSCO; } \\
\text { Science Direct e } \\
\text { Wiley }\end{array}$ & $\begin{array}{c}\text { Collaborative } \\
\text { Planning } \\
\text { Forecasting } \\
\text { Replenishment; } \\
\text { CPFR } \\
\end{array}$ & $\begin{array}{l}\text { Título, re- } \\
\text { sumo e } \\
\text { palavras- } \\
\text { chaves }\end{array}$ & $\begin{array}{l}\text { Até mar- } \\
\text { ço/2014 }\end{array}$ & 47 & $2010(8)$ \\
\hline $\begin{array}{c}\text { Holl- } \\
\text { mann et } \\
\text { al. } \\
(2015)\end{array}$ & $\begin{array}{c}\text { Emerald; EBSCO; } \\
\text { Science Direct e } \\
\text { Wiley }\end{array}$ & $\begin{array}{c}\text { Collaborative } \\
\text { Planning } \\
\text { Forecasting } \\
\text { Replenishment; } \\
\text { CPFR } \\
\end{array}$ & $\begin{array}{l}\text { Título, re- } \\
\text { sumo e } \\
\text { palavras- } \\
\text { chaves }\end{array}$ & $\begin{array}{l}\text { Até mar- } \\
\text { ço/2014 }\end{array}$ & 50 & $2010(8)$ \\
\hline $\begin{array}{l}\text { Panahi- } \\
\text { far et al. } \\
(2015)\end{array}$ & $\begin{array}{l}\text { ISI Web of Scien- } \\
\text { ce; Taylor \& Fran- } \\
\text { cis; Google Scho- } \\
\text { lar TM ; Emerald e } \\
\text { uma busca mais } \\
\text { ampla na web } \\
\text { sem descrição de } \\
\text { detalhes }\end{array}$ & $\begin{array}{l}\text { CPFR; collaborati- } \\
\text { ve planning; col- } \\
\text { laborative fore- } \\
\text { casting; } \\
\text { collaborative re- } \\
\text { plenishment; col- } \\
\text { laboration }\end{array}$ & $\begin{array}{l}\text { Título dos } \\
\text { documen- } \\
\text { tos }\end{array}$ & 1998 a 2013 & 93 & $2010(12)$ \\
\hline $\begin{array}{l}\text { Pesqui- } \\
\text { sa Atual }\end{array}$ & $\begin{array}{c}\text { Atualização Tho- } \\
\text { mé et al. (2014); } \\
\text { Hollmann et al. } \\
\text { (2015); Panahifar } \\
\text { et al. (2015); } \\
\text { Scopus; ISI Web } \\
\text { of Science e EBS- } \\
\text { CO }\end{array}$ & $\begin{array}{c}\text { Collaborative } \\
\text { Planning Forecas- } \\
\text { ting Replenish- } \\
\text { ment; }\end{array}$ & $\begin{array}{l}\text { Título, re- } \\
\text { sumo e } \\
\text { palavras- } \\
\text { chaves }\end{array}$ & $\begin{array}{c}\text { Até agos- } \\
\text { to/2017 }\end{array}$ & 138 & $2010(16)$ \\
\hline
\end{tabular}

n.m. não mencionado

Fonte: o Autor

A Figura 4 apresenta os resultados de publicações sobre CPFR na evolução dos anos a partir das revisões sistemáticas na literatura sobre o tema, incluindo os resultados desta pesquisa e dos artigos de Thomé et al. (2014), Hollmann et al. (2015) e Panahifar et al. (2015a). Kubdge e Bansod (2010) não está presente na Figura 4, pois esta revisão não apresentou de forma separada os artigos selecionados.

Pode-se notar que a quantidade de estudos está bem representada em todos os períodos desde as primeiras publicações em 1998. Nos resultados das revisões é possível observar que o número de pesquisas cresceu quase que constantemente até o ano de 2010, com exceção do ano de 2009 que apresentou uma forte queda. Já no ano de 2010 todos os autores encontraram um pico no número de publicações. As revisões também verificaram uma queda a partir de 2010, demonstrando 
que pesquisadores continuam estudando CPFR, contundo, o mesmo deixa de ser um tema emergente e tão atrativo. Com a atual pesquisa, essa tendência de desaceleração é observada de forma mais clara, pois além da continuação da busca de artigos até agosto de 2017 (Tabela 1), a amostra de dados é mais extensa e corrobora com os resultados e análises encontradas em Thomé et al. (2014), Hollmann et al. (2015) e Panahifar et al. (2015a), além de artigos de outras bases. Portanto, é possível dizer que existem fortes indícios de que os estudos em CPFR estão perdendo relevância e atratividade por parte dos acadêmicos. 


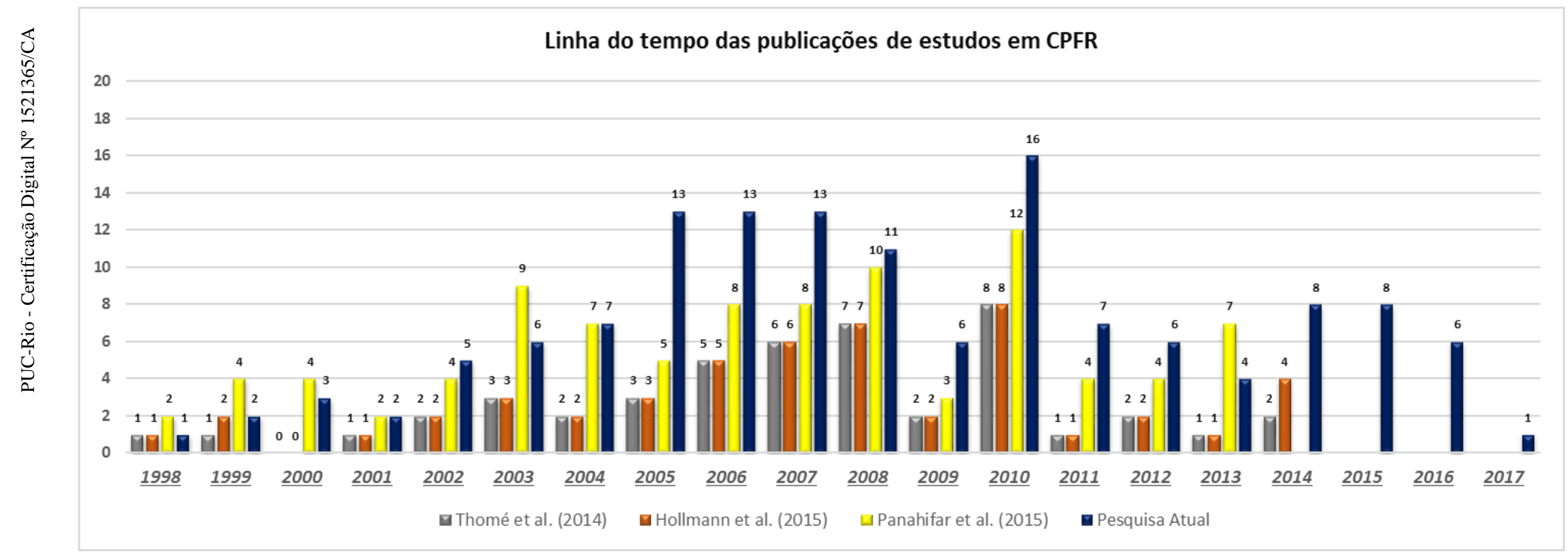

Fonte: o Autor

Figura 4 - Linha do Tempo das publicações de estudos em CPFR 


\subsubsection{Análise descritiva dos estudos empíricos selecionados}

Os resultados dos estudos empíricos em CPFR selecionados na pesquisa desta dissertação são apresentados na Figura 5. A primeira publicação acontece no ano de 1999 e o crescimento dos estudos empíricos se dá após o crescimento de estudos teóricos (Figura 6), atingindo o pico no ano de 2008 e 2015 (quatro publicações em cada ano). Os estudos empíricos são bem representados ao longo dos anos, mas dos 138 artigos selecionados nesta pesquisa, apenas 35 artigos são relacionados a estudos empíricos, ou seja, aproximadamente um quarto das publicações apresentam observações, dados ou experiência prática do CPFR no mundo real. Esse fato vai ao encontro dos artigos de Thomé et al. (2014) e Panahifar et al. (2015a), que ressaltam a carência de estudos empíricos em CPFR.

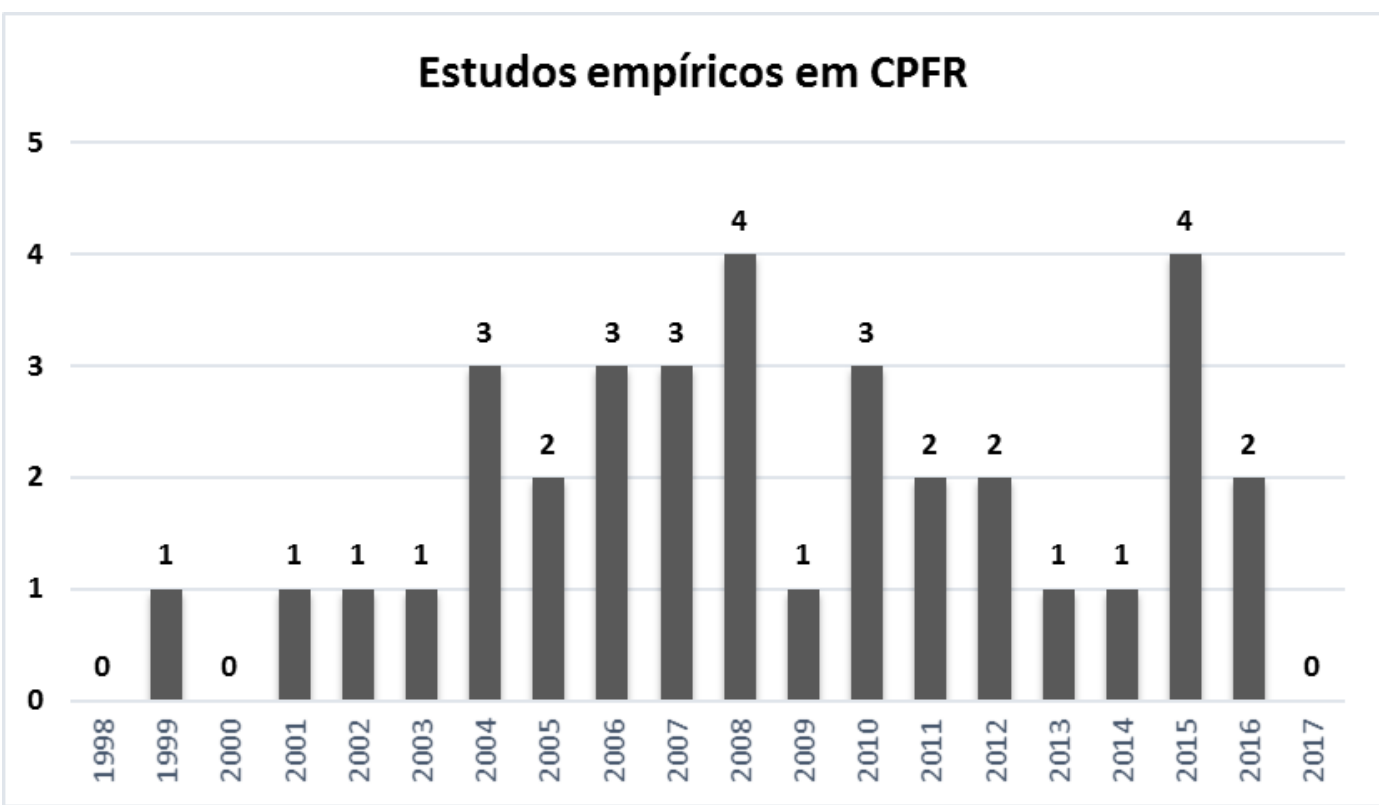

Fonte: o Autor

Figura 5 - Estudos empíricos em CPFR 


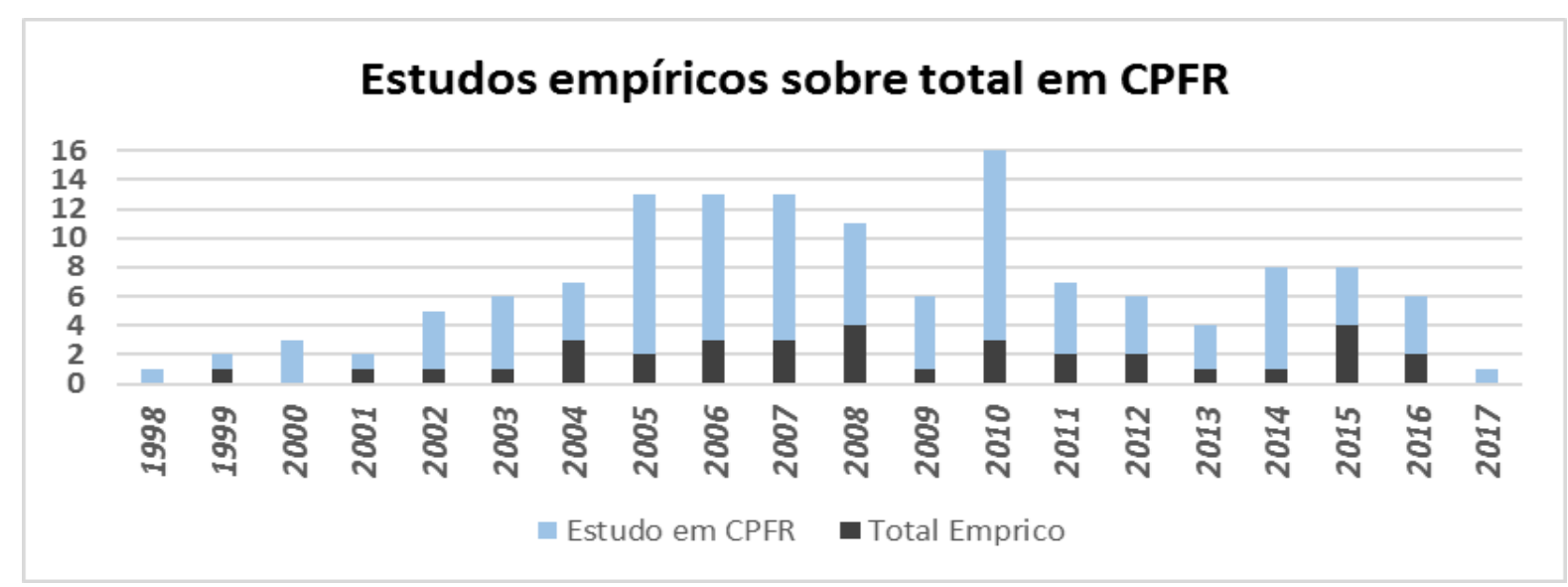

Fonte: o Autor

Figura 6 - Estudos empíricos sobre total em CPFR

\subsection{Passos para condução das pesquisas empíricas}

Esta seção trata das abordagens metodológicas utilizadas nos estudos empíricos selecionados para revisão. A tabela 2 apresenta a lista destes artigos empíricos selecionados, destacando seus fundamentos teóricos na segunda coluna e métodos de pesquisa adotados na terceira coluna. Os fundamentos teóricos citados na tabela são os que foram mencionados diretamente pelos autores dos artigos. A tabela 2 não cita as teorias que não estiveram explicitamente expostas nos artigos pelos seus autores. No caso dos métodos de pesquisa aplicados, foi realizado uma inferência para determinar o método de pesquisa utilizado no caso de os autores não terem o mencionado diretamente em seus estudos. Neste caso, um "I" foi indicado quando for inferido por parte do autor desta dissertação e "Q" para os citados pelos autores do artigo. 
Tabela 2 - Fundamentos teóricos e metodologia de pesquisa aplicados

\begin{tabular}{|c|c|c|}
\hline Referências & Fundamentos teóricos & Métodos de pesquisa \\
\hline Stank et al. (1999) & -- & Survey (Q) \\
\hline Barratt e Oliveira (2001) & -- & Survey (Q) \\
\hline McCarthy e Goilicic (2002) & -- & Estudo de caso múltiplo (Q) \\
\hline Skjoett-Larsen et al. (2003) & transaction cost theory & Survey $(\mathrm{Q})$ \\
\hline Chen et al. (2004) & -- & Estudo de caso simples (Q) \\
\hline Danese et al. (2004) & -- & Estudo de caso múltiplo (Q) \\
\hline Lin et al. (2004); & -- & Estudo de caso simples (Q) \\
\hline Wang et al. (2005) & -- & Estudo de caso simples (Q) \\
\hline Chung e Leung (2005) & -- & Estudo de caso simples (Q) \\
\hline Kohli e Sherer (2006) & -- & Estudo de caso múltiplo (Q) \\
\hline Danese (2006) & -- & Estudo de caso múltiplo (Q) \\
\hline Cassivi (2006) & -- & Survey (Q) \\
\hline Danese (2007) & -- & Estudo de caso múltiplo (Q) \\
\hline Småros (2007) & -- & Estudo de caso simples (Q) \\
\hline Chang et al. (2007) & bullwhip effect & Estudo de caso simples (Q) \\
\hline Vivaldini et al. (2008) & -- & Pesquisa ação (Q) \\
\hline Chang e Wang (2008) & -- & Estudo de caso simples (Q) \\
\hline Ghosh e Federowicz (2008) & -- & Estudo de caso simples (Q) \\
\hline D’Aubeterre et al. (2008) & -- & $\begin{array}{l}\text { Estudo de caso simples (Q) / Fo- } \\
\qquad \operatorname{cus} \operatorname{group}(\mathrm{Q})\end{array}$ \\
\hline Du et al. (2009) & -- & Estudo de caso simples (Q) \\
\hline Fu et al. (2010) & -- & Panel study (Q) \\
\hline Lehoux et al. (2010) & -- & Estudo de caso simples (Q) \\
\hline VICS (2010) & -- & Estudo de caso simples (Q) \\
\hline Sherer et al. (2011) & organizational learning & Estudo de caso simples (Q) \\
\hline Lehoux et al. (2011) & -- & Estudo de caso simples (Q) \\
\hline Dube et al. (2012) & -- & Survey (Q) \\
\hline $\begin{array}{l}\text { Ramanathan e Gunasekaran } \\
\qquad(2012)\end{array}$ & $\begin{array}{c}\text { Resource based view (RBV) } \\
\text { Resource dependent theory (RDT) }\end{array}$ & Survey (Q) \\
\hline Thomassen et al. (2013) & -- & Estudo de caso simples (Q) \\
\hline Lin e Ho (2014) & -- & Survey (Q) \\
\hline Panahifar et al. (2015b) & -- & Survey (Q) / Panel study (I) \\
\hline Panahifar e Heavey (2015c) & -- & Estudo de caso simples (Q) \\
\hline Gomes e Kliemann Neto (2015) & -- & Estudo de caso simples (Q) \\
\hline Nagashima et al. (2015) & -- & Estudo de caso múltiplo (Q) \\
\hline Demiray et al. (2016) & -- & Estudo de caso simples (Q) \\
\hline $\mathrm{Fu}(2016)$ & -- & Panel study (I) \\
\hline
\end{tabular}

Fonte: o Autor 
A maior parte dos estudos não endereçou diretamente (explicitamente) uma teoria. As poucas teorias endereçadas são teorias que originaram de outras disciplinas (não de gerência de operações), o que está em linha com o que é preconizado por Defee et al. (2010), Boer et al. (2015) e Thomé et al. (2017). As teorias identificadas foram: transaction cost theory, bullwhip effect, organizational learning, resource based view (RBV) e resource dependent theory (RDT), uma explicação de cada teoria pode ser encontrada em Defee et al. (2010) e Walker et al. (2015). O desenvolvimento de pesquisas empíricas com pouca fundamentação de teorias está aderente com a realidade da disciplina de gerência de operações (Thomé et al., 2017), o que não é uma surpresa quando analisada a prática de CPFR.

Os estudos empíricos em CPFR foram baseados na aplicação de seis metodologias de pesquisa, de forma isolada ou combinada, sendo elas: (i) estudo de caso simples, (ii) estudo de caso múltiplo, (iii) survey, (iv) panel study, (v) focus group, (vi) pesquisa ação. A Figura 7 apresenta o uso destes métodos ao longo dos anos associados as publicações dos estudos em CPFR. Na Figura 7 é possível notar que o método de pesquisa mais utilizado nesses estudos é o estudo de caso simples, com dezoito artigos. A primeira publicação dessa metodologia ocorre no ano de 2004, atingindo o maior número de estudos em 2008 (três estudos) e sendo bem representado até o ano de 2016, demonstrando uma tendência em aplicar esse método de pesquisa nos estudos empíricos em CPFR. Isto é corroborado por $\mathrm{Pa}$ nahifar et al. (2015a) que destacam que a maioria dos estudos utilizam a metodologia do estudo de caso simples. Oito artigos utilizam o survey como método de pesquisa, com publicações dispersas ao longo do tempo. Apesar das evidências retiradas de pesquisas de estudo de caso, a consistência empírica baseada em pesquisa do tipo survey em relação ao impacto do CPFR no desempenho da SC ainda é escassa (Yao et al., 2013; Thomé et al., 2014; Hollmann et al., 2015). Em seguida, a metodologia de pesquisa mais representada é a de estudo de caso múltiplo com seis publicações, sendo a maioria desses estudos ocorrendo entre 2004 a 2007, demonstrando que a utilização desse método se encontra de forma mais reduzida. Isto corrobora com Hollmann et al. (2015) que menciona que embora a literatura ofereça vários modelos de CPFR, há uma escassez de pesquisa de estudo de caso múltiplo na implementação do CPFR. Em menor quantidade, publicações 
adotando Panel Study (três artigos), Focus Group (um artigo) e Pesquisa Ação (um artigo) também foram encontradas.

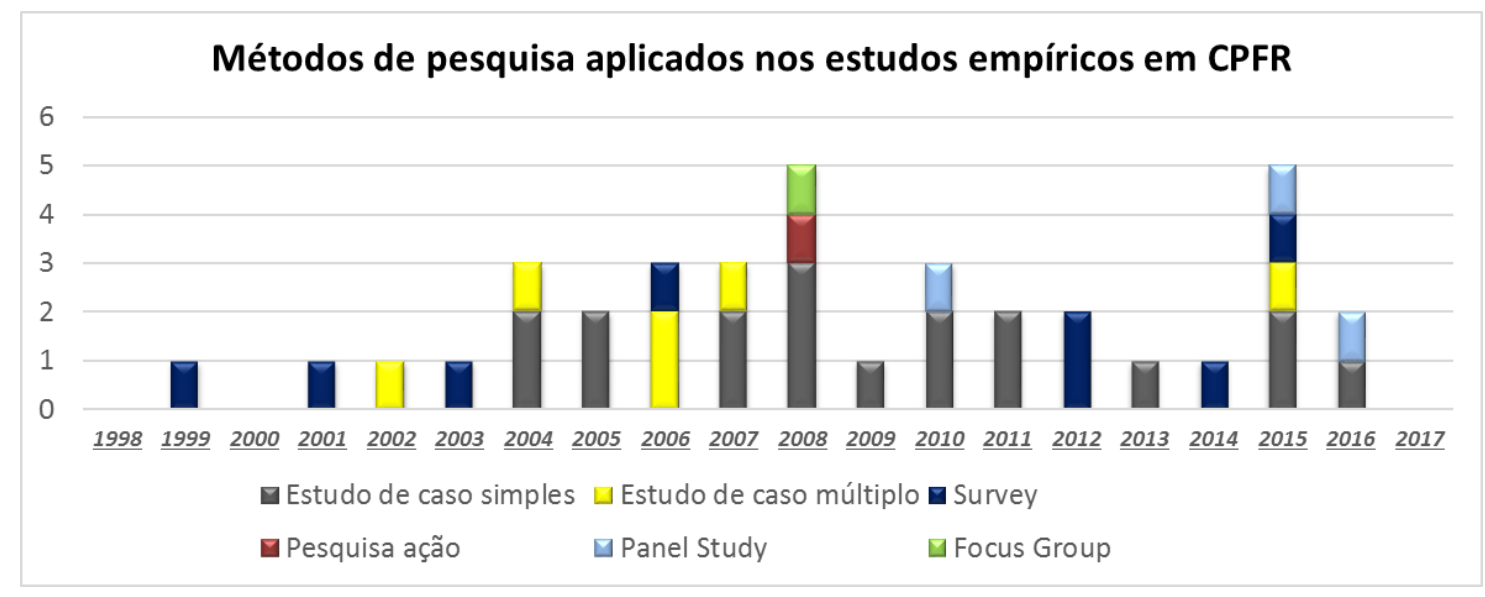

Fonte: o Autor

Figura 7 - Métodos de pesquisa aplicados nos estudos empíricos em CPFR

A força da evidência dos resultados obtidos dos estudos é considerada de médio a baixo impacto, usando como base as escalas de Reay et al. (2009) e Thomé et al. (2016b). A maior parte dos estudos se concentra em métodos de pesquisa como estudos de caso, simples ou múltiplos, e surveys, todos mais focados em particularidades dos estudos do que na busca de generalizações dos achados. Modelos matemáticos e de simulação aplicados buscando generalizações nos estudos não foram encontrados, o que equivaleria a um forte impacto de evidência dos resultados.

\subsection{Contribuição dos estudos}

A presente seção foca nas principais contribuições obtidas nos estudos selecionados, priorizando e focando a interface com o CPFR. Contribuições fora do escopo do CPFR não estão contemplados nesta dissertação.

A Tabela 9 do Apêndice 1 apresenta os objetivos de cada estudo selecionado, assim como suas perguntas de pesquisa, principais conclusões e direções futuras para pesquisas.

Os objetivos dos trabalhos em CPFR estão focados em propor e testar novas metodologias e/ou modelos de implementação do CPFR em diferentes contextos (Chung e Leung, 2005; Chang et al., 2007; Chang e Wang, 2008; Du et al., 2009; 
VICS, 2010; Lin e Ho, 2014; Demiray, 2016). Os artigos visam analisar principalmente as barreiras e/ou facilitadores de implementação do CPFR (Barratt e Oliveira, 2001; Panahifar et al., 2015b; Fu, 2016), os vários tipos de configuração e/ou nível de colaboração existentes em CPFR (Skjoett-Larsen et al., 2003; Danese et al., 2004; Danese, 2006; Danese, 2007; Lehoux et al., 2010; Lehoux et al., 2011), as dificuldades de implementação do CPFR (Vivaldini et al., 2008; Fu et al., 2010; Gomes e Kliemann Neto, 2015), a abordagem da tecnologia de informação e comunicação (TIC) inserida no CPFR (Wang et al., 2005; Kohli e Sherer, 2006; Cassivi, 2006; Thomassen et al., 2013), e a seleção do parceiro mais apropriado para colaborar (Panahifar e Heavey, 2015c).

Somente dois artigos focam diretamente suas perguntas de pesquisa em CPFR. Stank et al. (1999) procuram analisar qual o nível de associação entre a implementação do CPFR e a efetividade na implementação de mudanças nos processos operacionais, a eficácia na execução dos objetivos de desempenho operacional e as capacidades do sistema de informação. Dube et al. (2012) visam identificar por meio de duas perguntas de pesquisa quais são os benefícios e deficiências da prática do CPFR em indústrias de varejo e qual é a diferença entre a percepção de varejistas e fornecedores na compreensão do CPFR.

As principais conclusões obtidas são: empresas com altos níveis de implementação de CPFR aproveitam os sistemas de informação capazes de fornecer informações oportunas, precisas, fáceis de usar e interfuncionais em tempo real (Stank et al., 1999), o primeiro passo que os parceiros comerciais devem tomar para permitir a implementação do processo CPFR é desenvolver um ambiente adequado. Este ambiente deve ser fundado em dois conceitos: confiança e tecnologia (Barratt e Oliveira, 2001), abordagens alternativas para atualizar a previsão colaborativa podem ser utilizadas sem que haja investimento substancial em recursos humanos e tecnológicos exigidos pelo CPFR (McCarthy e Goilicic, 2002), sem uma comunicação adequada, os funcionários não entenderão o propósito ou as vantagens do conceito do CPFR (Skjoett-Larsen et al., 2003), educação e treinamento adequados devem ser fornecidos por meio de uma comunicação interna eficaz para ajudar os funcionários a entender o processo operacional, benefícios e o modelo de trabalho do CPFR (Chen et al., 2004), o CPFR é classificado pelos tipos de interdependência entre os atores envolvidos na implementação da prática (Danese et al., 2004), o sistema de informação baseado na 
$W e b$, desenvolvido por grandes varejistas que são os principais implementadores de CPFR, é uma plataforma muito prática para compartilhar dados de forma eficiente com todos os tamanhos de fornecedores (Wang et al., 2005), o compartilhamento de informações é a base para o sucesso do CPFR (Chung e Leung, 2005), não é necessário implementar tecnologia sofisticada para suportar o CPFR (Danese, 2006), o número de processos envolvidos na colaboração do CPFR depende das características do produto/mercado e da estrutura física da SC (Danese, 2007), é altamente provável que a metodologia Six Sigma seja incorporada no CPFR no futuro próximo (Chang e Wang, 2008), um fator de sucesso chave para o CPFR é integrar processos de CPFR em processos de negócios já existentes (D'Aubeterre et al., 2008), os fatores de impacto crítico para os varejistas que adotam o CPFR são a capacidade de comunicação e colaboração entre departamentos, gerenciamento de mudanças, capacidade de inovação organizacional, complexidade do sistema, objetivo mútuo, capacidade de integração de tecnologia e cultura, suporte da alta gerência, confiança e comunicação, segurança do sistema e intercâmbio eletrônico de dados (Fu et al., 2010), quando o VMI e o CPFR são empregados de forma conjunta resulta em um desempenho financeiro maior para toda a cadeia (VICS,2010), as práticas do CPFR combinadas com a tecnologia da informação fornecem uma visão mais ampla para todos os membros da SC (Dube et al., 2012), a implementação bem-sucedida do CPFR exige a presença de equipes de tecnologia de informação (TI) profissionais e competentes em ambas as partes e o apoio suficiente da alta gerência (Lin e Ho, 2014), a "liderança" desempenha um papel crítico na gestão de equipes na implementação do CPFR e para apoiar e encorajar uma atmosfera colaborativa interna e externa (Panahifar et al., 2015b), o sucesso do CPFR baseia-se basicamente na estratégia comum da SC dos parceiros, transação transparente e efetiva de informações relevantes, gerenciamento conjunto dos processos de planejamento (Demiray, 2016).

As propostas para estudos futuros se concentram em avaliar os fatores de estudo em uma amostra mais ampla de redes que envolvam pequenas e grandes empresas em várias indústrias buscando generalizações dos achados (Stank et al., 1999; Skjoett-Larsen et al., 2003; Danese et al., 2004; Danese, 2006; Danese, 2007; Småros, 2007; Vivaldini et al., 2008; Chang e Wang, 2008; Panahifar et al., 2015b; Nagashima et al., 2015; Fu, 2016), por meio de projetos de pesquisa baseados em casos e/ ou com base em survey (Danese et al., 2004; Danese, 2006; 
Danese, 2007). Isso reforça a importância de desenvolver estudos de caso múltiplo ou survey sobre o CPFR a fim de testar e expandir resultados de pesquisa em grandes amostras de empresas, representativas de diversas configurações de indústrias. Alguns fatores de indicações para pesquisa futura em CPFR são: analisar como empresas com produtos de diferentes características podem exigir diferentes estruturas de implementação em CPFR (Lin et al., 2004); investigar como gerenciar o alinhamento da demanda com a área de suprimento no CPFR (Chang e Wang, 2008); realizar estudos aprofundados para a seleção do parceiro mais adequado para colaborar no CPFR (Demiray, 2016); desenvolver e ajustar um incentivo financeiro para diferentes contextos de implementação do CPFR nas indústrias e também analisar como a concorrência afeta a eficiência das colaborações e a escolha do incentivo a implementar (Lehoux et al., 2011).

A Tabela 10 do Apêndice 2 apresenta as principais barreiras e facilitadores encontrados nos estudos para o CPFR. As principais barreiras encontradas foram: dificuldade de implementação, falta de integração interna, falta de suporte de gerenciamento e falta de confiança. A confiança foi a barreira predominante observada nos estudos empíricos e este achado confirma o que foi constatado em Panahifar et al. (2015a) e Hollmann et al. (2015), que indicaram a falta de confiança dos parceiros o inibidor mais importante e, se ausente, continua a ser o obstáculo mais obstrutivo para a adoção do CPFR. A falta de integração interna foi outro fator influente como inibidor para a prática do CPFR, Småros (2007) ressalta que a falta de integração interna pode fazer com que a informação seja perdida antes de ter sido inserida nos sistemas de controle do fabricante e os longos intervalos de produção podem reduzir significativamente o valor do acesso a informações oportunas, como dados de pontos de venda (em inglês, point of sales - POS) do novo produto.

Os principais facilitadores encontrados foram: processo de gestão de mudanças, predisposição cultural para compartilhar dados, estrutura organizacional flexível, estratégia de TI inovadora, compartilhamento de informações, prontidão, apoio da alta gerência, tecnologia empregada e confiança. Tecnologia empregada e confiança foram os facilitadores predominantes entre eles, o que corrobora com Hollmann et al. (2015), onde os principais facilitadores observados na literatura foram a confiança e tecnologia da informação e comunicação (TIC). Por meio de um survey, o mesmo achado foi identificado em Barratt e Oliveira (2001). Para Fu 
(2016) o apoio da alta gerência e a construção de relações de confiança são os fatores mais importantes para o sucesso do CPFR. Ghosh e Federowicz (2008) destacam a importância da mudança nos processos operacionais, da tecnologia empregada, da cultura da empresa em compartilhar dados e da confiança entre os membros parceiros de uma SC para facilitar o compartilhamento de informações importantes diante de uma implementação do CPFR. Fu (2016) ressalta por meio de um estudo de caso, que entre os dez principais fatores analisados, dois são os mesmos tanto para o varejista quanto para o fornecedor, sendo eles confiança e comunicação com o parceiro e apoio da alta gerência.

A relação do uso do CPFR com outras práticas do SCM a partir de estudos empíricos, como VMI e S\&OP, também foi alvo de alguns estudos. Gomes e Kliemann Neto (2015) apresentaram um estudo de caso de uma implementação malsucedida do CPFR em uma SC na indústria moveleira no Brasil. Nesse estudo foi indicado que a falta de vivência das empresas com métodos colaborativos mais simples, como o VMI, foi a principal causa de dificuldade de implementação não efetiva do CPFR. O estudo indicou que as empresas necessitam de uma preparação e experiências mínimas necessárias à implementação de métodos colaborativos mais avançados como o CPFR. Isso permitirá às empresas o aumento da confiança e do comprometimento ao longo do tempo, uma vez que percebem que o fato de se ajudarem traz melhorias. O uso do VMI também foi comparado com o CPFR e o Regular Replenishment (RR) em Lehoux et al. (2010), onde os resultados de pesquisa revelam que o CPFR é a melhor estratégia para otimizar os custos de transporte e inventário e gerar o maior lucro total do sistema. O VMI é o segundo melhor, uma vez que o custo do transporte pode diminuir significativamente. A abordagem RR obtém os menores benefícios do sistema. Ao analisar o lucro de cada parceiro separadamente, é observado que o CPFR gera o maior lucro para o produtor enquanto o modo RR é a estratégia mais lucrativa para o varejista. Especificamente, uma vez que o modo CPFR facilita a sincronização de todas as atividades, o produtor pode melhorar o planejamento de suas operações e reduzir consideravelmente o custo de transporte. Por outro lado, o varejista deve aceitar armazenar mais produtos. Quando o relacionamento é baseado em RR, o varejista pode encomendar produtos de acordo com suas necessidades.

A prática do S\&OP também é analisada com CPFR. No ano de 2010, VICS propôs um novo modelo de prática de colaboração na SC através de um estudo de 
caso ligando a prática do S\&OP e do CPFR com o objetivo de desenvolver um plano de negócios integrado que seja coordenado entre parceiros de negócios para gerenciar toda a SC e criar vantagem competitiva para cada participante da cadeia, denominado de Planejamento Integrado de Negócios (em inglês, Integrated Business Planning - IBP). O estudo de caso apresentado entre Lowe's Home Improvement e Whirlpool Corporation ilustrou como duas empresas estão colaborando para implementar um processo de IBP. Antes da parceria, as duas empresas basicamente tinham planos de negócios independentes que dirigiam suas vendas individuais e planos operacionais. Após o acordo de colaboração estabelecido, Lowe's e a Whirlpool desenvolveram relacionamentos nos níveis de vendas e marketing nas organizações, e as ligações de colaboração foram criadas. Baseado em um plano estruturado de revisão da demanda e da oferta, seus esforços de colaboração impulsionaram o planejamento de negócios para um único conjunto alinhado de previsões e planos de vendas. Com esse processo, eles foram capazes de concentrar sua colaboração em promoções, planejamento de novos produtos e de eventos especiais. O resultado final foi um calendário promocional integrado para cada categoria de produto. A visibilidade direta adicional nos planos de vendas possibilitou que as duas empresas estabelecessem um horizonte de planejamento de 3 a 6 meses. A união do CPFR com o S\&OP permitiu um crescimento de vendas unitárias de $12 \%$ em três anos, enquanto os custos gerais de estoque diminuíram 5\%, além de obter melhoria no nível de serviço ao cliente. As empresas acreditam que um dos principais impulsionadores dessas melhorias no desempenho foi a criação e a evolução de seu modelo de colaboração. 


\section{Análise dos blocos conceituais do CPFR}

Este capítulo apresenta as discussões dos resultados associados aos blocos conceituais do CPFR, terceira e última dimensão do framework de síntese para integração de cadeias focando em CPFR (Figura 3), tendo como base o framework de Thomé et al. (2014) (Figura 2).

\subsection{Contexto}

As implementações do CPFR ocorrem em diferentes contextos. Para Danese (2007), é essencial investigar fatores de contexto de implementação do CPFR para um ponto de vista prático, pois a compreensão desses fatores pode apoiar gerentes e a alta administração na escolha da decisão mais apropriada a ser tomada ao implementar o CPFR. Panahifar et al. (2015a) ressalta que mais pesquisas são necessárias para examinar a relação entre fatores de contexto, como o tamanho da empresa. De forma ao analisar os fatores de contexto em implementações do CPFR, esta dissertação visou encontrar nos estudos empíricos selecionados fatores como regiões ou países de implementação, tipos de indústrias, tamanho da empresa (e.g., número de funcionários), característica dos produtos, agregação dos produtos (categoria de produto, família ou SKU), a estratégia de produção (e.g., MTO ou MTS), horizonte de planejamento (curto, médio ou longo) e número de parceiros (complexidade da SC).

A Tabela 3 apresenta o contexto de regiões de implementações de CPFR, destacando-se a Ásia com mais citações (11), com Taiwan representando quase a metade destes estudos, seguida da Europa e da América do Norte (ambas com 9 citações), sendo o Estados Unidos o país mais evidenciado nos estudos (7 citações). A América do Sul é representada por duas implementações no Brasil e a África é representada por uma implementação na África do Sul. Sherer et al. (2011) apresentou um estudo de forma a compreender e desenvolver preposições sobre o impacto potencial das diferenças culturais associadas a implementação do CPFR com parceiros em diferentes países. 
Tabela 3 - Regiões e países de implementações em CPFR

\begin{tabular}{|c|c|c|}
\hline Regiões & País em destaque & Referências \\
\hline Ásia & Taiwan (5) & $\begin{array}{l}\text { McCarthy e Goilicic (2002); Chen et al. (2004); Lin et al. (2004); } \\
\text { Wang et al. (2005); Chung et al. (2005); Chang et al. (2007); } \\
\text { Chang e Wang (2008); Sherer et al. (2011); Ramanathan e Gu- } \\
\text { nasekaran (2012); Lin e Ho (2014); Fu(2016) }\end{array}$ \\
\hline Europa & Itália (2) & $\begin{array}{c}\text { Skjoett-Larsen et al. (2003); Danese et al. (2004); Danese } \\
\text { (2006); Danese (2007); Småros (2007); Sherer et al. (2011); } \\
\text { Thomassen et al. (2013); Panahifar e Heavey (2015c); Na- } \\
\text { gashima et al. (2015) }\end{array}$ \\
\hline $\begin{array}{c}\text { América do } \\
\text { Norte }\end{array}$ & Estados Unidos (7) & $\begin{array}{l}\text { Stank et al. (1999); Barratt e Oliveira (2001); McCarthy e Goilicic } \\
\text { (2002); Cassivi (2006); Ghosh e Federowicz (2008); Du et al. } \\
\text { (2009); VICS (2010); Lehoux et al. (2011); Sherer et al. (2011); }\end{array}$ \\
\hline $\begin{array}{c}\text { América do } \\
\text { Sul }\end{array}$ & Brasil (2) & Vivaldini et al. (2008); Gomes e Kliemann Neto, 2015 \\
\hline África & África do Sul (1) & Dube et al. (2012) \\
\hline
\end{tabular}

Fonte: o Autor

Diversas indústrias foram foco dos estudos, sendo os mais reportados: alimento (Stank et al., 1999; Danese, 2006; Danese, 2007; Småros, 2007; Vivaldini et al., 2008; Du et al., 2009; Dube et al., 2012; Fu, 2016), médica ou de saúde (Stank et al., 1999; Kohli e Sherer, 2006; Lin e Ho, 2014; Panahifar e Heavey, 2015c), farmacêutica (Stank et al., 1999; Danese et al., 2004; Danese, 2006; Danese, 2007; Thomassen et al., 2013; Lin e Ho, 2014), eletrônica (Stank et al., 1999; Wang et al., 2005; Kohli e Sherer, 2006; Nagashima et al., 2015), bens de consumo (McCarthy e Goilicic, 2002; Danese, 2006; Danese, 2007; Fu, 2016), química (Stank et al.,1999; McCarthy e Goilicic, 2002; Småros, 2007), vestuário (Stank et al., 1999; McCarthy e Goilicic, 2002; D’Aubeterre et al., 2008), automotiva (Danese et al., 2004; Panahifar et al., 2015b; Demiray, 2016), papel (Chang e Wang, 2008; Lehoux et al., 2010; Lehoux et al., 2011) e telecomunicação (Cassivi, 2006; Chang et al., 2007; Sherer et al., 2011).

Poucos artigos mencionam ou descrevem com detalhes o fator de contexto do tamanho das empresas apresentados nos estudos de caso. Contudo, os artigos que mencionam este contexto apresentam dimensões bem distintas, não podendo identificar alguma tendência específica para o uso do CPFR. Em relação ao fator de tamanho da empresa baseada nas receitas anuais delas, encontram-se desde \$12 milhões a cinco bilhões de dólares. No aspecto de turn over anuais as empresas variam entre \$225 milhões e dois bilhões e meio de dólares. Já em relação ao número de funcionários, constatam-se empresas desde 160 até 18.000 funcionários. 
Alguns surveys definem critérios para seleções de empresas para a amostra a partir do tamanho delas, por exemplo, Skjoett-Larsen et al. (2003) que selecionaram companhias com receitas anuais acima de 3 milhões e meio de dólares.

As características de produto é um fator visto como facilitador para a implementação do CPFR (Danese, 2007). Nagashima et al. (2015) apresentam resultados que para produtos com alta tecnologia empregada, demanda volátil e preços altos é necessária uma colaboração intensiva para ajudar os fabricantes a minimizar a incerteza na previsão de demanda. Danese (2007) indica que se empresas participantes da mesma SC estão inseridas no mesmo tipo de mercado e vendem os mesmos produtos, elas devem adotar um nível alto de colaboração, já quando comercializam e vendem produtos diferentes, tendem a colaborar em um nível de colaboração limitada. Lin et al. (2004) apontam que empresas com produtos de características diferentes devem requerer diferentes estilos de implementações de CPFR. Stank et al. (1999) argumentam que para produtos de altos valores e grandes volumes compensam grandes custos de implementações.

No fator de agregação de produtos, implementações de CPFR são mais mencionadas para unidades mantidas em estoque (em inglês, stock keeping units SKUs) (McCarthy e Goilicic, 2002; Danese, 2007; Småros, 2007; Ghosh e Federowicz, 2008; D’Aubeterre et al., 2008; Du et al., 2009; Nagashima et al., 2015; Demiray et al., 2016) seguida de família de produtos (Danese, 2004; Vivaldini et al., 2008; Lehoux et al., 2011) e categoria de produtos (Chen et al., 2004). Para a estratégia de produção, encontram-se implementações do CPFR tanto em maketo-stock (MTS) (Danese et al., 2004; Danese, 2007; Chang et al., 2008) e maketo-order (MTO) (Danese et al., 2004; Vivaldini et al., 2008; Lehoux et al., 2011).

O horizonte de planejamento é também um fator que varia entre as implementações do CPFR na SC. Encontram-se horizonte de planejamento curto, entre 4 a 6 semanas (Stank et al., 1999; Kohli e Sherer, 2006; Vivaldini et al., 2008), horizonte de planejamento médio, entre 3 a 4 meses (Småros, 2007; Du et al., 2009) e horizonte de planejamento longo, entre 6 a 24 meses (Danese, 2004; Lin et al., 2004; Chung e Leung, 2005; D’Aubeterre et al., 2008; VICS, 2010; Sherer et al., 2011; Lehoux et al., 2011; Gomes e Kliemann Neto, 2015; Demiray et al., 2016), não podendo assim precisar uma tendência.

O fator de contexto do número de parceiros influencia a implementação do CPFR na indústria. Para Danese (2007), uma SC de uma complexidade espacial 
baixa, ou seja, com poucos parceiros na SC, devem adotar um nível de profundidade de colaboração alta. Caso a complexidade da SC seja alta, com vários parceiros na cadeia, tende-se a adotar um nível de colaboração limitada.

\subsection{Inputs}

Os fatores de estudo dos inputs são apresentados na tabela 4, agrupados em demanda, inventário/produção, suprimentos/entrega e finanças. A maioria dos inputs ao implementar a prática do CPFR está relacionada a fatores de demanda (67 citações), com maior concentração em informações sobre vendas e previsão de venda/demanda, resultado que corrobora Thomé et al. (2014), que mencionam que grande parte dos inputs para o processo de CPFR estão relacionados a fatores de demanda, com maior concentração em aspectos relacionados a vendas, marketing e previsões. Já no fator de inventário/estoque (31 citações), o item de nível de estoque prevalece entre os demais insumos operacionais relacionados ao inventário. As variáveis de suprimento/entrega (25 citações) são menos frequentes nos estudos empíricos em CPFR, embora alguns autores tenham relatado a importância de informações relacionadas aos planos funcionais para a entrega. Os dados financeiros estão ausentes dos casos. 


\begin{tabular}{|c|c|c|c|c|c|c|c|c|c|c|c|c|c|}
\hline \multirow[t]{2}{*}{ Referência } & \multicolumn{5}{|c|}{ Demanda } & \multicolumn{4}{|c|}{ Inventário/Produção } & \multicolumn{3}{|c|}{ Suprimento/Entrega } & \multirow{2}{*}{$\begin{array}{c}\text { Finanças } \\
\begin{array}{c}\text { Planos finan- } \\
\text { ceiros }\end{array}\end{array}$} \\
\hline & $\begin{array}{l}\text { Informações } \\
\text { sobre ven- } \\
\text { das }\end{array}$ & $\begin{array}{l}\text { Previsão } \\
\text { de vendas/ } \\
\text { demanda }\end{array}$ & $\begin{array}{l}\text { Impacto } \\
\text { da de- } \\
\text { manda }\end{array}$ & $\begin{array}{l}\text { Planos funcio- } \\
\text { nais }\end{array}$ & $\begin{array}{l}\text { Ações de } \\
\text { marketing }\end{array}$ & $\begin{array}{c}\text { Nível de } \\
\text { inventário }\end{array}$ & $\begin{array}{l}\text { Política de } \\
\text { inventário }\end{array}$ & $\begin{array}{c}\text { Capacidade } \\
\text { de produ- } \\
\text { ção }\end{array}$ & $\begin{array}{c}\text { Planos } \\
\text { funcionais }\end{array}$ & $\begin{array}{c}\text { Nível de } \\
\text { serviço } \\
\text { alvo }\end{array}$ & $\begin{array}{l}\text { Planos funcio- } \\
\text { nais }\end{array}$ & Remessas & \\
\hline ank et al. (1999) & & & & & & $\mathrm{X}$ & & & & & & & \\
\hline 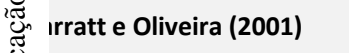 & $x$ & $\mathrm{X}$ & $\mathrm{X}$ & $\mathrm{X}$ & $\mathrm{X}$ & $\mathrm{X}$ & & & & & $\mathrm{X}$ & & \\
\hline cCarthy e Goilicic (2002) & $x$ & $\mathrm{X}$ & $\mathrm{X}$ & $\mathrm{X}$ & $\mathrm{X}$ & & & & & & $\mathrm{X}$ & & \\
\hline joett-Larsen et al. (2003) & & & & & $\mathrm{X}$ & & & & $\mathrm{X}$ & & & & \\
\hline in et al. (2004) & $x$ & $\mathrm{X}$ & & & & $\mathrm{X}$ & & & & $\mathrm{X}$ & & $\mathrm{X}$ & \\
\hline Inese et al. (2004) & $x$ & $\mathrm{X}$ & $\mathrm{X}$ & $\mathrm{X}$ & $\mathrm{X}$ & $\mathrm{X}$ & & & & $\mathrm{X}$ & $\mathrm{X}$ & & \\
\hline Lin et al. (2004) & $x$ & $\mathrm{X}$ & & & & $\mathrm{X}$ & & $\mathrm{X}$ & & & & & \\
\hline Wang et al. (2005) & $x$ & & & & & & & & & & & & \\
\hline Chung e Leung (2005) & $x$ & $\mathrm{X}$ & & & & $\mathrm{X}$ & & & & & $\mathrm{X}$ & $\mathrm{X}$ & \\
\hline Kohli e Sherer (2006) & $x$ & & & & & & & & & & & & \\
\hline Danese (2006) & $x$ & $\mathrm{X}$ & & $\mathrm{X}$ & $\mathrm{X}$ & $\mathrm{X}$ & & $\mathrm{X}$ & & & $\mathrm{X}$ & & \\
\hline Cassivi (2006) & & $\mathrm{X}$ & & & & & & $\mathrm{X}$ & & & & $\mathrm{X}$ & \\
\hline Danese (2007) & $x$ & $\mathrm{X}$ & & $\mathrm{X}$ & & $\mathrm{X}$ & & $\mathrm{X}$ & & & & & \\
\hline Småros (2007) & $x$ & & $\mathrm{X}$ & $\mathrm{X}$ & & & & & & & $\mathrm{X}$ & & \\
\hline Chang et al. (2007) & $x$ & $\mathrm{X}$ & $\mathrm{X}$ & & $\mathrm{X}$ & $\mathrm{X}$ & $\mathrm{X}$ & & & $\mathrm{X}$ & $\mathrm{X}$ & & \\
\hline Vivaldini et al. (2008) & $x$ & & & $\mathrm{X}$ & & $\mathrm{X}$ & $\mathrm{X}$ & & & & & & \\
\hline Chang e Wang (2008) & $x$ & $\mathrm{X}$ & & & & & $\mathrm{X}$ & & & & & $\mathrm{X}$ & \\
\hline Ghosh e Fedorowicz (2008) & $x$ & $\mathrm{X}$ & & & $\mathrm{X}$ & $\mathrm{X}$ & & & & & $\mathrm{X}$ & $\mathrm{X}$ & \\
\hline
\end{tabular}




\begin{tabular}{|c|c|c|c|c|c|c|c|c|c|c|c|c|c|}
\hline \multirow[t]{2}{*}{ Referência } & \multicolumn{5}{|c|}{ Demanda } & \multicolumn{4}{|c|}{ Inventário/Produção } & \multicolumn{3}{|c|}{ Suprimento/Entrega } & \multirow{2}{*}{\begin{tabular}{|c|} 
Finanças \\
$\begin{array}{c}\text { Planos finan- } \\
\text { ceiros }\end{array}$
\end{tabular}} \\
\hline & $\begin{array}{l}\text { Informações } \\
\text { sobre ven- } \\
\text { das }\end{array}$ & $\begin{array}{l}\text { Previsão } \\
\text { de vendas/ } \\
\text { demanda }\end{array}$ & $\begin{array}{l}\text { Impacto } \\
\text { da de- } \\
\text { manda }\end{array}$ & $\begin{array}{l}\text { Planos funcio- } \\
\text { nais }\end{array}$ & $\begin{array}{l}\text { Ações de } \\
\text { marketing }\end{array}$ & $\begin{array}{c}\text { Nível de } \\
\text { inventário }\end{array}$ & $\begin{array}{l}\text { Política de } \\
\text { inventário }\end{array}$ & $\begin{array}{l}\text { Capacidade } \\
\text { de produ- } \\
\text { ção }\end{array}$ & $\begin{array}{l}\text { Planos } \\
\text { funcionais }\end{array}$ & $\begin{array}{l}\text { Nível de } \\
\text { serviço } \\
\text { alvo }\end{array}$ & $\begin{array}{l}\text { Planos funcio- } \\
\text { nais }\end{array}$ & Remessas & \\
\hline${ }_{Z}^{\circ}$ Aubeterre et al. (2008) & $x$ & & $\mathrm{X}$ & $\mathrm{X}$ & $\mathrm{X}$ & $X$ & $\mathrm{X}$ & & & & $\mathrm{X}$ & $\mathrm{X}$ & \\
\hline (2009) & $x$ & $\mathrm{X}$ & & $\mathrm{X}$ & $\mathrm{X}$ & & $\mathrm{X}$ & $\mathrm{X}$ & $\mathrm{X}$ & & $\mathrm{X}$ & $\mathrm{X}$ & \\
\hline 唏 | et al. (2010) & & & & & & & & & & & & & \\
\hline CS (2010) & & $\mathrm{X}$ & & $\mathrm{X}$ & & $\mathrm{X}$ & & & & & & & \\
\hline$\stackrel{\ominus}{q}$ houx et al. (2011) & $x$ & & & & & & & & & & & & \\
\hline i erer et al. (2011) & & $\mathrm{X}$ & & & & $\mathrm{X}$ & & & & & & $\mathrm{X}$ & \\
\hline \multicolumn{14}{|l|}{ Dube et al. (2012) } \\
\hline Ramanathan e Gunasekaran (2012) & $x$ & & & & $\mathrm{X}$ & & & & & & $\mathrm{X}$ & & \\
\hline Lin e Ho (2014) & $x$ & & & & & $\mathrm{X}$ & & $\mathrm{X}$ & & & $\mathrm{X}$ & & \\
\hline \multicolumn{14}{|l|}{ Panahifar et al. (2015b) } \\
\hline \multicolumn{14}{|l|}{ Panahifar e Heavey (2015c) } \\
\hline \multicolumn{14}{|l|}{ Gomes e Kliemann Neto (2015) } \\
\hline Nagashima et al. (2015) & $x$ & $\mathrm{X}$ & & & & & & & & & & & \\
\hline Demiray (2016) & $x$ & $\mathrm{X}$ & & & & $\mathrm{X}$ & $\mathrm{X}$ & & & $\mathrm{X}$ & & $\mathrm{X}$ & \\
\hline Fu (2016) & & & & & & & & & & & & & \\
\hline
\end{tabular}

Fonte: o Autor 


\subsection{Reuniões e colaboração}

A reunião é definida como um veículo principal do CPFR usado nas organizações para facilitar o ajuste mútuo, sendo um dispositivo de ligação (Danese et al., 2004; Hollmann, 2014). No CPFR são estabelecidas reuniões para diferentes objetivos, como é possível identificar nos estudos empíricos selecionados. Reuniões com o objetivo de definir os pontos a serem desenvolvidos pela equipe de implementação e alinhar o foco e os objetivos do trabalho (Vivaldini et al., 2008), reuniões para discutir contratos de colaboração a serem firmados (Danese et al., 2004) ou para fornecer orientação e supervisão para o projeto CPFR (Chung e Leung, 2005). E também, reuniões que permitem analisar as diferenças e variações entre a demanda real e a demanda esperada (Ghosh e Fedorowic, 2008; D'Aubeterre et al., 2008). De modo a compreender como é estabelecido a estrutura do processo de reuniões em CPFR, esta seção descreve a partir dos estudos empíricos os participantes entre empresas e participantes internos das empresas, além de relacionamentos, nível de colaboração e regularidade.

Os participantes inseridos em projetos de implementação do CPFR na SC variam de uma cadeia a outra. A Tabela 5 apresenta os níveis na SC em que a colaboração e o compartilhamento de informações ocorrem. É possível notar que grande parte das relações ocorrem a jusante da cadeia entre fabricante e varejista/distribuidor tendo poucas exceções a montante da cadeia. Dube et al. (2012) confirmam que a crescente concorrência e a rápida implementação de tecnologias avançadas de informação incentivaram os varejistas e fabricantes a modificar suas cadeias de suprimentos e a utilizar modelos de CPFR para reduzir custos e melhorar a eficiência. Outro modo bastante citado é envolvendo o nível de fornecedor a esses participantes. O CPFR pode ser estendido para abranger mais de dois níveis de negociação entre parceiros, incluindo, por exemplo, fornecedores dos fabricantes (Gomes e Kliemann Neto, 2015). Outros tipos de níveis de relação de colaboração na cadeia são mencionados, mas em menor proporção. A partir de um survey, Cassivi (2006) divide em três grupos a forma de colaboração entre os parceiros, indicando que o primeiro grupo, que contém 17 empresas, realiza um planejamento de colaboração mínimo em ambos os lados da cadeia de suprimentos. O segundo e menor dos três grupos inclui sete empresas que tendem a planejar a co- 
laboração de forma mais tradicional concentrando-se principalmente em seus fornecedores. E por fim, as 16 empresas do terceiro grupo visam criar uma cadeia de suprimentos contínua, planejando a colaboração em ambos os lados da cadeia.

Tabela 5 - Participantes entre empresas do projeto CPFR

\begin{tabular}{|c|c|}
\hline Níveis envolvidos na SC & Referências \\
\hline Fornecedor - Fabricante - Varejista/Distribuidor & $\begin{array}{c}\text { Danese et al. (2004); Cassivi (2006); Danese (2007); } \\
\text { Vivaldini et al. (2008); Chang e Wang (2008); Du et } \\
\text { al. (2009); Gomes e Kliemann Neto (2015) }\end{array}$ \\
\hline Fabricante - Varejista/Distribuidor & $\begin{array}{c}\text { Stank et al. (1999); McCarthy e Goilicic (2002); Chen } \\
\text { et al. (2004); Lin et al. (2004); Wang et al. (2005); } \\
\text { Chung e Leung (2005); Kohli e Sherer (2006); } \\
\text { Danese (2006); Danese (2007); Småros (2007); } \\
\text { D'Aubeterre et al. (2008); VICS (2010); Lehoux et al. } \\
\text { (2010); Lehoux et al. (2011); Dube et al. (2012); } \\
\text { Nagashima et al. (2015); Demiray (2016); Fu (2016) }\end{array}$ \\
\hline Fornecedor - Varejista/Distribuidor & $\begin{array}{c}\text { Chang et al. (2007); Ghosh e Fedorowicz (2008); Lin } \\
\text { e Ho (2014) }\end{array}$ \\
\hline Fornecedor - Fabricante & Cassivi (2006); Danese (2007); \\
\hline Atacadista - Varejista & Thomassen et al. (2013) \\
\hline
\end{tabular}

Fonte: o Autor

Várias áreas ou departamentos internos das organizações que participam do projeto do CPFR são citados nos estudos empíricos, em destaque estão: vendas, compras, marketing, logística, finanças, produção e operações. Resultados revelam que uma das melhores maneiras de facilitar o sucesso do CPFR é colocar muito mais ênfase na integração de comunicação e colaboração entre os departamentos, como exemplo os departamentos de vendas, marketing, financeiro e compras (Fu et al., 2010). Da mesma maneira, a falta de integração interna dificulta a implementação do CPFR, pois a sua ausência pode fazer com que as informações sejam perdidas e os esforços de colaboração acabem (Småros, 2007; Chang e Wang, 2008).

O primeiro passo que os parceiros comerciais devem adotar para permitir a implementação do processo CPFR é desenvolver um ambiente adequado de relacionamento (Stank et al., 1999; Barratt e Oliveira, 2001). Os varejistas devem prestar atenção ao estabelecimento de relações de confiança com as partes interessadas e criar canais de comunicação para manter essas parcerias (Chang et al., 2008; Fu et al., 2010; Fu, 2016). Durante a adoção do CPFR e a integração de seus processos, podem surgir problemas organizacionais internos e externos muito sérios. Portanto, ambas as partes prestam mais atenção às questões de gerencia- 
mento de relações, e pode haver menos preocupação com os problemas tecnológi$\cos (\mathrm{Fu}, 2016)$. A utilização do CPFR requer mudanças significativas nos processos de negócios. A incerteza diminui à medida que os benefícios se tornam evidentes ao longo do tempo (Sherer et al., 2011). Existe uma clara diferença em como o varejista e os fornecedores analisam a relação entre eles. No estudo de caso apresentado em Ghosh e Fedorowicz (2008), o poder do varejista definiu a natureza do relacionamento entre eles. O parceiro maior mantinha claramente mais poder. O varejista possuía a infraestrutura de tecnologia usada para suportar CPFR, e assim controlou como e quando a informação foi trocada, e até mesmo cobrada aos fornecedores pela participação. No caso em que o fornecedor possuía o poder entre o comprador e o fornecedor, o fornecedor se recusou a pagar a taxa solicitada e o varejista recuou devido à importância desse fornecedor. Sherer et al. (2011) apontam que culturas com alta incerteza evitam mais tempo para implementar CPFR. A incerteza pode ser reduzida por meio do desenvolvimento de novas relações e/ou fornecer documentação de processos e benefícios.

O que influencia o nível de colaboração na SC é o grau de confiança entre os parceiros e da comunicação existente entre eles (Fu, 2016). Uma abordagem realista para o CPFR é começar focando em algumas relações e processos, expandindo o conceito ao longo do tempo para lidar com mais processos e relações (Skjoett-Larsen et al., 2003). Para Danese (2007), a profundidade da colaboração depende dos objetivos do CPFR. Em particular, quando o objetivo da colaboração do CPFR é a eficiência, as empresas tendem a limitar a colaboração à troca de dados (ou seja, nível de comunicação). Quando o objetivo da colaboração do CPFR é a capacidade de resposta, as empresas tendem a colaborar em um nível de colaboração total ou limitada. Nagashima et al. (2015) apontam que a intensidade da colaboração entre fornecedor e varejista foi determinada utilizando os modelos CPFR, citados como: CPFR básico, CPFR em desenvolvimento, e o último nível, CPFR avançado. Realizando uma análise de dados por meio do método ANOVA no setor de produtos eletrônicos foi constatado que para um nível de CPFR avançado, ou seja, com alta intensidade de colaboração, a precisão da previsão obteve um resultado positivo. Já sem adoção do CPFR, ou seja, sem nenhuma colaboração, resultados apontaram que a precisão da previsão obteve um resultado negativo. Enquanto que, as intensidades de colaboração baixas (CPFR básico) e moderada (CPFR em desenvolvimento) não obtiveram efeito. Os resultados sugerem 
que os profissionais devem colaborar, principalmente para evitar o efeito negativo da ausência de colaboração. No entanto, é esperado uma influência positiva da colaboração apenas adotando o CPFR avançado.

A regularidade de reunião varia de uma SC para outra: uma reunião semanal entre o varejista e os fornecedores enfoca as variações entre os dois conjuntos de previsões e as ordens reais (Ghosh e Fedorowicz, 2008); a SupplyCo realiza reuniões quinzenais para analisar as diferenças e variações entre a demanda real e a demanda esperada (D’Aubeterre et al., 2008); os parceiros realizam uma reunião a cada 3 meses de acordo com o contrato de colaboração assinado (Demiray et al., 2016); planos de negócios conjuntos a cada semestre na Rede B e todos os anos são realizados na Rede C (Danese et al., 2004).

\subsection{Organização}

A prontidão organizacional (capacidade tecnológica adequada, funcionários treinados, suficiência financeira e disposição e cultura organizacional para colaborar com parceiros comerciais) é um fator de sucesso chave (Skjoett-Larsen et al., 2003; Du et al., 2009). A sua definição é considerada um critério para a escolha do parceiro de negócio mais apropriado para implementar o CPFR (Demiray et al., 2016). As empresas devem reconhecer a importância do nível de serviço oferecido ao cliente e saber que as diferenças culturais podem afetar a evolução do processo (Sherer et al., 2011). Alguns critérios escolhidos para o parceiro de negócio mais apropriado para a implementação do CPFR são: comunicação, equipe técnica, relações comerciais, situação financeira e cooperação (Demiray et al., 2016). A falta de integração interna (Småros, 2007) e de treinamento colaborativo de previsão (Chen et al., 2007) são citados como impedimentos organizacionais. É importante treinar os integrantes da equipe para explorar os benefícios da colaboração (McCarthy e Goilicic, 2002; Du et al., 2009). Sem uma comunicação adequada, os funcionários não conseguem entender o propósito ou as vantagens do conceito, como resultado, os funcionários irão se opor quando suas funções forem afetadas e se recusarão a seguir os procedimentos que apoiem a mentalidade CPFR (Skjoett-Larsen et al., 2003). Portanto, educação e treinamento adequados devem ser fornecidos por meio de uma comunicação interna eficaz para ajudar os funcionários a entender o processo operacional, benefícios e modelo de funciona- 
mento do CPFR (Chen et al., 2004), conforme já mencionado na discussão dos facilitadores do CPFR. Resultados indicam que tanto o custo implementado relacionado quanto o risco de falha na implementação diminuirão se os varejistas tiverem experiência suficiente para implementar o CPFR (Fu et al., 2010). Um fator que muito contribui para confiar em seu parceiro o processo de implementação do CPFR é estar bem estruturado tecnologicamente para a gestão de informações (Vivaldini et al., 2008).

A composição da equipe de implementação do CPFR é papel fundamental para o sucesso da prática (Danese, 2007). Em McCarthy e Goilicic (2002), os vendedores, os gerentes de compras e os de produção dos parceiros envolvidos são os principais componentes. Chen et al. (2004) incluem gerentes de tecnologia da informação e de logística. Para Sherer et al. (2011) é importante que o líder de projeto já tenha experiência anterior com o CPFR ou outro método colaborativo. No estudo de caso apresentado em Gomes e Kliemann Neto (2015), a implementação do CPFR foi liderada pelo gerente de compras e logística da empresa fabricante de adesivos. Chung e Leung (2005) expõem no estudo de caso os componentes da equipe em: um líder de projeto, um representante logístico, um de vendas, um de atendimento ao cliente e um da área de planejamento e previsão de cada empresa. Já em Vivaldini et al. (2008), os envolvidos no projeto de implementação do CPFR foram nove profissionais corporativos da rede de fast food, doze representantes dos fornecedores, seis do provedor de serviço logístico e trinta funcionários dos restaurantes da rede de fast food. O contrato de acordo de colaboração é elaborado pela alta gerência (Danese et al., 2004). Em Demiray et al. (2016) os parceiros organizaram uma equipe de ambas as empresas para monitorar os medidores de desempenho e calcular o benefício obtido com a colaboração.

A maioria da estrutura e processos do CPFR são baseados no modelo de nove passos de VICS (Stank et al., 1999; Barratt e Oliveira, 2001; Chen et al., 2004; Danese et al., 2004; Lin et al., 2004; Wang et al., 2005; D'Aubeterre et al., 2008; Nagashima et al., 2015). No entanto, devido a rigidez de etapas, custos e complexidade (McCarthy e Golicic, 2002; Skjoett-Larsen et al., 2003; Småros, 2007; Du et al., 2009) alguns se baseiam no modelo de processo VICS para adaptar a um novo modelo (Danese, 2007; Chang e Wang, 2008; Du et al., 2009). A empresa analisada no estudo de caso seguiu as principais etapas básicas do CPFR, ao mesmo tempo em que o adaptava à realidade do planejamento e operações da 
empresa (Wang et al., 2005). Du et al. (2009) consideram o modelo do VICS (2004) muito complicado para implementar e propõe um novo modelo para produtos agrícolas. Outros estudos expõem os próprios modelos. Chang et al. (2007) propõem um modelo de CPFR de seis passos, incluindo um provedor de serviços de aplicativos. Já Demiray et al. (2016) elaboram um roadmap de sete fases com o de objetivo fornecer uma metodologia completa para os profissionais e acadêmicos interessados na prática do CPFR.

\subsection{Tecnologia da informação e comunicação}

Os desenvolvimentos recentes nas novas tecnologias para armazenar, trocar, processar e comunicar informações dentro e entre empresas, ou seja, tecnologia da informação e comunicação (TIC), são ferramentas importantes para todas as etapas do processo de CPFR. Thomassen et al. (2013) exploram que além do sistema de planejamento de recursos empresariais (em inglês, Enterprise Resource Planning - ERP) tradicionalmente conhecido por apoiar o planejamento e controle de operações dentro das empresas, o CPFR pode ser suportado também por outros tipos de aplicações avançadas de TIC, incluindo, por exemplo, sistemas automatizados de reposição, sistemas avançados de planejamento e agendamento (em inglês, Advanced Planning and Scheduling Systems - APS), software colaborativo e intercâmbio eletrônico de dados (em inglês, Electronic Data Interchange - EDI). Dube et al. (2012) concluem por meio de um survey que os parceiros de negócios entendem a importância do compartilhamento de informação e a comunicação efetiva com o CPFR e ressaltam que a implementação de sistemas ERP podem beneficiar tanto os varejistas e fornecedores, permitindo uma redução nos custos de compras e estoque, além de resultar na melhoria geral no compartilhamento de informações e na tomada de decisões mais eficientes. Para Vivaldini et al. (2008) um processo como o de implementação do CPFR, fundamentalmente, se apoia na tecnologia da informação e comunicação. Assim, é primordial estar apoiado num sistema de dados robusto, com processamento ágil e seguro, capaz de trabalhar com todas as interfaces necessárias.

A ECR Europe (2002) enfatiza que tecnologias simples podem ser usadas como fax, planilhas de vendas, e-mails em pedidos e previsão, bem como ferramentas TIC mais complexas como EDI, portais web, previsão e simulação conjun- 
ta sincronizadas. Os resultados mostram que os fundamentos da infraestrutura de tecnologia da informação e comunicação, como a internet e os cabos de rede, são fatores críticos para implementação do CPFR (Fu et al., 2010). Qualquer expansão a longo prazo de uma iniciativa CPFR deve ser suportada por um desenvolvimento de TIC consistente (Barratt e Oliveira, 2001). A tecnologia de informação tem o potencial de beneficiar as organizações que estão planejando adotar o CPFR, bem como as organizações que já o adotaram (D”Autberrere, 2008).

A partir de uma busca por meio dos estudos empíricos selecionados, foi observado que sistemas desenvolvidos pelas empresas baseado na internet são os mais utilizados por elas (11 citações), além de TIC mais simples, como e-mail e planilhas (5 citações cada uma). As interfaces de usuário baseadas na Web são muito fáceis de aprender e usar. Muitos fornecedores, que podem ter pouca infraestrutura de informações, podem ser conectados ao sistema por pequenos investimentos em serviços e dispositivos de acesso à internet. Como a maioria das pequenas empresas não possuem seus próprios sistemas de informação e infraestrutura de TI, esta é a melhor maneira de implementar o processo CPFR nestas empresas, possibilitando que a empresa crie e amplie sua rede de fornecedores (Wang et al., 2005).

\subsection{Métricas}

As métricas são medidas principalmente por variáveis relacionadas ao mercado, finanças e operações (Thomé et al., 2014). O número de citações relacionadas as medidas operacionais (27 citações) superam em grande quantidade as citações relatadas em relação ao mercado e a finanças ( 9 e 8 citações respectivamente). Essa ocorrência constata com o que foi encontrado em Thomé et al. (2014) e Hollmann et al. (2015), que mencionam o fato de que os indicadores financeiros estão ausentes das métricas sendo menos representados como resultado do processo. Na métrica de operações nos estudos empíricos em CPFR analisados, destacase gestão de estoque como a principal, nas quais os itens de estoque total, taxa de preenchimento de estoque e falta de estoque são as medidas mais citadas nesses estudos. Demiray (2016) constata a partir de um estudo de caso que a vantagem mais importante ao implementar a prática do CPFR foi que o estoque total dos parceiros da SC diminuiu em $10 \%$ enquanto a taxa de preenchimento aumentou. O 
CPFR possibilitou melhorar ambos os indicadores de desempenho ao mesmo tempo, mesmo sendo mais fácil elevar a taxa de preenchimento aumentando o estoque em mãos. Chung e Leung (2005) observaram em um projeto piloto de CPFR implementado no setor de varejo na China, problemas da falta de estoque ocorrendo ocasionalmente devido à mudança de engenharia frequente no design do produto eletrônico. Lin et al. (2004) abordam que após um período de implementação do CPFR, a análise dos resultados obtidos nas medidas de desempenho é um fator chave para comparar se ganhos significativos ocorrem com a implementação da prática e destaca-se a partir de um estudo de caso a seleção de nove principais medidas de desempenho definidas pela equipe de projeto do CPFR.

A Tabela 6 sintetiza as métricas encontradas em toda a revisão da literatura de estudos empíricos em CPFR, agrupadas em: mercado, finanças e operações. Percebe-se, contudo, que ainda existe uma carência de estudos que focam em métricas para CPFR, o que corrobora com Thomé et al. (2014) e Thomé et al. (2012) no que tange a prática de S\&OP. 


\begin{tabular}{|c|c|c|c|c|c|c|c|c|c|c|c|c|c|}
\hline \multirow[t]{2}{*}{ Referência } & \multicolumn{3}{|c|}{ Finanças } & \multicolumn{4}{|c|}{ Mercado } & \multicolumn{6}{|c|}{ Operações } \\
\hline & Receitas & Rentabilidade & Custos & $\begin{array}{l}\text { Tempo de } \\
\text { mercado }\end{array}$ & $\begin{array}{c}\text { Acurácia } \\
\text { de previ- } \\
\text { são }\end{array}$ & Vendas & $\begin{array}{l}\text { Incerteza } \\
\text { de de- } \\
\text { manda }\end{array}$ & $\begin{array}{l}\text { Gestão de } \\
\text { estoque }\end{array}$ & $\begin{array}{l}\text { Gestão } \\
\text { de mate- } \\
\text { rial }\end{array}$ & $\begin{array}{l}\text { Fluxo de } \\
\text { Material }\end{array}$ & $\begin{array}{l}\text { Cumprimento } \\
\text { de pedidos }\end{array}$ & $\begin{array}{l}\text { Nível de } \\
\text { serviço }\end{array}$ & Produção \\
\hline Stank et al. (1999) & & & & & & & & & & $\mathrm{x}$ & $\mathrm{x}$ & & \\
\hline Barratt e Oliveira (2001) & & & & & & & & $\mathrm{x}$ & & & & & \\
\hline McCarthy e Goilicic (2002) & & $\mathrm{x}$ & $\mathrm{x}$ & & $\mathrm{x}$ & & & $\mathrm{x}$ & & & $\mathrm{x}$ & $\mathrm{x}$ & \\
\hline \multicolumn{14}{|l|}{ Skjoett-Larsen et al. (2003) } \\
\hline Chen et al. (2004) & & $\mathrm{X}$ & & & $\mathrm{x}$ & & & $\mathrm{x}$ & & & & & \\
\hline \multicolumn{14}{|l|}{ Danese et al. (2004) } \\
\hline Lin et al. (2004) & & & & & $\mathrm{x}$ & & & $\mathrm{x}$ & & & & & \\
\hline \multicolumn{14}{|l|}{ Wang et al. (2005) } \\
\hline Chung e Leung (2005) & & & & & $\mathrm{x}$ & & & $\mathrm{x}$ & & & $\mathrm{x}$ & & \\
\hline \multicolumn{14}{|l|}{ Kohli e Sherer (2006) } \\
\hline \multicolumn{14}{|l|}{ Danese (2006) } \\
\hline \multicolumn{14}{|l|}{ Cassivi (2006) } \\
\hline Danese (2007) & & & & & & & & $\mathrm{x}$ & & & & $\mathrm{x}$ & \\
\hline \multicolumn{14}{|l|}{ Småros (2007) } \\
\hline Chang et al. (2007) & & & & & $\mathrm{x}$ & & & & & & & $\mathrm{x}$ & \\
\hline Vivaldini et al. (2008) & & & & & & & & $\mathrm{x}$ & & $\mathrm{x}$ & & $\mathrm{x}$ & \\
\hline Chang e Wang (2008) & & & & & $\mathrm{x}$ & & & & & & & & \\
\hline Ghosh e Fedorowicz (2008) & & & & & & & & & & & & & \\
\hline
\end{tabular}




\begin{tabular}{|c|c|c|c|c|c|c|c|c|c|c|c|c|c|}
\hline \multirow{2}{*}{ Referência } & \multicolumn{3}{|c|}{ Finanças } & \multicolumn{4}{|c|}{ Mercado } & \multicolumn{6}{|c|}{ Operações } \\
\hline & Receitas & Rentabilidade & Custos & $\begin{array}{l}\text { Tempo de } \\
\text { mercado }\end{array}$ & $\begin{array}{c}\text { Acurácia } \\
\text { de previ- } \\
\text { são }\end{array}$ & Vendas & $\begin{array}{l}\text { Incerteza } \\
\text { de de- } \\
\text { manda }\end{array}$ & $\begin{array}{l}\text { Gestão de } \\
\text { estoque }\end{array}$ & $\begin{array}{c}\text { Gestão } \\
\text { de mate- } \\
\text { rial }\end{array}$ & $\begin{array}{l}\text { Fluxo de } \\
\text { Material }\end{array}$ & $\begin{array}{l}\text { Cumprimento } \\
\text { de pedidos }\end{array}$ & $\begin{array}{l}\text { Nível de } \\
\text { serviço }\end{array}$ & Produção \\
\hline \multicolumn{14}{|l|}{ D'Aubeterre et al. (2008) } \\
\hline Du et al. (2009) & & $\mathrm{x}$ & & & $\mathrm{x}$ & $\mathrm{x}$ & & $\mathrm{x}$ & & & $\mathrm{x}$ & & \\
\hline Fu et al. (2010) & & & & & & & & $\mathrm{x}$ & & & & & \\
\hline Lehoux et al. (2010) & & & $\mathrm{x}$ & & & & & $\mathrm{x}$ & & & & & \\
\hline Vics (2010) & & & $\mathrm{x}$ & & & & & & & & & $\mathrm{x}$ & \\
\hline Lehoux et al. (2011) & & & $\mathrm{x}$ & & & & & $\mathrm{x}$ & & & & & \\
\hline Sherer et al. (2011) & & & & & $\mathrm{x}$ & & & $\mathrm{x}$ & & & & $\mathrm{x}$ & \\
\hline \multicolumn{14}{|l|}{ Dube et al. (2012) } \\
\hline \multicolumn{14}{|c|}{ Ramanathan e Gunasekaran (2012) } \\
\hline Thomassen et al. (2013) & & & $\mathrm{x}$ & & & & & & & & & & \\
\hline \multicolumn{14}{|l|}{ Lin e Ho (2014) } \\
\hline \multicolumn{14}{|l|}{ Panahifar et al. (2015b) } \\
\hline \multicolumn{14}{|l|}{ Panahifar e Heavey (2015c) } \\
\hline \multicolumn{14}{|c|}{ Gomes e Kliemann Neto (2015) } \\
\hline \multicolumn{14}{|l|}{ Nagashima et al. (2015) } \\
\hline Demiray (2016) & & & & & & & & $\mathrm{x}$ & & $\mathrm{x}$ & $\mathrm{x}$ & & \\
\hline $\mathrm{Fu}(\mathbf{2 0 1 6})$ & & & & & & & & & & & & & \\
\hline
\end{tabular}

Fonte: o Autor 


\subsection{Outcomes e Resultados}

Os outcomes em CPFR são apresentados na Tabela 7 e foram divididos em: plano colaborativo, previsão colaborativa e reabastecimento colaborativo. Apenas os principais itens relacionados a cada outcome foram mencionados na Tabela 7 de forma a facilitar a sua análise. Itens que não foram citados nos artigos ou itens mencionados apenas uma vez, como exemplo, planos sincronizados de produção e reabastecimento (Wang et al., 2005) e desenvolver conjuntamente reabastecimento de inventário (Danese, 2006) não fizeram parte da tabela. Os itens de previsão de vendas conjunta e previsão de pedidos conjunta associadas em outcomes de previsão colaborativa predominaram. Danese (2007) por meio de um estudo de caso múltiplo identifica, por exemplo, duas ou mais empresas compartilhando dados/informações sozinhas sem coordenar ou sincronizar seus planos. Em outros casos, as empresas colaboram como devem coordenar seus planos por meio de uma tomada de decisão conjunta ou para resolver conjuntamente as "exceções" de previsão de vendas ou pedidos. Stank et al. (1999) exploraram os níveis de envolvimento em colaboração interorganizacional e outcomes operacionais entre empresas que utilizam o CPFR. Os resultados revelaram níveis moderados de plano colaborativo, previsão e reabastecimento em todas as empresas na amostra. Níveis mais elevados de implementação são mais observados no plano colaborativo e reabastecimento colaborativo do que para a previsão colaborativa.

Os resultados em CPFR identificados nos estudos são apresentados na Tabela 8 e foram divididos em: financeiro, mercado e operacional. Os resultados são medidos principalmente por variáveis associadas ao operacional, como custos (e. g., investimento em estoque), qualidade (e.g., nível de serviço) e entrega (e.g., custo do frete). VICS (2010) apresenta em seu estudo de caso a diminuição dos custos medido por meio do investimento em estoque e do aumento da qualidade mediante a melhora do nível de serviço. Lehoux et al. (2010) comparam o custo do frete e de estoque do CPFR com o VMI e o RR, o custo do frete do CPFR é $18 \%$ menor do que o custo de envio de outros modelos, e para o mesmo cenário, o custo do estoque implementando o CPFR é até 44\% menor. Em seguida, os resultados medidos por variáveis relacionadas ao mercado aparecem também em gran- 
de quantidade, sendo estes relacionados a fatores de vendas e tempo de mercado, Thomé et al. (2014) ressaltaram a partir de sua revisão a força destes fatores de resultados. Em menor quantidade, resultados medidos a partir de finanças também foram mencionados, com destaque para rentabilidade e receitas. 


\begin{tabular}{|c|c|c|c|c|c|c|c|}
\hline \multirow[t]{2}{*}{ Referência } & \multicolumn{2}{|c|}{ Plano Colaborativo } & \multicolumn{4}{|c|}{ Previsão Colaborativa } & \multirow{2}{*}{$\begin{array}{c}\text { Reabastecimento } \\
\text { Reabastecimento colabo } \\
\text { rativo/reposição coorde- } \\
\text { nada }\end{array}$} \\
\hline & Plano conjunto & \begin{tabular}{|} 
Planejamento \\
e tomada de decisão conjun- \\
ta
\end{tabular} & $\begin{array}{c}\text { Desenvolver conjun- } \\
\text { tamente as previsões } \\
\text { da demanda }\end{array}$ & $\begin{array}{l}\text { Previsão de vendas } \\
\text { conjunta }\end{array}$ & $\begin{array}{l}\text { Previsão de pedidos } \\
\text { conjunta }\end{array}$ & $\begin{array}{l}\text { Previsão de vendas } \\
\text { conjunta }\end{array}$ & \\
\hline Stank et al. (1999) & $\mathrm{x}$ & $\mathrm{x}$ & $\mathrm{x}$ & & $\mathrm{x}$ & & $\mathrm{x}$ \\
\hline Barratt e Oliveira (2001) & & $\mathrm{x}$ & & $\mathrm{x}$ & & & \\
\hline McCarthy e Goilicic (2002) & & & $\mathrm{x}$ & & & & \\
\hline \multicolumn{8}{|l|}{ Skjoett-Larsen et al. (2003) } \\
\hline \multicolumn{8}{|l|}{ Chen et al. (2004) } \\
\hline Danese et al. (2004) & & $\mathrm{x}$ & & $\mathrm{x}$ & $\mathrm{x}$ & $\mathrm{x}$ & \\
\hline Lin et al. (2004) & & & & $\mathrm{x}$ & & & $\mathrm{x}$ \\
\hline Wang et al. (2005) & & & $\mathrm{x}$ & & & & \\
\hline Chung e Leung (2005) & & & & & & $\mathrm{x}$ & \\
\hline Kohli e Sherer (2006) & & & & & $\mathrm{x}$ & & \\
\hline Danese (2006) & & $\mathrm{x}$ & & $\mathrm{x}$ & $\mathrm{x}$ & & \\
\hline Cassivi (2006) & $\mathrm{x}$ & & & & & $\mathrm{x}$ & \\
\hline Danese (2007) & & $\mathrm{x}$ & & $\mathrm{x}$ & $\mathrm{x}$ & & \\
\hline \multicolumn{8}{|l|}{ Småros (2007) } \\
\hline Chang et al. (2007) & & & $\mathrm{x}$ & $\mathrm{x}$ & $\mathrm{x}$ & & $\mathrm{x}$ \\
\hline \multicolumn{8}{|l|}{ Vivaldini et al. (2008) } \\
\hline Chang e Wang (2008) & & & & $\mathrm{X}$ & $\mathrm{x}$ & & $\mathrm{x}$ \\
\hline
\end{tabular}




\begin{tabular}{|c|c|c|c|c|c|c|c|}
\hline \multirow[t]{2}{*}{ Referência } & \multicolumn{2}{|c|}{ Plano Colaborativo } & \multicolumn{4}{|c|}{ Previsão Colaborativa } & \multirow{2}{*}{$\begin{array}{c}\text { Reabastecimento } \\
\begin{array}{c}\text { Reabastecimento colabo } \\
\text { rativo/reposicăa coorde- } \\
\text { nada }\end{array}\end{array}$} \\
\hline & Plano conjunto & $\begin{array}{c}\text { Planejamento } \\
\text { e tomada de decisão conjun- } \\
\text { ta }\end{array}$ & $\begin{array}{l}\text { Desenvolver conjun- } \\
\text { tamente as previsões } \\
\text { da demanda }\end{array}$ & $\begin{array}{l}\text { Previsão de vendas } \\
\text { conjunta }\end{array}$ & $\begin{array}{l}\text { Previsão de pedidos } \\
\text { conjunta }\end{array}$ & $\begin{array}{l}\text { Previsão de vendas } \\
\text { conjunta }\end{array}$ & \\
\hline Ghosh e Fedorowicz (2008) & & & & & & & \\
\hline D'Aubeterre et al. (2008) & & & $\mathrm{x}$ & & $\mathrm{x}$ & & \\
\hline Du et al. (2009) & & & & & & & \\
\hline Fu et al. (2010) & & & & & & & \\
\hline Lehoux et al. (2010) & & $\mathrm{x}$ & & & & & \\
\hline Vics (2010) & & & & & & & \\
\hline Lehoux et al. (2011) & & $\mathrm{x}$ & & & & & \\
\hline Sherer et al. (2011) & $\mathrm{x}$ & $\mathrm{x}$ & & & & & \\
\hline Dube et al. (2012) & & & & & & & \\
\hline Ramanathan e Gunasekaran (2012) & & & & & & & $\mathrm{x}$ \\
\hline Thomassen et al. (2013) & & & & & & $\mathrm{x}$ & $\mathrm{x}$ \\
\hline Lin e Ho (2014) & & & & & & & \\
\hline Panahifar et al. (2015b) & & & & & & & \\
\hline Panahifar e Heavey (2015c) & & & & & & & \\
\hline Gomes e Kliemann Neto (2015) & & & & & & & \\
\hline Nagashima et al. (2015) & & & & & & & \\
\hline Demiray (2016) & $\mathrm{x}$ & & & & & & \\
\hline u (2016) & & $\mathrm{x}$ & & & & & \\
\hline
\end{tabular}

Fonte: o Autor 


\begin{tabular}{|c|c|c|c|c|c|c|c|c|c|c|}
\hline \multirow[t]{2}{*}{ Referência } & \multicolumn{3}{|c|}{ Financeiro } & \multicolumn{3}{|c|}{ Mercado } & \multicolumn{4}{|c|}{ Operacional } \\
\hline & Receitas & Rentabilidade & Custos & $\begin{array}{l}\text { Tempo de } \\
\text { mercado }\end{array}$ & Vendas & Outros & Custos & Entrega & Qualidade & Flexibilidade \\
\hline Stank et al. (1999) & & & $\mathrm{x}$ & & & & $\mathrm{x}$ & $\mathrm{x}$ & $\mathrm{x}$ & $\mathrm{x}$ \\
\hline Barratt e Oliveira (2001) & & & & & & & $\mathrm{x}$ & $\mathrm{x}$ & $\mathrm{x}$ & \\
\hline McCarthy e Goilicic (2002) & $x$ & & & $\mathrm{x}$ & & & $\mathrm{x}$ & & $\mathrm{x}$ & \\
\hline Skjoett-Larsen et al. (2003) & & & & $\mathrm{x}$ & & $\mathrm{x}$ & & & & \\
\hline Chen et al. (2004) & & & & $\mathrm{x}$ & & & $\mathrm{x}$ & & $\mathrm{x}$ & $\mathrm{x}$ \\
\hline Danese et al. (2004) & & & & & & & & & & \\
\hline Lin et al. (2004) & & & & & & & & & & \\
\hline Wang et al. (2005) & & & & & & & $\mathrm{x}$ & & & \\
\hline Chung e Leung (2005) & & $\mathrm{x}$ & & $\mathrm{x}$ & & & $\mathrm{x}$ & & $\mathrm{x}$ & $\mathrm{x}$ \\
\hline Kohli e Sherer (2006) & & & & & & & & & & \\
\hline Danese (2006) & & & & & & & & & & \\
\hline Cassivi (2006) & & & & & & & & & & \\
\hline Danese (2007) & & & & $\mathrm{x}$ & & $\mathrm{x}$ & $\mathrm{x}$ & $\mathrm{x}$ & $\mathrm{x}$ & \\
\hline Småros (2007) & & & & & & & & $\mathrm{x}$ & & \\
\hline Chang et al. (2007) & & $\mathrm{x}$ & & & & & $\mathrm{x}$ & & $\mathrm{x}$ & $\mathrm{x}$ \\
\hline Vivaldini et al. (2008) & & $\mathrm{x}$ & & & & & & $\mathrm{x}$ & $\mathrm{x}$ & \\
\hline Chang e Wang (2008) & $x$ & & & & & & $\mathrm{x}$ & & & \\
\hline Ghosh e Fedorowicz (2008) & & & & & & & $\mathrm{x}$ & & $\mathrm{x}$ & \\
\hline
\end{tabular}




\begin{tabular}{|c|c|c|c|c|c|c|c|c|c|c|}
\hline \multirow[t]{2}{*}{ Referência } & \multicolumn{3}{|c|}{ Financeiro } & \multicolumn{3}{|c|}{ Mercado } & \multicolumn{4}{|c|}{ Operacional } \\
\hline & Receitas & Rentabilidade & Custos & $\begin{array}{l}\text { Tempo de } \\
\text { mercado }\end{array}$ & Vendas & Outros & Custos & Entrega & Qualidade & Flexibilidade \\
\hline D'Aubeterre et al. (2008) & & & & & & & & & & \\
\hline Du et al. (2009) & & & & & $\mathrm{x}$ & & $\mathrm{x}$ & & & \\
\hline Fu et al. (2010) & & & & & & & & & & \\
\hline Lehoux et al. (2010) & & & & & & & & & & \\
\hline VICS (2010) & & & & & $\mathrm{x}$ & & $\mathrm{x}$ & $\mathrm{x}$ & $\mathrm{x}$ & $\mathrm{x}$ \\
\hline Lehoux et al. (2011) & & & & & & & & & & \\
\hline Sherer et al. (2011) & & $\mathrm{x}$ & & $\mathrm{x}$ & & & $\mathrm{x}$ & $\mathrm{x}$ & $\mathrm{x}$ & \\
\hline Dube et al. (2012) & & & & & & & & & & \\
\hline Ramanathan e Gunasekaran (2012) & & & & & $\mathrm{x}$ & & & & & \\
\hline Thomassen et al. (2013) & & & & & & & $\mathrm{x}$ & & $\mathrm{x}$ & \\
\hline Lin e Ho (2014) & & & & & & & $\mathrm{x}$ & $\mathrm{x}$ & $\mathrm{x}$ & \\
\hline Panahifar et al. (2015b) & & & & & & & & & & \\
\hline Panahifar e Heavey (2015c) & & & & & & & & & $\mathrm{x}$ & $\mathrm{x}$ \\
\hline Gomes e Kliemann Neto (2015) & & & & & & $\mathrm{x}$ & $\mathrm{x}$ & & & \\
\hline Nagashima et al. (2015) & & & & & $\mathrm{x}$ & & $\mathrm{x}$ & & $\mathrm{x}$ & \\
\hline Demiray (2016) & $\mathrm{x}$ & & & $\mathrm{x}$ & & & $\mathrm{x}$ & $\mathrm{x}$ & $\mathrm{x}$ & \\
\hline $\mathrm{Fu}(\mathbf{2 0 1 6})$ & & & & & & & & & & \\
\hline
\end{tabular}

Fonte: o Autor 


\section{CONCLUSÕES}

Esta dissertação fornece uma revisão sistemática destinada a realizar uma atualização das revisões sistemáticas já encontradas na literatura sobre CPFR, seguindo assim o oitavo passo proposto em Thomé et al. (2016a) para a condução desta abordagem metodológica. A dissertação ainda expande o escopo das revisões existentes ao ampliar as bases de dados utilizadas, mas concentra-se na análise dos estudos empíricos. O passo a passo para conduções de revisões sistemáticas em gerência de operações de Thomé et al. (2016a) foi adotada. Duzentos e trinta e quatro resumos e 40 artigos de texto completo foram inicialmente recuperados e 35 foram analisados para a revisão final. A dissertação apresenta seus resultados guiados por um framework de síntese para integração de cadeias de Thomé et al. (2017) adaptado da prática de S\&OP para a de CPFR. A presente pesquisa seguiu uma metodologia sistemática e objetivamente verificável de síntese de pesquisa, permitindo assim a replicação e a verificação objetiva dos resultados.

Apesar de já existir um grande volume de publicações relacionadas ao CPFR, uma queda tem sido observada a partir do ano de 2010, corroborando resultados e análises encontradas em Thomé et al. (2014), Hollmann et al. (2015) e Panahifar et al. (2015a). Uma expectativa da aplicação abaixo do esperado em relação ao CPFR também tem sido observada no mundo industrial, e o mesmo já é destacado na literatura (Hollmann, 2014; Panahifar et al., 2015a; Panahifar et al., 2016), o que vai ao encontro dos achados nessa pesquisa, sendo possível afirmar que existem fortes indícios de que o tema de CPFR está perdendo relevância e atratividade por parte dos acadêmicos e praticantes da indústria.

Os estudos empíricos relacionados ao CPFR são bem representados ao longo dos anos, mas apenas um quarto das publicações está relacionada a estudos empíricos, reforçando a observação em Thomé et al. (2014) e Panahifar et al. (2015a), que apontam a carência de estudos empíricos em CPFR. Poucas teorias foram endereçadas diretamente nestes estudos, estando elas associadas a origem em outras disciplinas (não de gerência de operações), o que está em linha com o que é preconizado por Defee et al. (2010), Boer et al. (2015) e Thomé et al. 
(2017). As teorias identificadas foram transaction cost theory, bullwhip effect, organizational learning, resource based view (RBV) e resource dependent theory (RDT). A maioria dos estudos empíricos em CPFR foi baseado na aplicação do estudo de caso simples como metodologia de pesquisa, como já observado em Panahifar et al. (2015a). Em menor quantidade, foram encontrados outros métodos de pesquisa, como survey, estudo de caso múltiplo, panel study, focus group e pesquisa ação. Isso reforça a questão de apenas uma média força de evidência associada aos resultados dos estudos em CPFR usando-se como base as escalas de Reay et al. (2009) e Thomé et al. (2016b), corroborando assim com os achados de Thomé et al. (2017) para S\&OP. Recomenda-se refazer esta pesquisa no futuro tendo como enfoque outras práticas de integração de cadeias, não apenas para ampliar o uso e aplicação do framework de síntese para integração de cadeias de Thomé et al. (2017), buscando auxiliar em sua validação externa, mas também para verificar se os achados referentes a fundamentação teórica destes estudos e a força de suas evidências estão limitadas ao CPFR e ao S\&OP, ou podem ser generalizados às práticas de integração de cadeias como um todo.

Nesta dissertação foram apresentados os objetivos dos estudos empíricos selecionados, assim como suas perguntas de pesquisa, principais conclusões e direções futuras para pesquisas. As principais barreiras observadas nestes estudos empíricos foram dificuldade de implementação, falta de integração interna, falta de suporte de gerenciamento e falta de confiança. A confiança foi a barreira predominante observada nos estudos empíricos, corroborando Panahifar et al. (2015a) e Hollmann et al. (2015). Já os principais facilitadores identificados foram processo de gestão de mudanças, predisposição cultural para compartilhar dados, estrutura organizacional flexível, estratégia de TI inovadora, compartilhamento de informações, prontidão, suporte da alta gerência, tecnologia empregada e confiança. Tecnologia empregada e confiança foram os facilitadores predominante entre eles, o que também corrobora Hollmann et al. (2015). As relações do uso do CPFR com outras práticas do SCM também foram analisadas, mas apenas confirmadas com VMI e S\&OP. A falta de vivência com estas duas práticas por parte das empresas estudadas nos artigos analisados antes de implementar o CPFR foi um dos motivos associados a dificuldade de implementar o CPFR nas indústrias (VICS, 2010; Gomes e Kliemann Neto, 2015). A análise mais profunda de iniciativas colaborativas na SC associadas ao CPFR é recomendada para futuras pesquisas. 
Não se pode observar grandes tendências em relação aos diversos fatores de contexto analisados, com exceção das características do produto e complexidade espacial da cadeia, que podem influenciar no CPFR. Em inputs, destaque para os fatores ligados a demanda, corroborando Thomé et al. (2014), e para a ausência de fatores ligados a finanças. A importância de reuniões e colaborações como dispositivos de ligação nas organizações é destacado na literatura (e.g., Danese et al., 2004; Hollmann et al., 2014). Verificou-se o envolvimento dos diversos elos da cadeia nestas reuniões do CPFR, contudo o destaque é a concentração a jusante da cadeia entre fabricantes e varejistas/distribuidores. Poucos casos analisaram o montante da cadeia (e.g., entre fornecedores e fabricantes). Também foram poucos os casos que ocorreram uma relação que não fosse diádica (entre dois membros). Conclui-se assim que a maior parte dos estudos foca a jusante da cadeia entre os membros associados a manufatura do produto e a sua distribuição, o que caracteriza assim o CPFR mais para uma prática de integração externa na cadeia com clientes do que uma integração externa com a cadeia como um todo. No âmbito interno, destaca-se também a importância da integração horizontal entre as áreas funcionais de vendas, marketing, finanças, operações, logística, produção e compras.

A implementação do CPFR é considerada um grande desafio que deve normalmente vir após a implementação de práticas de integração interna como o S\&OP ou outras práticas de integração mais simples como o VMI. Diversas áreas na empresa e dos demais membros da cadeia envolvidos com o CPFR devem estar associados com a implementação do CPFR, entre eles a alta gerência. Os nove passos do modelo de VICS (2004) são os mais utilizados, porém adaptações deste modelo também são frequentemente encontradas na indústria, corroborando assim com os achados de Hollmann et al. (2015). A TIC é considerada fundamental para que o CPFR seja bem implementado com correto funcionamento. Destacam-se como exemplos de TIC: ERP e APS. Apesar da importância de métricas para acompanhar a execução de um planejamento como o CPFR, a literatura ainda carece de estudos que tenham como enfoque as métricas, o que já foi constatado em Thomé et al. (2014). Este é um gap da literatura que merece ser abordado em estudos futuros. Os principais outcomes obtidos com o CPFR concentraram-se em variáveis associadas a previsão colaborativa, com maior enfoque em previsão de vendas conjunta e previsão de pedidos conjunta. No que tange aos resultados obti- 
dos, a literatura destaca resultados operacionais associados a redução de custos e aumento da qualidade e entrega, seguido de resultados relacionados ao mercado, como fatores de venda e tempo de mercado. Melhoras em resultados financeiros são menos descritos na literatura, onde o aumento da rentabilidade é o resultado mais destacado.

A revisão da literatura em estudos empíricos também permitiu identificar outros caminhos a serem traçados para pesquisas futuras, como desenvolver mais estudos de caso múltiplo ou surveys sobre o CPFR (Danese et al., 2004; Danese, 2006; Danese, 2007), a fim de testar e expandir resultados dos fatores de pesquisa sobre o tema. As propostas para ampliar os estudos de caso já existentes sobre CPFR são bons candidatos para a replicação, e a verificação de sua generalização para amostras maiores e diferentes indústrias (Stank et al., 1999; Skjoett-Larsen et al., 2003; Danese et al., 2004; Danese, 2006; Danese, 2007; Småros, 2007; Vivaldini et al., 2008; Chang e Wang, 2008; Panahifar et al., 2015b; Nagashima et al., 2015; Fu, 2016). Isto vai ao encontro da necessidade de ampliar a força de evidência dos estudos associados ao CPFR. Por fim, recomenda-se preencher as direções futuras de pesquisa em CPFR identificadas nos estudos empíricos por meio dessa dissertação, sendo elas: analisar como empresas com produtos de diferentes características podem exigir diferentes estruturas de implementação em CPFR (Lin et al.; 2004); investigar como gerenciar o alinhamento da demanda com a área de suprimento no CPFR (Chang e Wang, 2008); realizar estudos aprofundados para a seleção do parceiro mais adequado para colaborar no CPFR (Demiray, 2016); desenvolver e ajustar um incentivo financeiro para diferentes contextos de implementação do CPFR nas indústrias e também analisar como a concorrência afeta a eficiência das colaborações e a escolha do incentivo a implementar (Lehoux et al., 2011). 


\section{Referências Bibliográficas}

Andraski, J. C.; Haedicke, J. CPFR: time for the breakthrough? Supply Chain Management Review, v. 7, n. 3, p. 54-60. 2003.

Attaran, M.; Attaran, S. Collaborative supply chain management: the most promising practice for building efficient and sustainable supply chains. Business Process Management Journal, v. 13, n. 3, p. 390-404. 2007.

Audy, J. F.; Lehoux, N.; D’Amours, S.; Rönnqvist, M. A framework for an efficient implementation of logistics collaborations. International Transactions in Operational Research, v. 19, n. 5, p. 633-657. 2012.

Aviv, Y. Gaining benefits from joint forecasting on supply chain performance. Manufacturing and Service Operations Management, v. 4, n. 1, p. 55-74. 2002.

Bailey, K.; Francis, M. Managing information flows for improved value chain performance. International Journal of Production Economics, v. 111, n. 1, p. 2-12. 2008.

Barratt, M.; Oliveira, A. Exploring the experiences of collaborative planning initiatives. International Journal of Physical Distribution \& Logistics Management, v. 31, n. 4, p. 266-289. 2001.

Boer, H.; Holweg, M.; Kilduff, M.; Pagell. M; Schmenner, R.; Voss, C. Making a meaningful contribution to theory. International Journal of Operations \& Production Management, v. 35, n.9, p. 1231-1252. 2015.

Burnette, R. CPFR: fact, fiction, or fantasy? Journal of Business Forecasting, v. 29, n. 4, p. 32-35. 2010.

Büyüközkan, G.; Vardaloğlu, Z. Analyzing of CPFR success factors using fuzzy cognitive maps in retail industry. Expert Systems with Applications, v. 39, n. 12, p. 10438-10455. 2012.

Caridi, M.; Cigolini, R.; De Marco, D. Improving supply-chain collaboration by linking intelligent agents to CPFR. International Journal of Production Research, v. 43, n. 20, p. 4191-4218. 2005.

Caridi, M.; Cigolini, R.; Marco, D. Linking autonomous agents to CPFR to improve SCM. Journal of Enterprise Information Management, v. 19, n. 5, p. 465-482. 2006. 
Cassivi, L. Collaboration planning in a supply chain. Supply Chain Management: An International Journal, v. 11, n. 3, p. 249-258. 2006.

Chang, K. K.; Wang, F. K. Applying six sigma methodology to collaborative forecasting. The International Journal of Advanced Manufacturing Technology, v. 39, n. 9-10, p. 1033-1044. 2008.

Chang, T. H.; Fu, H. P.; Lee, W. I.; Lin, Y.; Hsueh, H. C. A study of an augmented CPFR model for the 3C retail industry. Supply Chain Management: An International Journal, v. 12, n. 3, p. 200-209. 2007.

Chen, M. C.; Chang H. H.; Chang, S. C.; Chen, S. M. Development of manufacturer-retailer relationships through collaborative management: A case study. International Journal of Innovation and Technology Management, v. 1, n. 3, p. 307-323. 2004.

Chung, W. W. C.; Leung, W. F. Collaborative planning, forecasting and replenishment: A case study in copper clad laminate industry. Production Planning and Control, v. 16, n. 6, p. 563-574. 2005.

Cigolini, R.; Rossi, T. A note on supply risk and inventory outsourcing. Production Planning \& Control, v. 17, n. 4, p. 424-437. 2006.

Cooper, H. Research synthesis and meta-analysis: a step-by-step approach. California: Sage Publications, p. 280-296. 2010.

D'Aubeterre, F.; Singh, R.; Iyer, L. A semantic approach to secure collaborative inter-organizational ebusiness processes (SSCIOBP). Journal of the Association for Information Systems, v. 9, n. 3-4, p. 231-266. 2008.

Danese, P. Collaboration forms, information and communication technologies, and coordination mechanisms in CPFR. International Journal of Production Research, v. 44, n. 6, p. 3207-3226. 2006.

Danese, P. Designing CPFR collaborations: insights from seven case studies. International Journal of Operations \& Production Management, v. 27, n. 2, p. 181-204. 2007.

Danese, P. Towards a contingency theory of collaborative planning initiatives in supply networks. International Journal of Production Research, v. 49, n. 4, p. 1081-1103. 2011.

Danese, P.; Romano, P.; Vinelli, A. Managing business processes across supply networks: the role of coordination mechanisms. Journal of Purchasing and Supply Management, v. 10, n. 4-5, p. 165-177. 2004.

Defee, C. C.; Williams, B.; Randall, W. S.; Thomas, R. An inventory of theory in logistics and SCM research. The International Journal of Logistics Management, v. 21, n. 3, p. 404-489. 2010. 
Demiray, A., Akay, D., Tekin, S.; Boran, F.E. A holistic and structured CPFR roadmap with an application between automotive supplier and its aftermarket customer. International Journal of Advanced Manufacturing Technology, v.1, p. 1-20. 2016.

Denyer, D.; Tranfield, D. Producing a Systematic Review. In The Sage Hanbook of Organizational Research Methods, p. 671-689. 2009.

Derrouiche, R.; Neubert, G.; Bouras, A. Supply chain management: a framework to characterize the collaborative strategies. International Journal of Computer Integrated Manufacturing, v. 21, n. 4, p. 426-439. 2008.

Du, X. F.; Leung, S. C. H.; Zhang, J. L.; Lai, K. K. Procurement of agricultural products using the CPFR approach. Supply Chain Management: An International Journal, v. 14, n. 4, p. 253-258. 2009.

Dube, P.; Muyengwa, G.; Battle, K. Study of collaborative planning, forecasting and replenishments in South Africa retail industry. CIE42 Proceedings, 16-18 July 2012. 2012.

ECR, Europe. A Guide to CPFR Implementation (ECR Europe facilitated by Accenture), Brussels:2001. 105 p.

ECR, Europe, European CPFR insights, (ECR Europe facilitated by Accenture), Brussels:2002. 89 p.

Flynn, B. B.; Sakakibara, S.; Schroeder, R. G.; Bates, K. A.; \& Flynn, E. J. Empirical research methods in operations management. Journal of Operations Management, v.9, p. 250-284. 1990.

Fu, H. P.; Chu, K. K.; Lin, S. W.; Chen, C. R. A study on factors for retailers implementing CPFR - A fuzzy AHP analysis. Journal of Systems Science and Systems Engineering, n. 19, v. 2, p. 192-209. 2010.

$\mathrm{Fu}, \mathrm{H}$. P. Comparing the factors that influence the adoption of CPFR by retailers and suppliers. International Journal of Logistics Management, v. 27, n. 3, p. 931-946. 2016.

Ghosh, A.; Fedorowicz, J. The role of trust in supply chain governance. Business Process Management Journal, v. 14, n. 4, p. 453-470. 2008.

Gomes, L. C. Métodos colaborativos em cadeias de suprimentos. Update. v.1, n.1, p.111-136. 2014.

Gomes, L.C.; Kliemann Neto, F.J. Métodos colaborativos na gestão de cadeia de suprimentos: desafios de implementação. Revista de Administracao de Empresas, v. 55, n. 5, p. 563-577. 2015. 
Hollmann, R. L. Uma revisão sistemática da literatura em Planejamento, Previsão e Reabastecimento Colaborativo. Dissertação de Mestrado. Departamento de Engenharia Industrial, Rio de Janeiro: Pontifícia Universidade Católica do Rio de Janeiro, 65p. 2014.

Hollmann, R. L.; Scavarda, L. F.; Thomé, A. M. T. Collaborative planning, forecasting and replenishment: a literature review. International Journal of Productivity and Performance Management, v. 64, n. 7, p. 971-993. 2015.

Ivert, L. K.; Dukovska-Popovska, I.; Kaipia, R.; Fredriksson, A.; Dreyer, H. C.; Johansson, M. I.; Chabada, L.; Damgaard, C. M.; Tuomikangas, N. Sales and operations planning: responding to the needs of industrial food producers. Production Planning \& Control, v. 26, n. 4, p. 280- 295. 2015a.

Ivert, L. K.; Dukovska-Popovska, I.; Fredriksson, A.; Dreyer, H. C.; Kaipia, R. Contingency between S\&OP design and planning environment. International Journal of Physical Distribution \& Logistics Management, v. 45, n. 8, p. 747773. $2015 b$.

Ji, Y. F.; Yang, H. L.; Bullwhip effect elimination in supply chain with CPFR. Proceedings of the 2005 International Conference on Management Science \& Engineering (12th), pp. 737-740. 2005.

Kohli, R.; Sherer, S. A. Deriving value from information technology: role of concordance investments. AMCIS 2006 Proceedings. 2006.

Kubde, R. A.; Bansod, S. V. Collaborative planning forecasting and replenishment initiatives: a state of art. Asian Journal of Industrial Engineering. v. 2, n. 3, p. 89-104. 2010.

Kuk, G. Effectiveness of vendor-managed inventory in the electronics industry: determinants and outcomes. Information \& Management, v. 41, p. 645-654. 2004.

Lehoux, N.; D'Amours, S.; Langevin, A. A win-win collaboration approach for a two-echelon supply chain: a case study in the pulp and paper industry. European Journal of Industrial Engineering, v. 4, n. 4, p. 493-514. 2010.

Lehoux, N.; D'Amours, S.; Frein, Y.; Langevin, A.; Penz, B. Collaboration for a two-echelon supply chain in the pulp and paper industry: the use of incentives to increase profit. The Journal of the Operational Research Society, v. 62, n. 4, p. 581-592. 2011.

Lewis, L. CPFR solutions. Progressive Grocer, v. 79, n. 4, p. 28-32. 2000.

Lin, J. T.; Yang, C. H.; Lin, T. M. A CPFR implementation methodology study a carpenter mechanical industry case study. International Journal of Electronic Business Management, v. 2, n. 3, p. 172-178. 2004. 
Lin, R. H.; Ho, P. Y. The study of CPFR implementation model in medical SCM of Taiwan. Production Planning and Control, v. 25, n. 3, p. 260-271. 2014.

McCarthy, T. M.; Goilicic, S. L. Implementing collaborative forecasting to improve supply chain performance. International Journal of Physical Distribution \& Logistics Management, v. 32, n. 6, p. 431-454. 2002.

Mentzer, J. T.; DeWitt, W. J.; Keebler, J. S.; Min, S.; Nix, N. W.; Smith, C. D.; Zacharia, Z. G. Defining supply chain management. Journal of Business Logistics. v. 22, n. 2, p. 1-24. 2001.

Moher, D.; Liberati, A.; Tetzlaff, J.; Altman, D. G.; The PRISMA Group. Preferred Reporting Items for Systematic Reviews and Meta-Analyses: The PRISMA Statement. 2009.

Nagashima, M.; Wehrle, F. T.; Kerbache, L.; Lassagne, M. Impacts of adaptive collaboration on demand forecasting accuracy of different product categories throughout the product life cycle. Supply Chain Management, v. 20, n. 5, p. 415-433. 2015.

Noroozi, S.; Wikner, J. Sales and operations planning in the process industry: A literature review. International Journal of Production Economics, v. 188, p. 139-155. 2017.

Panaihfar, F.; Heavey, C.; Byrne, P. J. A framework for Collaborative Planning, Forecasting and Replenishment (CPFR): State of the Art. Journal of Enterprise Information Management, v. 28, n. 6, p. 838-871. 2015a.

Panaihfar, F.; Byrne, P. J.; Heavey, C. A hybrid approach to the study of CPFR implementation enablers. Production Planning \& Control, v. 26, n. 13, p. 10901109. $2015 b$.

Panaihfar, F.; Heavey, C.; Byrne, P. J. Developing retailer selection factors for collaborative planning, forecasting and replenishment. Industrial Management and Data Systems, v. 115, p. 1292 - 1324. 2015c.

Panaihfar, F.; Ghadimi, P.; Amir, A. H.; Heavey, C.; Byrne, P. J. A Study on CPFR Implementation Critical Factors for the Automotive Spare Part Industry. 8th EUROSIM Congress on Modelling and Simulation. 2016.

Pires, S. R. I. Gestão da cadeia de suprimentos: conceitos, estratégias, práticas e casos. Editora Atlas, v. 2, 2009.

Ramanathan, U. Supply chain collaboration for improved forecast accuracy of promotional sales. International Journal of Operations \& Production Management. v. 32, n. 6, p. 676-695. 2012.

Ramanathan, U.; Gunasekaran, A. Supply chain collaboration: impact of success in long-term partnerships. International Journal of Production Economics, v. 147, n. Part B, p. 252-259. 2014. 
Reay, T.; Berta, W.; Kohn, M.K. What's the evidence on evidence-based management?. The Academy of Manage-ment Perspectives, v. 23, n. 4, p. 5-18. 2009.

Rousseau, D.; Manning, J.; Denyer, D. Evidence in Management and Organizational Science. The Academy of Management Annals, v. 2, n. 1, p. 475-515. 2008 .

Sari, K. On the benefits of CPFR and VMI: a comparative simulation study. International Journal of Production Economics, v. 113, n. 2, p. 575-586. 2008.

Scavarda, L. F.; Hellingrath, B.; Kreuter, T.; Thomé, A. M. T.; Seeling, M. X.; Fischer; J.-H.; Mello, R. A case method for Sales and Operations Planning: a learning experience from Germany. Production, 27(spe), e20162199. http://dx.doi.org/10.1590/0103-6513.219916. 2017.

Schachtman, N. Trading partners collaborate to increase sales. Information Week, n. 807, p. 72-76. 2000.

Seifert, D. Collaborative Planning Forecasting and Replenishment: How to Create a Supply Chain Advantage. New York: AMACOM, 2003. 411p.

Sherer, S. A.; Kohli, R.; Yao, Y. Do cultural differences matter in it implementation? a multinational's experience with collaborative technology. Journal of Global Information Management, v. 19, n. 4, p. 1-17. 2011.

Simatupang, T. M.; Sridharan, R. An integrative framework for supply chain collaboration. The International Journal of Logistics Management, v. 16, n. 2, p. 257-274. 2005.

Skjoett-Larsen, T.; Thernøe, C.; Andresen, C. Supply chain collaboration: theoretical perspectives and empirical evidence. International Journal of Physical Distribution \& Logistics Management, v. 33, n. 6, p. 531-549. 2003.

Småros, J. Forecasting collaboration in the European grocery sector: observations from a case study. Journal of Operations Management, v. 25, n. 3, p. 702-716. 2007.

Småros, J.; Lehtonen, J. M.; Appelqvist, P.; Holmstrom, J. The impact of increasing demand visibility on production and inventory control efficiency. International Journal of Physical Distribution \& Logistics Management, v. 33, n. 4, p. 336-354. 2003.

Stank, T. P.; Daugherty, P. J.; Autry, C. W. Collaborative planning: supporting automatic replenishment programs. Supply Chain Management: An International Journal, v. 4, n. 2, p. 75-85. 1999. 
Tranfield, D.; Denyer D.; Smart, P. Towards a Methodology for Developing Evidence-Informed Management Knowledge by Means of Systematic Review. British Journal of Management, v. 14, p. 207-222. 2003.

Thomassen, M.; Dreyer, H.; Jonsson, P. Exploring the Impact of ICT in CPFR: A Case Study of an APS System in a Norwegian Pharmacy Supply Chain. 19th Advances in Production Management Systems, p. 120-127. 2013.

Thomé, A. M. T.; Scavarda, L. F.; Fernandez, N. S.; Scavarda, A. J. Sales and operations planning: A research synthesis. International Journal of Production Economics, v. 138, n. 1, p. 1-13. 2012.

Thomé, A. M. T.; Hollmann, R. L.; Scavarda, L. F. Research Synthesis in Collaborative Planning Forecast and Replenishment. Industrial Management and Data Systems, v. 114, n. 6, p. 949-965. 2014.

Thomé, A. M. T.; Scavarda, L. F.; Scavarda, A. J. Conducting systematic literature review in operations management. Production Planning \& Control, v. 27, n. 5 , p. 408-420. 2016 a.

Thomé, A. M. T.; Scavarda, A.; Ceryno, P. S.; Remmen, A. Sustainable new product development: a longitudinal review. Clean Technologies and Environmental Policy, v. 18, n. 7, p. 2195-2208. 2016b.

Thomé, A. M. T.; Scavarda, L. F.; Kreuter, T.; Hellingrath, B. Towards theorydriven Sales and Operations Planning empirical research. Memorando técnico número 2/2017, Departamento de Engenharia Industrial da Pontifícia Universidade Católica do Rio de Janeiro. 2017.

Thomassen, M.; Dreyer, H.; Jonsson, P. Exploring the Impact of ICT in CPFR: A Case Study of an APS System in a Norwegian Pharmacy Supply Chain. Advances in Production Management Systems. Competitive Manufacturing for Innovative Products and Services, p. 120-127. 2013.

Tuomikangas, N.; Kaipia, R. A coordination framework for sales and operations planning (S\&OP): synthesis from the literature. International Journal of Production Economics, v. 151, p. 243-262. 2014.

Valentine, J. C. Judging the Quality of Primary Research. In The Handbook of Research Synthesis and Meta-Analysis. $2^{\mathrm{a}}$ ed, editado por Cooper, H.; Hedges, L. V.; Valentine, J. C., p. 129-146. 2009.

VICS. CPFR Guidelines, 1998. Available in: 〈http://www.cpfr.org>. Access: Jan./2016.

VICS. CPFR an overview. Voluntary Interindustry Commerce Standards VICS, 2004. Available in: 〈http://www.gs1us.org>. Access: Jan./2016. 
VICS. Linking CPFR and S\&OP: a roadmap to Integrated Business Planning. Voluntary Interindustry Commerce Standards - VICS, 2010. Available in: <http://www.gs1us.org>. Access: Jan./2016.

Vivaldini, M.; Bernadi de Souza, F.; Pires, S. R. I. Implementação de um sistema Collaborative Planning, Forecasting, and Replenishment em uma grande rede de fast food por meio de um prestador de serviços logísticos. Gestão e Produção, v. 15, n. 3, p. 477-489. 2008.

Wang, W.; Yuan, Y.; Archer, N.; Guan, J. Critical factors for CPFR success in the chinese retail industry. Journal of Internet Commerce, v. 4, n. 3, p. 23-29. 2005.

Wang, W. J.; Xu, Q. A Bayesian Combination Forecasting Model for Retail Supply Chain Coordination. Journal of Applied Research and Technology, v. 12, n. 2, p. 315-324. 2014.

Walker, H.; Chicksand, D.; Radnor, Z.; Watson, G. Theoretical perspectives in operations management: an analysis of the literature. International Journal of Operations \& Production Management, v. 35, n.8, p. 1182-1206. 2015.

Yao, Y.; Kohli, R.; Sherer, S. A.; Cederlund, J. Learning curves in collaborative planning, forecasting, and replenishment (CPFR) information systems: An empirical analysis form a mobile phone manufacturer. Journal of Operations Management, v. 31, n. 6, p. 285-297. 2013.

Yuan, X.; Shen, L.; Ashayeri, J. Dynamic simulation assessment of collaboration strategies to manage demand gap in high-tech product diffusion. Robotics and Computer-Integrated Manufacturing, v. 26, n. 6, p. 647-657. 2010. 


\begin{tabular}{|c|c|c|c|c|}
\hline \multicolumn{5}{|c|}{ Tabela 9 - Estudos empíricos em CPFR } \\
\hline ferência & Objetivo do artigo & Perguntas de pesquisa & Principais conclusões do artigo & Direções futuras para pesquisa \\
\hline 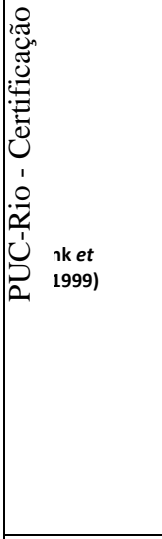 & $\begin{array}{l}\text { Este artigo apresenta os resultados de um survey, avaliando os níveis } \\
\text { atuais de envolvimento na colaboração inter-organizacional entre empre- } \\
\text { sas que utilizam o CPFR. } \\
\text { A pesquisa também fornece uma indicacãão de mudanças no processo, } \\
\text { eficácia operacional e capacidades do sistema de informação associadas a } \\
\text { estratégias colaborativas. }\end{array}$ & 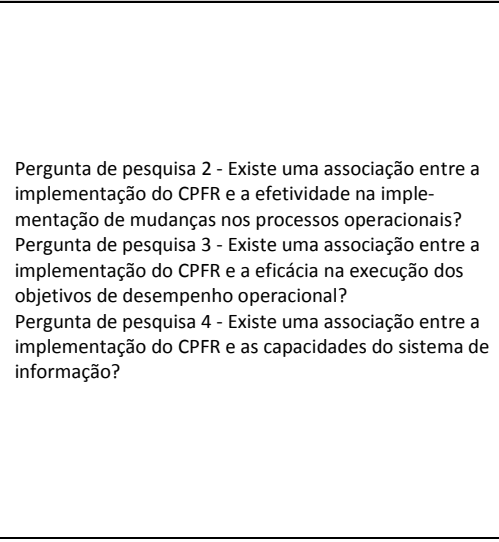 & 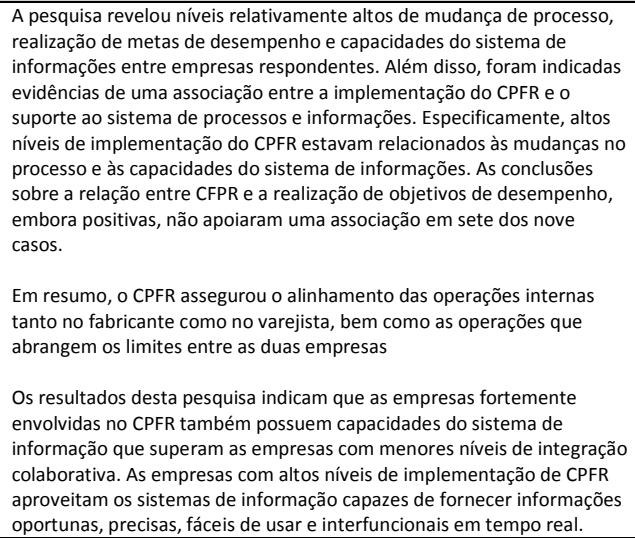 & $\begin{array}{l}\text { Esta pesquisa não verifica a existência de aprimoramentos de } \\
\text { desempenho com uma base ampla relacionados à imple- } \\
\text { mentação do CPFR. Outra questão que está além do alcance } \\
\text { da pesquisa atual, mas que merece consideração de pesquisa } \\
\text { futura, envolve possiveis diferençasa nas percepcõos de } \\
\text { fabricantes e varejistas quanto ao impacto de programas de } \\
\text { reabastecimento automático e o CPFR. }\end{array}$ \\
\hline $\begin{array}{l}\text { Barratt e } \\
\text { Oliveira (2001) }\end{array}$ & $\begin{array}{l}\text { Com base em uma revisão da literatura existente e um levantamento } \\
\text { abrangente dos participantes nas implementações de CPFR existentes, } \\
\text { este artigo identifica os inibidores criticicos e faz algumas propostas sobre } \\
\text { como esses inibidores podem ser superados. }\end{array}$ & & $\begin{array}{l}\text { O primeiro passo que os parceiros comerciais devem tomar para permit- } \\
\text { ir a implementação do processo CPFR é desenvolver um ambiente } \\
\text { adequado. Este ambiente deve ser fundado em dois conceitos: confiança } \\
\text { e tecnologia. Esse conceito pode ser considerado co-dependente, na } \\
\text { medida em que o desenvolvimento de interfaces de tecnologia da } \\
\text { informação entre parceiros comerciais não pode ser concluído sem o } \\
\text { desenvolvimento da confiança entre os parceiros comerciais. Desen- } \\
\text { volver a confiança é um objetivo de longo prazo para as organizações, } \\
\text { embora seja necessário começar em algum lugar. } \\
\text { Qualquer expansão a longo prazo de uma iniciativa CPFR deve ser } \\
\text { suportada por um desenvolvimento de TI consistente. Tendo desen- } \\
\text { volvido um ambiente amigável para o CPFR e desenvolvido para gerar } \\
\text { mudanças passo a passo e incremental para a implementaçăo de uma } \\
\text { iniciativa CPFR }\end{array}$ & $\begin{array}{l}\text { Devido ao está́io relativamente embrionário do conceito } \\
\text { CPFR, a maioria dos aspectos vulneráveis à crítica estão } \\
\text { associados à falta de informação e, portanto, exigem mais } \\
\text { investigação e estudo: } \\
\text { - Todosos os pilotosos anteriores foram bem sucedidos? } \\
\text { - Se não, qual foi a causad do revés para sessas iniciativas? } \\
\text { - Quais os objetivos definidos, mas não alcançados? } \\
\text { - O que foi aprendido? }\end{array}$ \\
\hline $\begin{array}{l}\text { McCarthy e } \\
\text { Goilicic (2002) }\end{array}$ & $\begin{array}{l}\text { Este artigo aborda a lacuna existente em métodos colaborativos ao } \\
\text { questionar especificamente a pergunta: como as empresas se envolvem } \\
\text { em uma previsão colaborativa de interfaces e como essas abordagens } \\
\text { para a previsão colaborativa influenciam o desempenho da SC e, assim, o } \\
\text { desempenho da empresa? A presente pesquisa explora as previsões }\end{array}$ & & $\begin{array}{l}\text { Os resultados do estudo revelam abordagens alternativas para atualizar } \\
\text { a previsão colaborativa que não exigem o investimento substancial em } \\
\text { recursos humanos e tecnológicos exigidos pelo CPFR. Além disso, os } \\
\text { resultados mostram que essas abordagens alternativas podem resultar } \\
\text { em maior capacidade de resposta e garantia de disponibilidade de }\end{array}$ & \\
\hline
\end{tabular}




\begin{tabular}{|c|c|c|c|c|}
\hline Ud ferência & Objetivo do artigo & Perguntas de pesquisa & Principais conclusões do artigo & Direções futuras para pesquisa \\
\hline $\bar{i}$ & colaborativas em geral, incluindo a prática do CPFR. & & $\begin{array}{l}\text { produtos, inventário otimizado e custos associados e aumento de } \\
\text { receitas e ganhos para as empresas individuais e para o SC. }\end{array}$ & \\
\hline 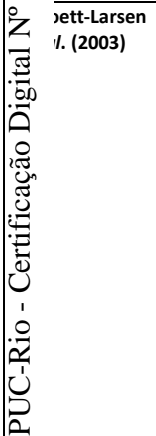 & 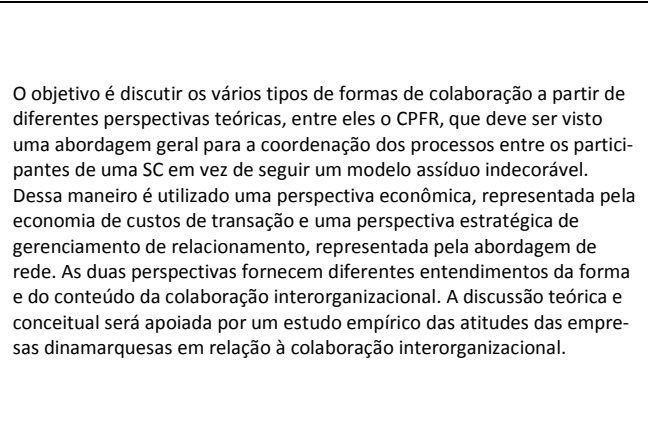 & & 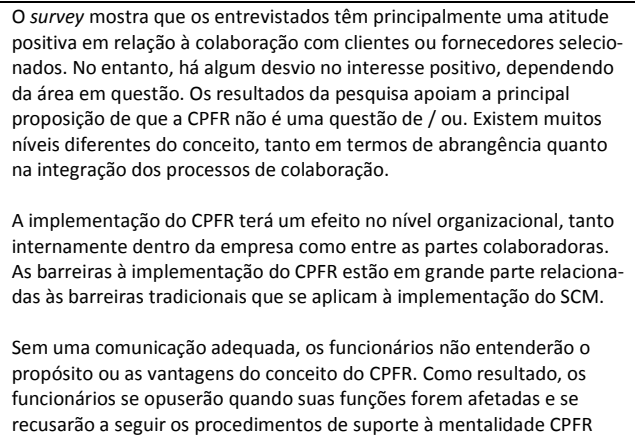 & $\begin{array}{l}\text { Este estudo é principalmente exploratório, portanto estudos } \\
\text { mais rigorosos são necessários para obter conhecimentos } \\
\text { mais sólidos sobre como as empresas nas cadeias de su- } \\
\text { primentos estão colaborando por meio do CPFR. }\end{array}$ \\
\hline \begin{tabular}{|l} 
Chen et al. \\
(2004)
\end{tabular} & $\begin{array}{l}\text { Neste artigo, um estudo de caso sobre a implementaç̃o do CPFR em } \\
\text { Rexon, Taiwan é conduzido para fornecer uma referência a outras empre- } \\
\text { sas. O principal objetivo da Rexon de implementar o CPFR é fortalecer sua } \\
\text { parceria de varejo, melhorara a precisãa das previsões de demanda e } \\
\text { reduzir custos de estoque e outros custos operacionais relacionados. }\end{array}$ & & 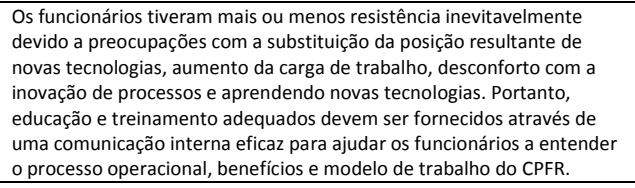 & \\
\hline $\begin{array}{l}\text { Danese et al. } \\
\text { (2004) }\end{array}$ & $\begin{array}{l}\text { O artigo fornece um quadro teórico e apresenta um estudo de caso } \\
\text { múltiplo que contribui para explicar as relaçōes entre os mecanismos de } \\
\text { coordenação e as características de interdependência entre os atores } \\
\text { envolvidos na implementação do CPFR. }\end{array}$ & & 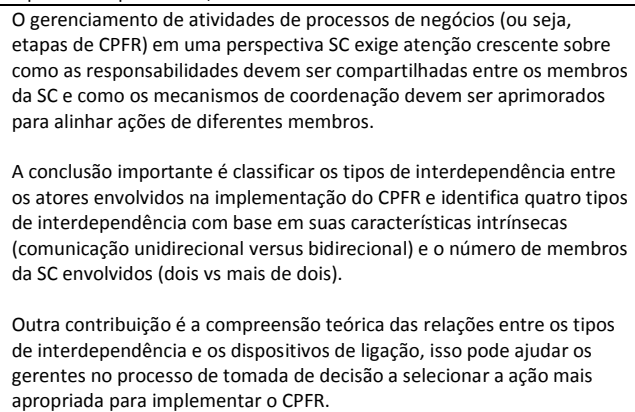 & $\begin{array}{l}\text { Pesquisas futuras devem avaliar uma amostra mais ampla de } \\
\text { redes que envolvem pequenas e grandes empresas em várias } \\
\text { indústrias através de projetos de pesquisa baseados em casos } \\
\text { e / ou com base em pesquisa. A oportunidade de adotar a a } \\
\text { teoria desenvolvida comou uma ferramenta gerencial exige o } \\
\text { teste de resultados da pesquisa em outros processos de } \\
\text { negócios e amostras maiores de empresaspor meio de uma } \\
\text { ampla gama de indústrias. } \\
\text { As novas oportunidades de pesquisa estão na exploração de } \\
\text { (i) outros fatores contingentes, como a incerteza ambiental e } \\
\text { a disponibilidade de tecnologias de informacãão e comuni- } \\
\text { cação, e (ii) outros mecanismos de coordenação. }\end{array}$ \\
\hline $\begin{array}{l}\text { Lin et al. } \\
\text { (2004) }\end{array}$ & $\begin{array}{l}\text { Este artigo propõe uma metodologia de implementação do CPFR e } \\
\text { apresenta por meio de uma indústria mecañica de escultura em madeira } \\
\text { um estudo de caso. O VICS tem vindo a encontrar maneiras de compensar } \\
\text { as falhas do CPFR por muitos casos de implementação de CPFR. Este } \\
\text { artigo procura descobrir elementos essenciais para propor a imple- } \\
\text { mentação do CPFR e um procedimento importante de acordo com artigos }\end{array}$ & & $\begin{array}{l}\text { Resultados de compararação dos medidores de desempenho de uma } \\
\text { implementação do CPFR analisados, apontam que se o valor de precisão } \\
\text { da previsão de vendas fosse de } 60 \% \text { e ovalor alvo previamente } \\
\text { acordado fosse de } 80 \% \text {, ambos os lados descobririam as causas de } \\
\text { incompatibilidade: o varejista não tomou em consideração eventos de } \\
\text { promoçãao, de modo que o valor de previsão de vendas do varejista é }\end{array}$ & $\begin{array}{l}\text { Esta pesquisa melhora a discussão dos principais procedimen- } \\
\text { tos envolvidos na implementacăao do CPFR, mas nãa inves- } \\
\text { tigou o efeito de outros fatores, como o desempenho das } \\
\text { empresas e o clima de organização sobre a implementação do } \\
\text { CPFR. Empresas com produtos de diferentes caracteristicas } \\
\text { podem exigir diferentes estilos de implementação de CPFR. }\end{array}$ \\
\hline
\end{tabular}




\begin{tabular}{|c|c|c|c|c|}
\hline fferência & Objetivo do artigo & Perguntas de pesquisa & Principais conclusões do artigo & Direções futuras para pesquisa \\
\hline 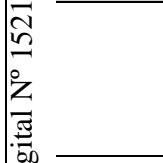 & relativos. & & 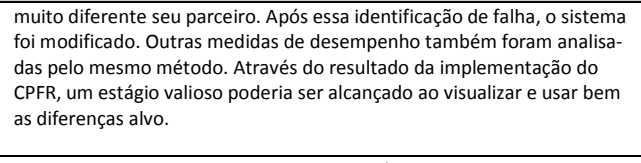 & 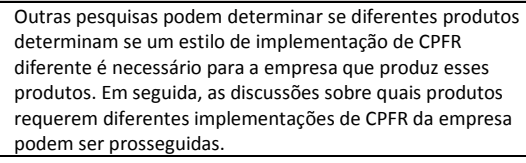 \\
\hline 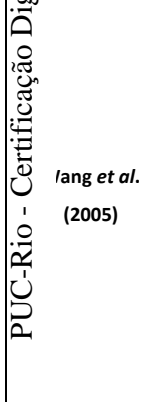 & 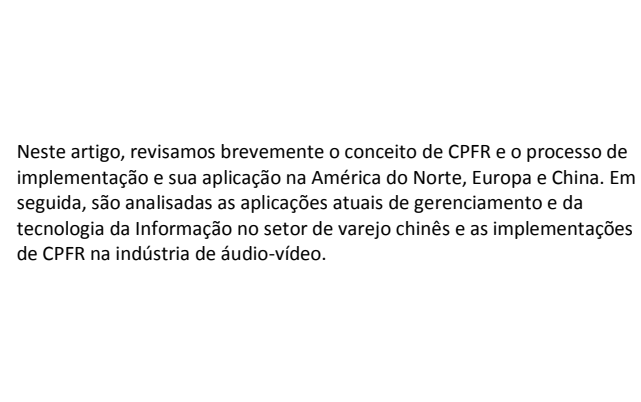 & & 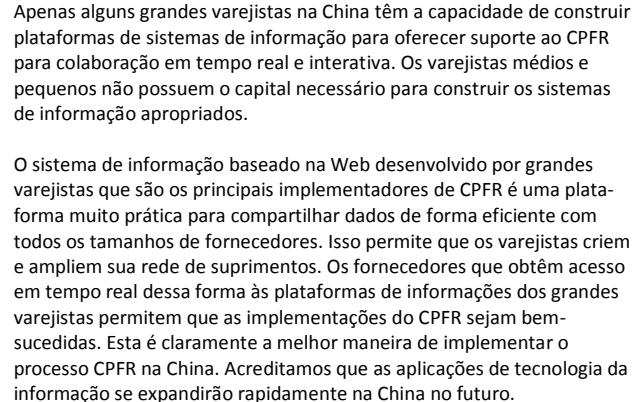 & \\
\hline $\begin{array}{l}\text { Chung e Leung } \\
(2005)\end{array}$ & 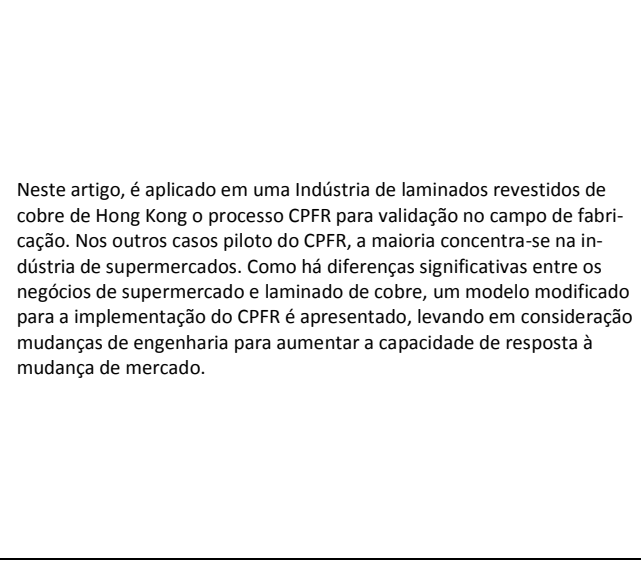 & & 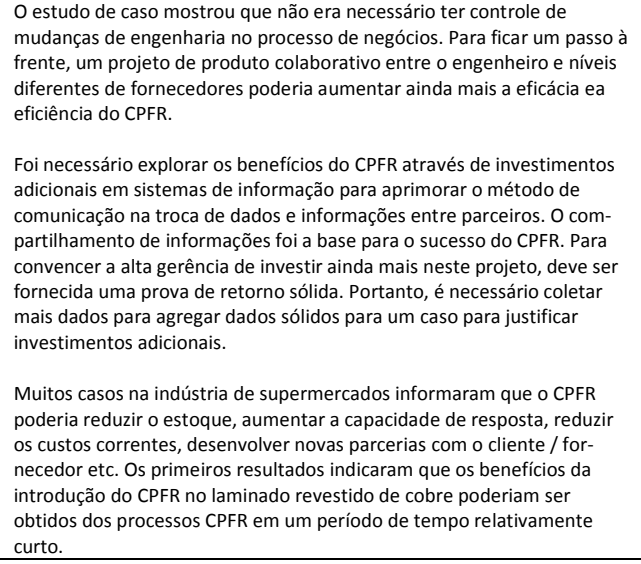 & \\
\hline $\begin{array}{c}\text { Kohli e Sherer } \\
\text { (2006) }\end{array}$ & 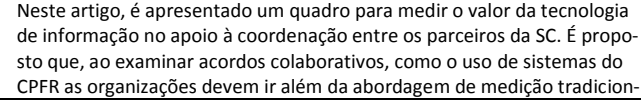 & & 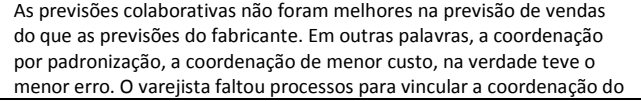 & \\
\hline
\end{tabular}




\begin{tabular}{|c|c|c|c|c|}
\hline$\bigcup$ ferência & Objetivo do artigo & Perguntas de pesquisa & Principais conclusões do artigo & Direções futuras para pesquisa \\
\hline 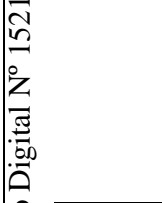 & $\begin{array}{l}\text { al envolvendo investimentos complementares e considerar o impacto dos } \\
\text { investimentos de concordancia. Enquanto os investimentos complemen- } \\
\text { tares enviolvem mudancas organizacionais e de processos voltadas para a } \\
\text { implementação bem sucedida de sistemas CPFR, os investimentos de } \\
\text { concordância envolvem ajuste mútuo de processos inter-organizacionais } \\
\text { e relacionamentos para o sucesso colaborativo sustentado resultante do } \\
\text { uso do sistema. Éarresentado resultados preliminares de dois estudos de } \\
\text { caso em que um par de parceiros em cada caso tentaram explorar CPFR. }\end{array}$ & & $\begin{array}{l}\text { parceiro com coordenação interna sem mecanismos de comunicação e } \\
\text { nenhum mecanismo para investimentos de concordância para explorar o } \\
\text { CPFR. } \\
\text { As organizações precisam de investimentos de concordância para obter } \\
\text { maior valor dos investimentos em TI. }\end{array}$ & \\
\hline 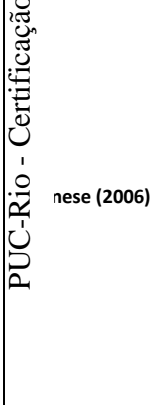 & $\begin{array}{l}\text { Este trabalho tem como objetivo investigar as differenças na imple- } \\
\text { mentação do CPFR quanto ao tipo de colaboração entre empresas imple- } \\
\text { mentada, eas TIC's e mecanismos de coordenação adotados para realizar } \\
\text { o CPFR. Além disso, procura analisara as relaçôes entre essas dimensões, a } \\
\text { fim de compreender e explicar a lógica das escollhas gerenciais que levam } \\
\text { as empresas a implementar diferentes configuraçôes de CPFR. }\end{array}$ & & 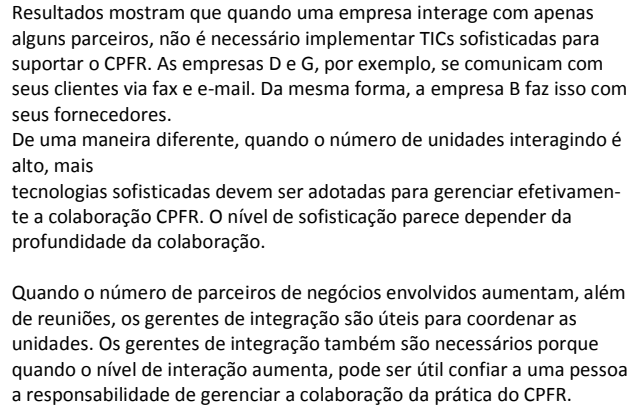 & $\begin{array}{l}\text { Embora os resultados da pesquisa em CPFR sejam encoraja- } \\
\text { dores, a oportunidade de usar os relacionamentos encontra- } \\
\text { dos nesta pesquisa como uma ferramenta gerencial exige o } \\
\text { teste de resultados de essquisa em grandes amostras se } \\
\text { empresas, representativas de uma ampla gama de indústrias. } \\
\text { Os estudos de caso analisados são de fato limitados a uma } \\
\text { amostra relativamente pequena e apenas a algumas indústri- } \\
\text { as. Pesquisas futuras devem avaliar uma amostra mais ampla } \\
\text { de redes envolvendo empresas grandes e pequenas em várias } \\
\text { indústrias através de projetos de pesquisa baseados em casos } \\
\text { e / ou com base em survey. }\end{array}$ \\
\hline Cassivi (2006) & $\begin{array}{l}\text { Os objetivos neste artigo são identificar as ferramentas de colaboração } \\
\text { eletrônica usadas em uma SC e analisar como elas afetam diferentes } \\
\text { parceiros ao longo da SC e categorizar as empresas de de acordo com seu } \\
\text { nivel de planejamento da colaboração na sC com parceiros a montante e } \\
\text { a jusante; E observar como processos, relacionamentos e desempento } \\
\text { podem variar de uma configuraçăo para outra. }\end{array}$ & & $\begin{array}{l}\text { O estudo de campo demonstrou que o processo e as inovações relacion- } \\
\text { adas a tecnnologia são reforçadas pelo desenvolvimento de atividades de } \\
\text { colaboraçăao eletrônica dentro da SC de equipamentos de telecomuni- } \\
\text { caçôes. } \\
\text { A visibilidade da informação é muitas vezes vista como um elemento } \\
\text { critico na manutenção de uma cadeia de suprimento eficiente, mas a } \\
\text { única maneira de obter visibilidade é planejar e executar açôes colabora- } \\
\text { tivas com parceiros tanto a montante como a jusante. }\end{array}$ & \\
\hline Danese (2007) & $\begin{array}{l}\text { Compreender a lógica por trás das escolhas gerenciais que levam empre- } \\
\text { sas a implementar differentes tipos de colaboraçăo em CPFR por meio de } \\
\text { um estudo de caso múttiplo. }\end{array}$ & & 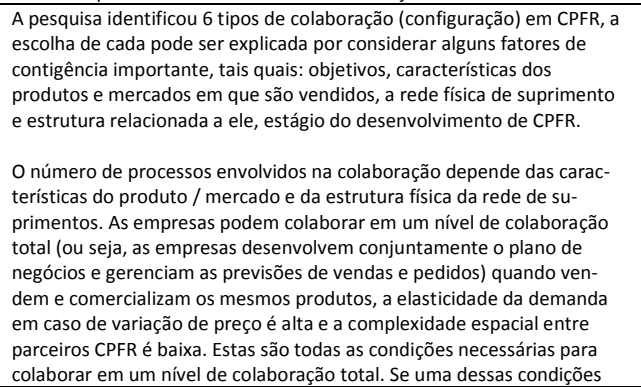 & $\begin{array}{l}\text { Pesquisas futuras devem avaliar uma amostra mais ampla de } \\
\text { redes envolvendo empresas grandes e pequenas em várias } \\
\text { indústrias através de projetos de pesquisa baseados em casos } \\
\text { e / ou com base em pesquisa. De fato, embora os resultados } \\
\text { da pesquisa sejam encorajadores, a oportunidade de usar os } \\
\text { relacionamentos encontrados nesta pesquisa como uma } \\
\text { ferramenta gerencial exige o teste de resultados da pesquisa } \\
\text { em amostras maiores de empresas, representativas de uma } \\
\text { gama mais ampla de indústrias. }\end{array}$ \\
\hline
\end{tabular}




\begin{tabular}{|c|c|c|c|c|}
\hline fferência & Objetivo do artigo & Perguntas de pesquisa & Principais conclusões do artigo & Direções futuras para pesquisa \\
\hline in & & & $\begin{array}{l}\text { não for satisfeita, a colaboração será limitada ao simples gerenciamento } \\
\text { de previsões de pedidos }\end{array}$ & \\
\hline 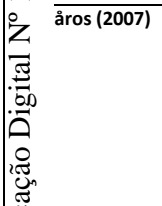 & $\begin{array}{l}\text { Este artigo apresenta um estudo de caso exploratório sobre previsão } \\
\text { colaborativa. São examinados quatro projetos de colaboração (entre eles } \\
\text { o CPFR) envolvendo um total de quatro fabricantes e um varejista que } \\
\text { atua no setor de supermercado europeu. Ao ostudar as experiencias } \\
\text { positivas enegativas das empresas, identificam-se fatores que têm } \\
\text { impacto na viabilidade e no valor da previsão colaborativa. }\end{array}$ & & $\begin{array}{l}\text { Uma conclusão importante do estudo é que muitos modelos de } \\
\text { colaboracăão, principalmente o CPFR, parecem se basear em premissas } \\
\text { inválidas sobre as necessidades, recursos e processos de previsão dos } \\
\text { varejistas, bem como as capacidades dos fabricantes para se beneficiar } \\
\text { da demanda ou informaçōes de previsão disponibilizadas através da } \\
\text { colaboração. }\end{array}$ & $\begin{array}{l}\text { Realizar estudos aprofundados sobre as poucas imple- } \\
\text { mentações em larga escala existentes métodos colaborativos } \\
\text { de previsão, como o CPFR, para entender melhor quais foram } \\
\text { os custose os benefícios reais desses e como os fabricantes } \\
\text { conseguem que a informação de previsão seja disponibilizada } \\
\text { pelos varejistas. }\end{array}$ \\
\hline 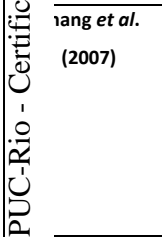 & $\begin{array}{l}\text { Propor e testar um modelo de CPFR (A-CPFR) aumentado em um contexto } \\
\text { varejista-fornecedor com o objetivo de melhorar a precisão da previsão e, } \\
\text { em seguida, reduzir o "efeito chicote" na SC. }\end{array}$ & & $\begin{array}{l}\text { Resultados mostram que o desvio absoluto médio da previsão e a } \\
\text { variação do inventário são ambos melhores no modelo proposto do que } \\
\text { no modelo CPFR existente. O modelo proposto pode, assim, melhorar a } \\
\text { precisãa da previsasa de vendas, reduzir os niveis de inventário e reduzir } \\
\text { o "efeito chicote". } \\
\text { O estudo aponta que é dificiil para um fornecedor fazer ajustes opor- } \\
\text { tunos em resposta às mudanças na demanda do mercado se esse } \\
\text { fornecedor não obter informações de mercado importante do varejista. }\end{array}$ & \\
\hline $\begin{array}{l}\text { Vivaldini et al. } \\
\text { (2008) }\end{array}$ & $\begin{array}{l}\text { Este estudo busca contribuir para o entendimento do processo de imple- } \\
\text { mentação do CPFR, demonstrando os processos operacionais que } \\
\text { compõem a SCM colaborativa, as dificuldades identificadas e aspectos } \\
\text { relevantes. Além disso, o artigo apresenta o CPFR num seguimento } \\
\text { differenciado, fora dos casos comumente descritos em redes de super- } \\
\text { mercados. }\end{array}$ & & 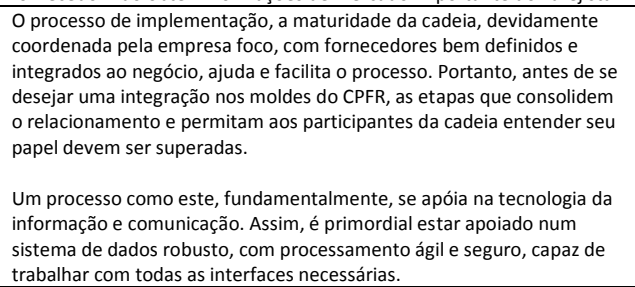 & 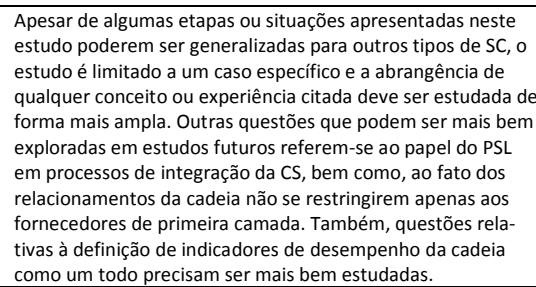 \\
\hline $\begin{array}{l}\text { Chang e Wang } \\
\text { (2008) }\end{array}$ & $\begin{array}{l}\text { O objetivo deste trabalho é aplicar a metodologia Six Sigma e propor um } \\
\text { modelo de melhoria contínua em diferentes fases do CPFR, expor que o } \\
\text { método Seis Sigma pode ser empregado para melhorar a precisão da } \\
\text { previsão no modelo CPFR. }\end{array}$ & & 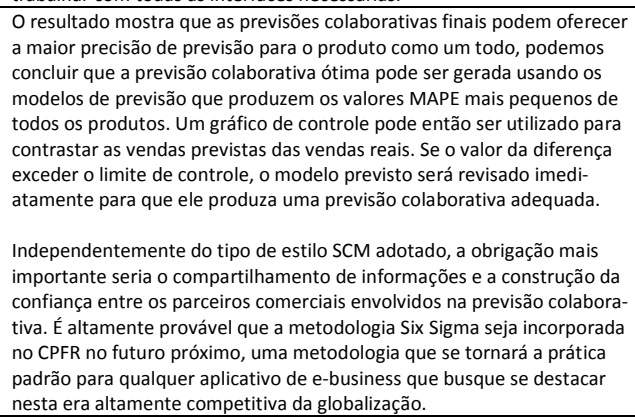 & $\begin{array}{l}\text { As pesquisas realizadas no futuro devem extrair os dados de } \\
\text { um periodo de temmo mais longo e devem incluir outras } \\
\text { indústrias pertencentes aos diferentes cenários. Além disso, é } \\
\text { sugerido investigar como gerenciar o alinhamento da de- } \\
\text { manda com a área de suprimento no CPFR. }\end{array}$ \\
\hline
\end{tabular}




\begin{tabular}{|c|c|c|c|c|}
\hline ferência & Objetivo do artigo & Perguntas de pesquisa & Principais conclusões do artigo & Direções futuras para pesquisa \\
\hline 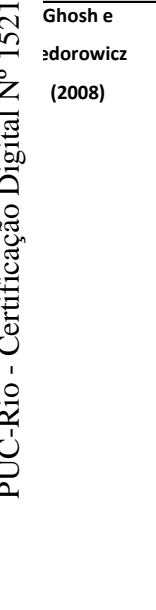 & 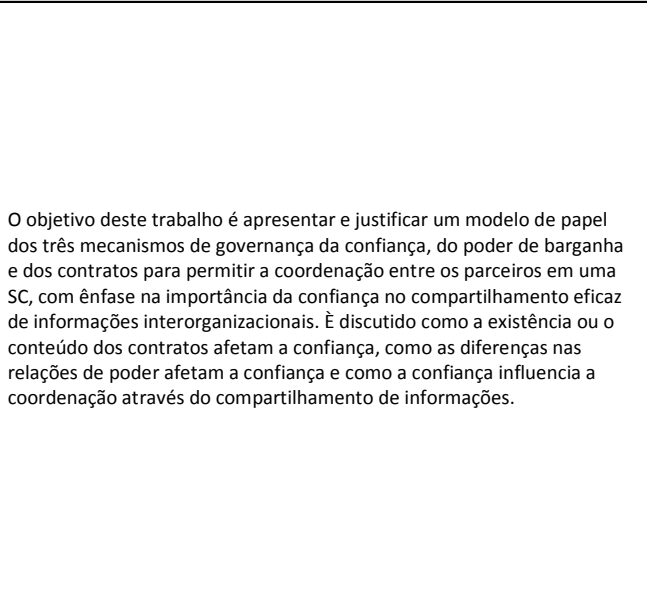 & & 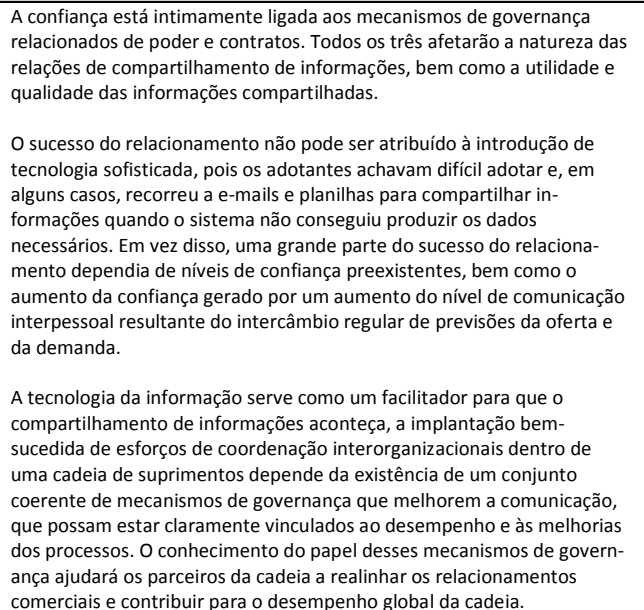 & \\
\hline $\begin{array}{l}\text { D'Aubeterre et } \\
\text { al. (2008) }\end{array}$ & $\begin{array}{l}\text { É aplicado uma abordagem para mostrar como os modelos padrão do } \\
\text { setor de CPFR podem ser aprimorados utilizando o projeto proposto. Um } \\
\text { estudo de caso para ilustrar a aplicabilidade da Abordagem Semântica } \\
\text { para garantir processos colaborativos inter-organizacionais eBusiness } \\
\text { (SScIOBPP) no mapeamento dos principais processos de negócios das } \\
\text { organizaçós para resolver problemas de processos e segurança no } \\
\text { projeto de fatores de negócios seguros em toda SC de informações. }\end{array}$ & & $\begin{array}{l}\text { Um fator de sucesso chave para CPFR é integrar processos de CPFR em } \\
\text { processos de negócios existentes. Neste contexto, o artefato de tecno- } \\
\text { logia de informação proposto pode ser usado para desenvolver envoltó- } \\
\text { rios semânticos para alimentar dinamicamente dados e informações } \\
\text { CPFR para o MRP e outros sistemas ERP. } \\
\text { Resultados apontam que a TI tem o potencial de beneficiar as organi- } \\
\text { zaçōes que estão planejando adotar o CPFR, bem como as organizaçōes } \\
\text { que já o adotaram. }\end{array}$ & \\
\hline Du et al. (2009) & $\begin{array}{l}\text { O objetivo deste estudo é aplicar um framework de CPFR para desenvolv- } \\
\text { er um modelo de gerenciamento de compras de produtos agrícolas para } \\
\text { que a precisão das previsões de demanda de produtos agrícolas possa ser } \\
\text { melhorada fazendo previsóes colaborativas com base no com- } \\
\text { partilhamento de informaçōes. }\end{array}$ & & $\begin{array}{l}\text { O modelo de aquisição de produtos agrícolas com CPFR ajuda compra- } \\
\text { dores e vendedores a minimizar o desperdício de produtos e reduzir } \\
\text { custos e riscos. O modelo proposto tem uma influência positiva no } \\
\text { controle de estoque eda empresa e vantagens competitivas quando o } \\
\text { CPFR foi implantado no processo de aquisiçãa de produtos agrícolas. Em } \\
\text { uma palavra, as indústrias agricolas serão os principais beneficiários do } \\
\text { CPFR. } \\
\text { Os benefícios são que os compradores podem reduzir as perdas de } \\
\text { inventário e economizar custos de gerenciamento. }\end{array}$ & \\
\hline Fu et al. (2010) & $\begin{array}{l}\text { O objetivo deste estudo é analisar a importância dos fatores críticos de } \\
\text { impacto que afetam as empresas quando implementam o modelo CPFR. } \\
\text { Os resultados deste estudo podem destacar as prioridades dos principais } \\
\text { fatores de impacto que afetam a implementaçăo do CPFR e fornecer } \\
\text { informaçōes mais precisas como referência valiosa para os varejistas no }\end{array}$ & & $\begin{array}{l}\text { Os resultados deste estudo mostram que os fatores de impacto crítico } \\
\text { para os varejistas que adotam o CPFR são a capacidade de comunicação } \\
\text { e colaboração entre departamentos, gerenciamento de mudanças, } \\
\text { capacidade de inovação organizacional, complexidade do sistema, } \\
\text { objetivo mútuo, capacidade de integrar tecnologia e cultura, suporte da }\end{array}$ & \\
\hline
\end{tabular}




\begin{tabular}{|c|c|c|c|c|}
\hline ferência & Objetivo do artigo & Perguntas de pesquisa & Principais conclusões do artigo & Direções futuras para pesquise \\
\hline & $\begin{array}{l}\text { que se refere à alocą̧ăo de recursos ótimos quando implementam esses } \\
\text { projetos. }\end{array}$ & & 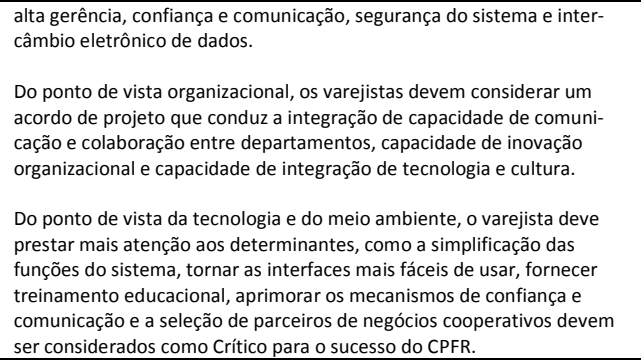 & \\
\hline $\begin{array}{l}\text { houx et al. } \\
\text { (2010) }\end{array}$ & 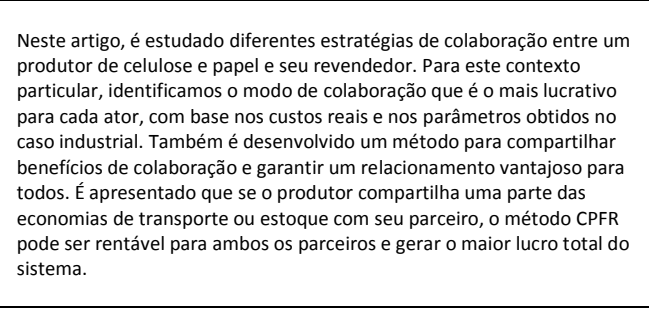 & & 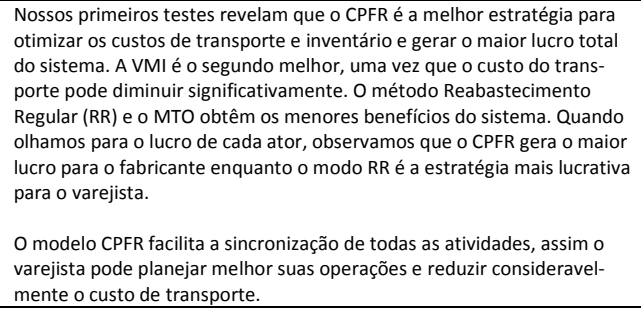 & \\
\hline VICS (2010) & 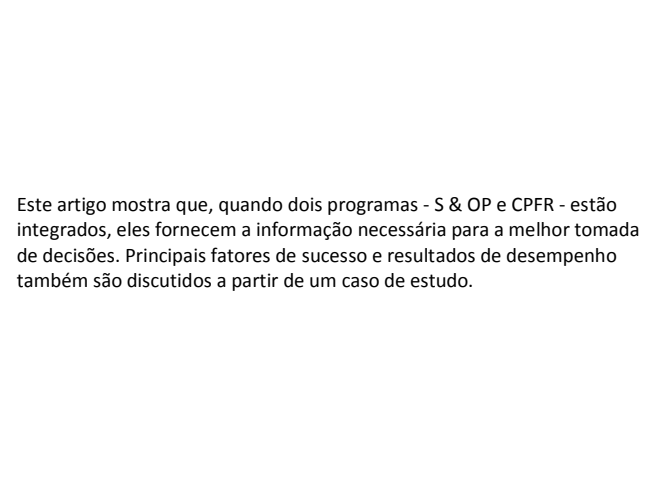 & & 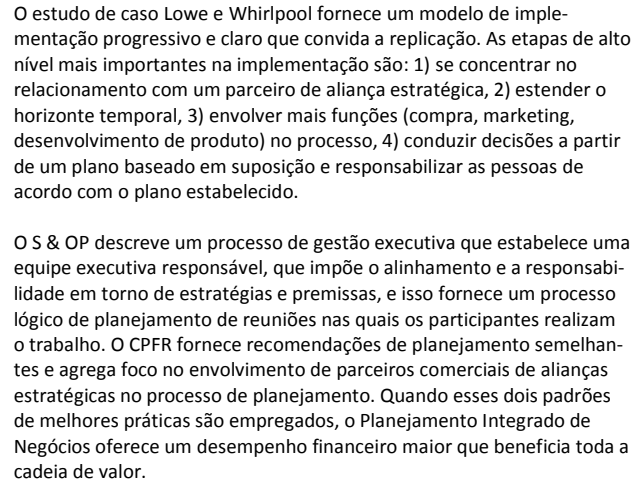 & \\
\hline $\begin{array}{l}\text { Sherer et al. } \\
\text { (2011) }\end{array}$ & 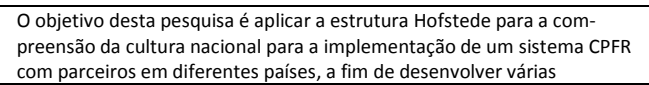 & & 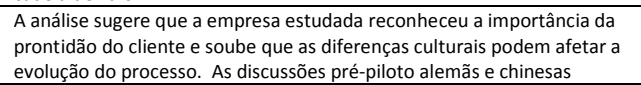 & \\
\hline
\end{tabular}




\begin{tabular}{|c|c|c|c|c|}
\hline ferência & Objetivo do artigo & Perguntas de pesquisa & Principais conclusões do artigo & Direçoes futuras para pesquisa \\
\hline & 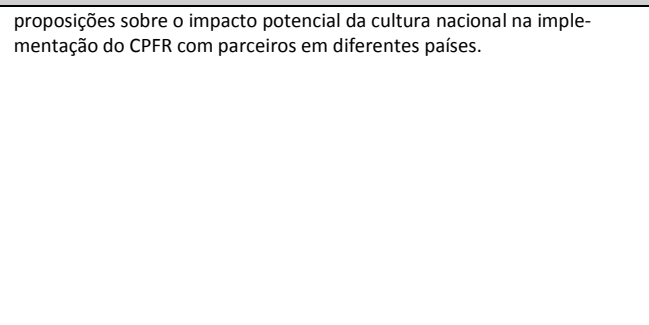 & & 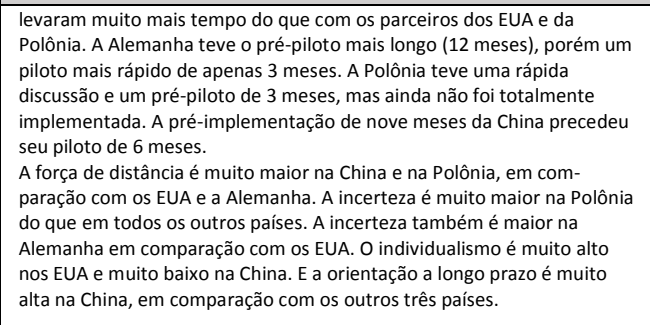 & \\
\hline $\begin{array}{l}\text { Lehoux et al. } \\
\text { (2011) }\end{array}$ & 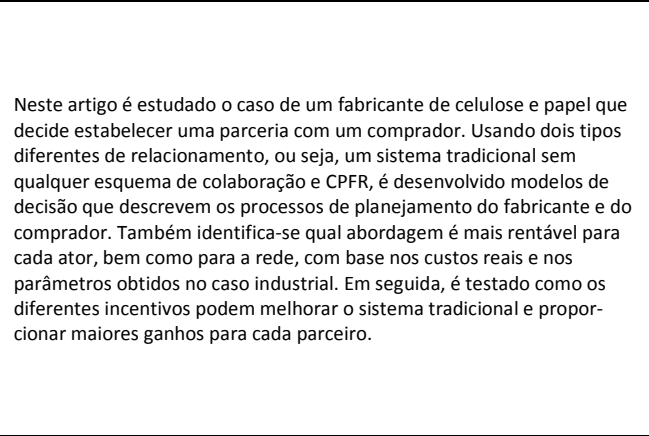 & & 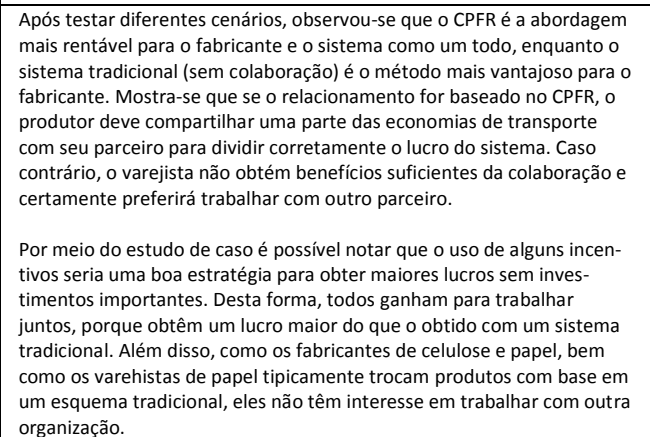 & 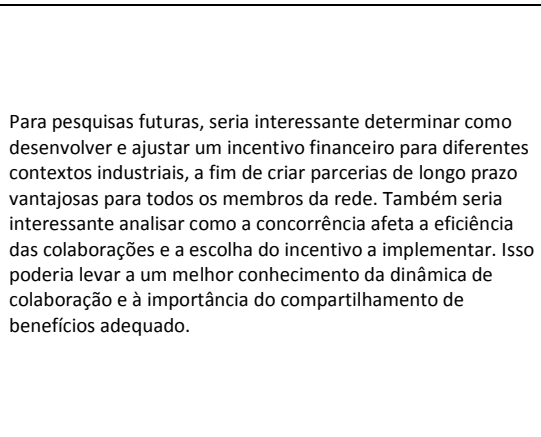 \\
\hline $\begin{array}{l}\text { Dube et } a l \text {. } \\
\text { (2012) }\end{array}$ & 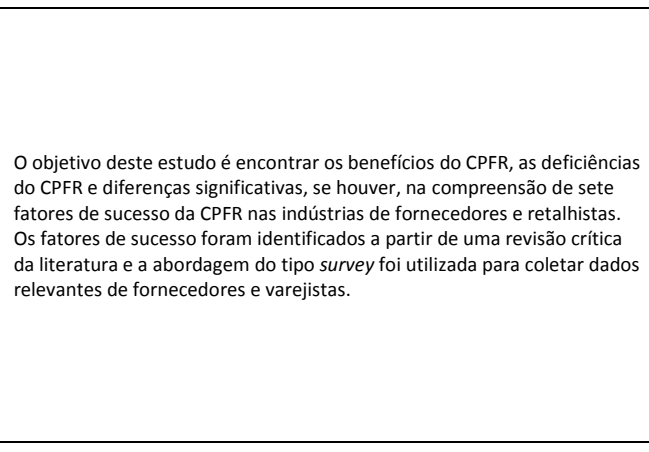 & 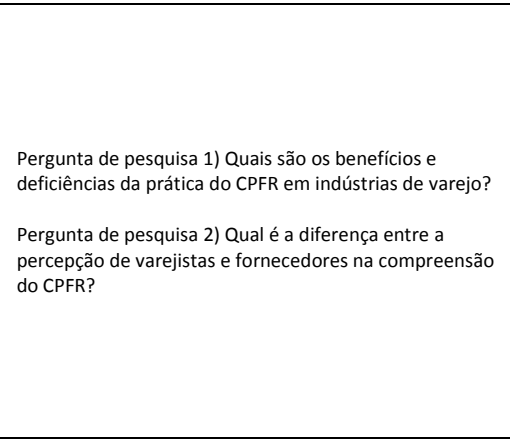 & 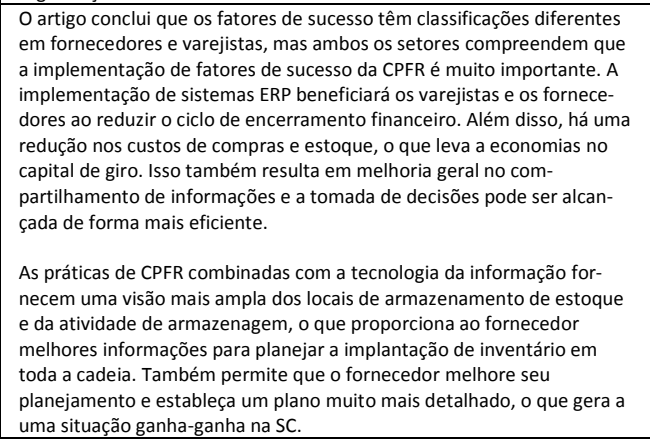 & \\
\hline
\end{tabular}




\begin{tabular}{|c|c|c|c|c|}
\hline fferência & Objetivo do artigo & Perguntas de pesquisa & Principais conclusões do artigo & Direções futuras para pesquisa \\
\hline 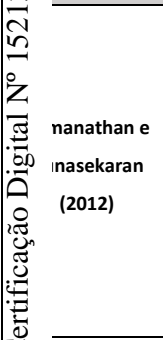 & 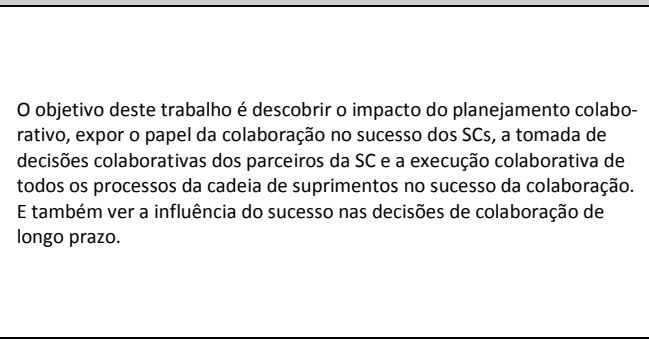 & & 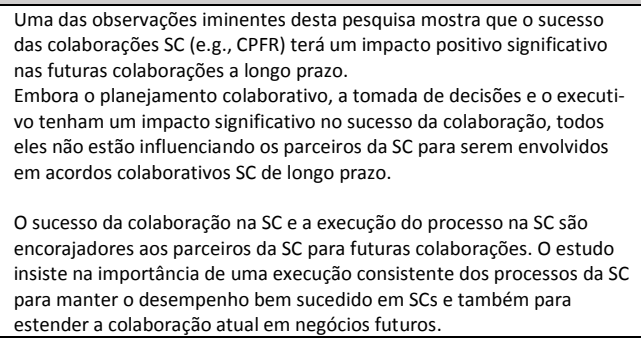 & \\
\hline $\begin{array}{l}\text { Thomassen et } \\
\text { al. (2013) }\end{array}$ & 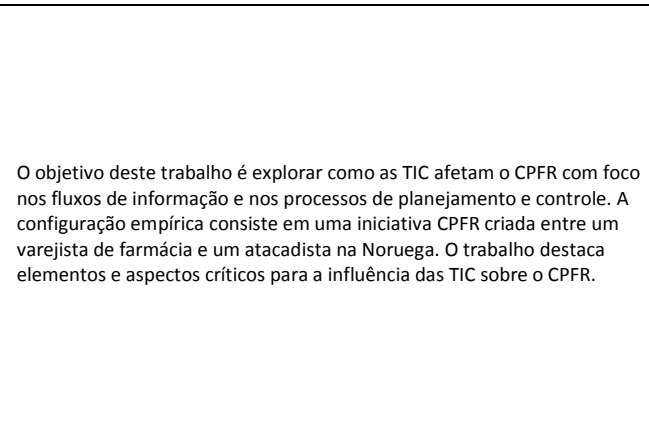 & & 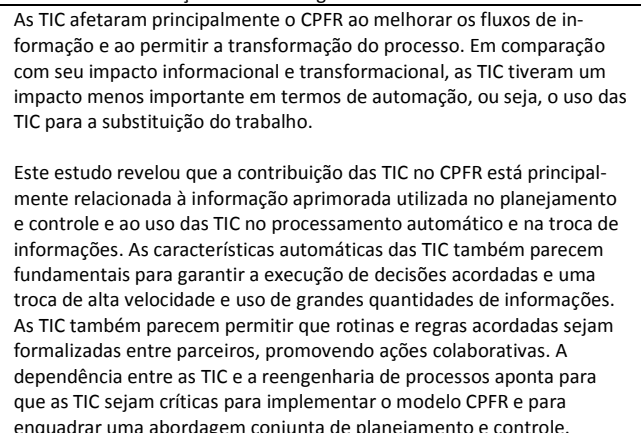 & \\
\hline Line Ho (2014) & 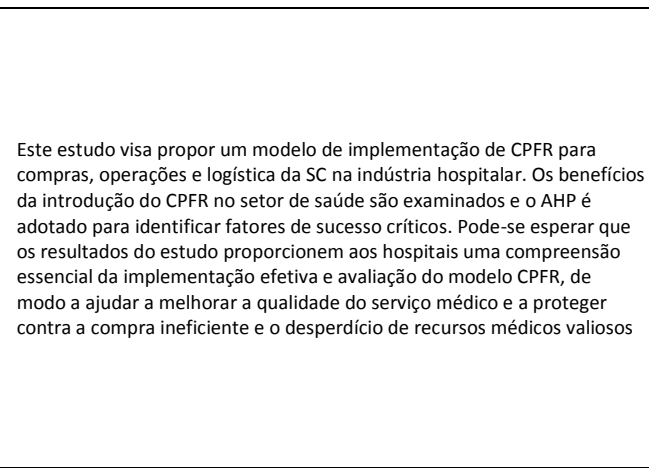 & & 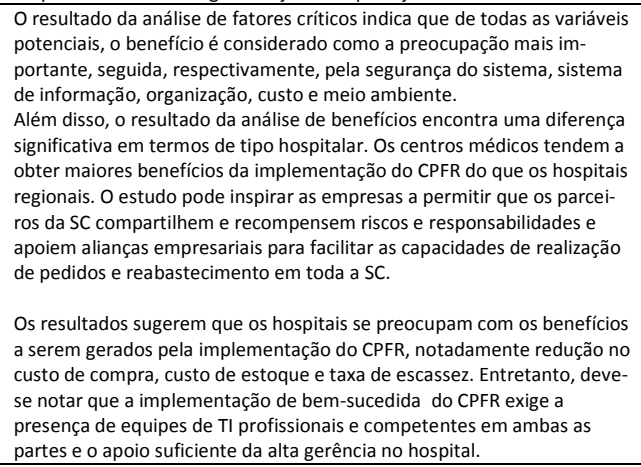 & \\
\hline
\end{tabular}




\begin{tabular}{|c|c|c|c|c|}
\hline ferência & Objetivo do artigo & Perguntas de pesquisa & Principais conclusões do artigo & Direções futuras para pesquisa \\
\hline 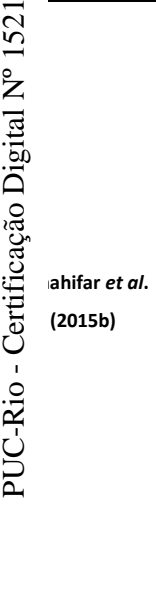 & $\begin{array}{l}\text { O objetivo deste trabalho é identificare e analisar facilitadores do CPFR } \\
\text { com base em um setor da SC, onde a colaboração estreita é considerada } \\
\text { essencial para uma operação bem-sucedida. Para o objetivo deste estudo, } \\
\text { a sC automotivos foi analisada para desenvolver um modelo que atendaa } \\
\text { os capacitadores identificados mais significativos e classifique os mais } \\
\text { dominantes, antes da fase de implementaçăo do CPFR. }\end{array}$ & & 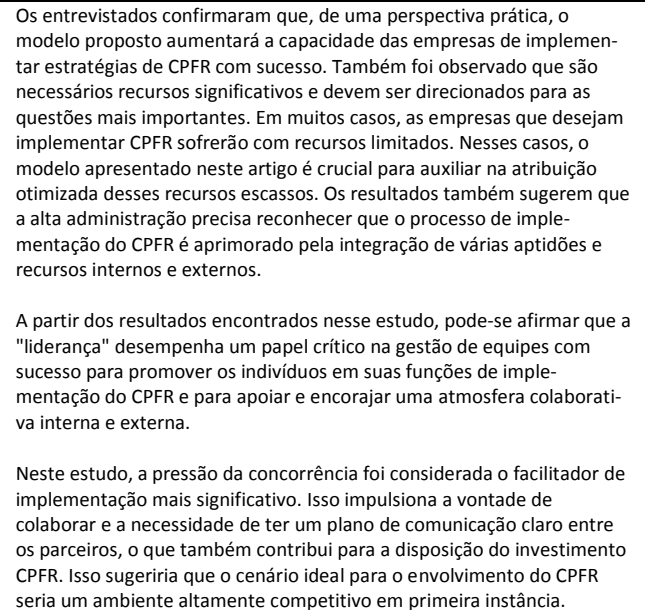 & 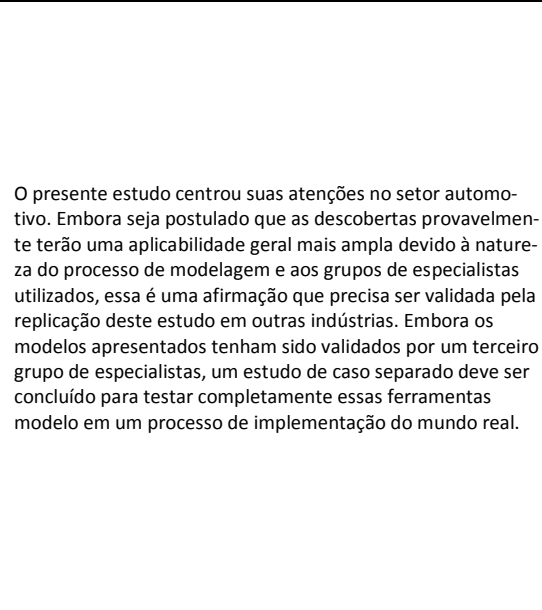 \\
\hline $\begin{array}{c}\text { Panahifar e } \\
\text { Heavey (2015c) }\end{array}$ & $\begin{array}{l}\text { O objetivo deste trabalho é apresentar e explorar os principais fatores } \\
\text { considerados pelos fabricantes na seleção de um (s) varejista (s) apropri- } \\
\text { ado (s) para implementar a prática do CPFR e as relaçôes entre esses } \\
\text { fatores. }\end{array}$ & & $\begin{array}{l}\text { Os fatores de seleção de parceiros mais importantes, que incluem cinco } \\
\text { dimensões e } 24 \text { fatores, são introduzidos. Dos critérios identificados, } \\
\text { três fatores são críticos ao selecionar varejistas para implementação de } \\
\text { CPFR: a familiaridade do fabricante com o varejista, habilidades e } \\
\text { treinamento de força de trabalho e orientaçẫo e capacidade do serviço } \\
\text { ao cliente. } \\
\text { Os resultados indicam que a familiaridade do fabricante com o } \\
\text { revendedor é o fator mais importante ao tentar selecionar um varejista } \\
\text { para um projeto de implementação do CPFR. } \\
\text { Para uma implementação bem sucedida de CPFR, a tecnologia é um } \\
\text { elemento importante, no entanto, também não é uma barreira dom- } \\
\text { inante. }\end{array}$ & $\begin{array}{l}\text { Há uma escassez de pesquisa focada na área de seleção de } \\
\text { varejistas no contexto de um esquema colaborativo como o } \\
\text { CPFR. }\end{array}$ \\
\hline $\begin{array}{c}\text { Gomes e } \\
\text { Kliemann Neto } \\
\text { (2015) }\end{array}$ & $\begin{array}{l}\text { O objetivo do artigo é investigar os métodos colaborativos referentes à } \\
\text { coordenaçãa da SC e analisars suas caracteristicas e dificiuldades de } \\
\text { implementacãa.o Uma revisão sistemática apontou o o PFR como o método } \\
\text { colaborativo mais abordado, posteriormente, um estudo de caso } \\
\text { identificou dificuldades na implementação que colaboraram com o que } \\
\text { foi pesquisado na literatura. }\end{array}$ & & $\begin{array}{l}\text { A presente pesquisa demonstrou uma característica do CPFR voltada } \\
\text { puramente à coordenaçãa da SC, e não à otimização ou melhoria opera- } \\
\text { cional. Logo, uma sugestão para trabalhos futuros é a busca por méto- } \\
\text { dos colaborativos focados na otimização operacional da SC, que venha a } \\
\text { complementar essa ausência identificada no CPFR ou em métodos } \\
\text { similares. }\end{array}$ & \\
\hline $\begin{array}{l}\text { Nagashima et } \\
\text { al. (2015) }\end{array}$ & $\begin{array}{l}\text { Neste estudo, é apresentado uma avaliação empirica do impacto de uma } \\
\text { estratésia de colaboração adaptativa sobre precisão de previsão na } \\
\text { indústria eletrônica de consumo para explorar como implementar } \\
\text { efetivamente a colaboração, o modelo CPFR foi adotado para fornecedor } \\
\text { e varejista. Usando um conjunto de dados de } 169 \text { produtos vendidos por }\end{array}$ & & $\begin{array}{l}\text { O nível de especialização do varejista é um elemento chave na determi- } \\
\text { nação da intensidade de colaboração: a colaboracăão intensiva pode ser } \\
\text { mais benéfica com varejistas altamente especializados, desde o desen- } \\
\text { volvimento de produtos até as vendas, porque a colaboração exige } \\
\text { investimentos significativos a longo prazo, o que coincide com as estra- }\end{array}$ & $\begin{array}{l}\text { Pesquisas adicionais com bancos de dados estendidos são } \\
\text { necessárias para desenvolver mais descobertas que possam } \\
\text { ser de grande valor para auxiliar a gerentes na cadeia que } \\
\text { precisam tomar decisões estratégicas sobre como alocar } \\
\text { recursos limitados. }\end{array}$ \\
\hline
\end{tabular}




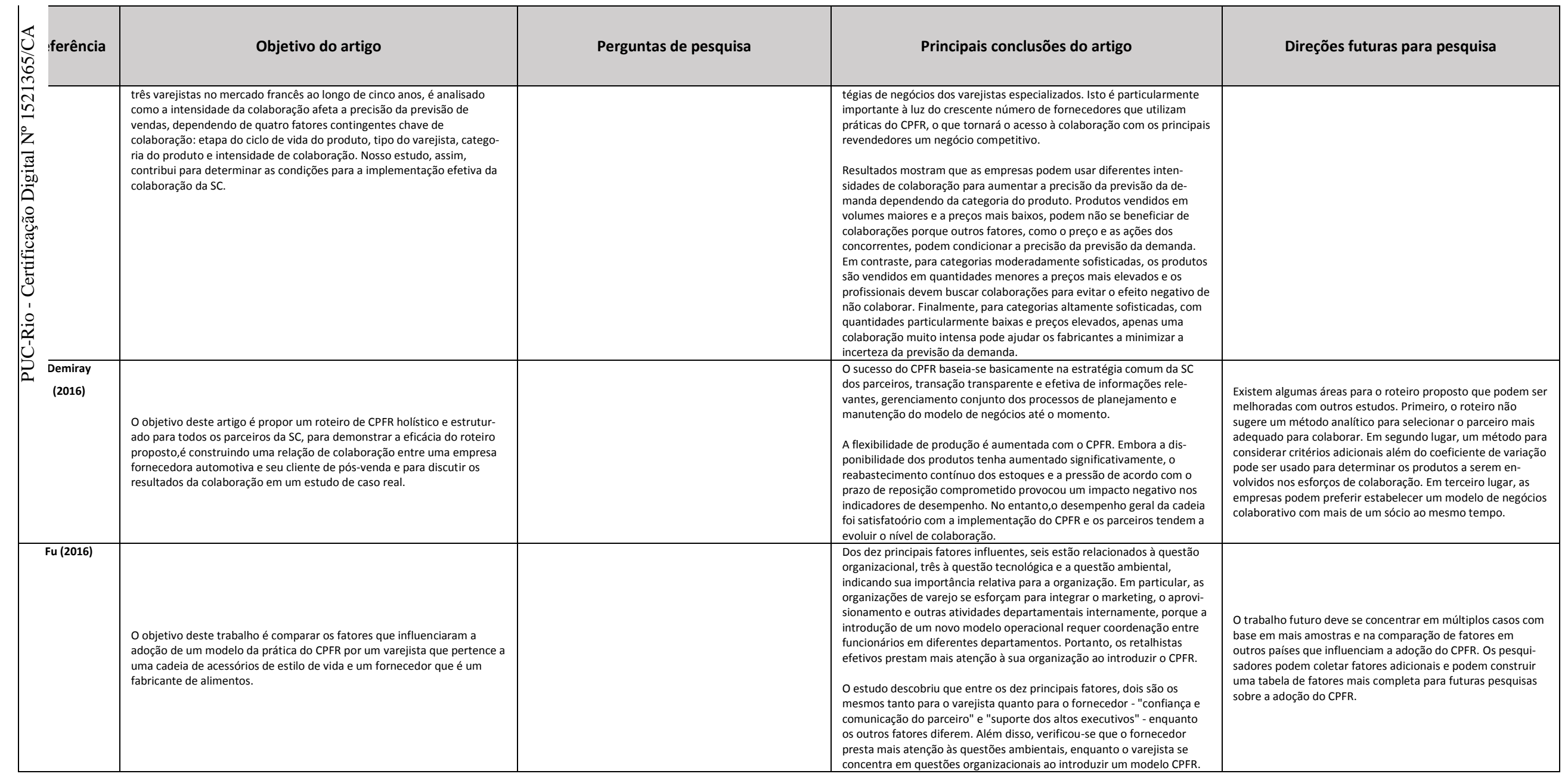

Fonte: o Autor 


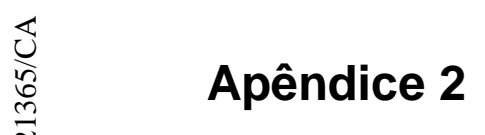

Tabela 10 - Principais barreiras e facilitadores em CPFR

\begin{tabular}{|c|c|c|c|c|c|c|c|c|c|c|c|c|c|}
\hline \multirow[t]{2}{*}{ Referência } & \multicolumn{4}{|c|}{ Principais barreiras } & \multicolumn{9}{|c|}{ Principais facilitadores } \\
\hline & $\begin{array}{l}\text { Dificuldade } \\
\text { de imple- } \\
\text { mentação }\end{array}$ & $\begin{array}{c}\text { Falta de inte- } \\
\text { gração interna }\end{array}$ & $\begin{array}{c}\text { Falta de } \\
\text { suporte de } \\
\text { gerencia- } \\
\text { mento }\end{array}$ & $\begin{array}{l}\text { Falta de } \\
\text { confiança }\end{array}$ & $\begin{array}{l}\text { Processo de } \\
\text { gestão de } \\
\text { mudanças }\end{array}$ & $\begin{array}{c}\text { Predisposição } \\
\text { cultural para } \\
\text { compartilhar } \\
\text { dados }\end{array}$ & $\begin{array}{c}\text { Estrutura } \\
\text { organizacional } \\
\text { flexível }\end{array}$ & $\begin{array}{l}\text { Estratégia de } \\
\text { TI inovadora }\end{array}$ & $\begin{array}{c}\text { Compartilhamento } \\
\text { de informaç̃es }\end{array}$ & Prontidão & $\begin{array}{c}\text { Apoio da alta } \\
\text { gerência }\end{array}$ & \begin{tabular}{|l|} 
Tecnologia \\
empregada
\end{tabular} & Confiança \\
\hline Stank et al. (1999) & & & & & & & & & & & & & $\mathrm{x}$ \\
\hline Barratt e Oliveira (2001) & & $\mathrm{x}$ & & $\mathrm{x}$ & & & & & & & & $\mathrm{x}$ & $\mathrm{x}$ \\
\hline McCarthy e Goilicic (2002) & & & & & & & & & $\mathrm{X}$ & & $\mathrm{x}$ & & \\
\hline Skjoett-Larsen et al. (2003) & & & & $\mathrm{x}$ & & & & & & $\mathrm{x}$ & & & $\mathrm{x}$ \\
\hline Chen et al. (2004) & $\mathrm{x}$ & & & & $\mathrm{x}$ & & & & & $\mathrm{x}$ & & & \\
\hline \multicolumn{14}{|l|}{ Danese et al. (2004) } \\
\hline \multicolumn{14}{|l|}{ Lin et al. (2004) } \\
\hline Wang et al. (2005) & & & & & $\mathrm{x}$ & & & & $\mathrm{x}$ & & & & $\mathrm{x}$ \\
\hline Chung e Leung (2005) & $\mathrm{x}$ & & & & $\mathrm{x}$ & & & & & & & & \\
\hline Kohli e Sherer (2006) & & & & & & & & & & & $\mathrm{X}$ & & \\
\hline \multicolumn{14}{|l|}{ Danese (2006) } \\
\hline Cassivi (2006) & & & & & & & & $\mathrm{x}$ & & & & & \\
\hline Danese (2007) & & & & & & & & & & & & & $\mathrm{x}$ \\
\hline Småros (2007) & & $\mathrm{x}$ & & $\mathrm{X}$ & & & & & & & & $\mathrm{x}$ & $\mathrm{x}$ \\
\hline
\end{tabular}




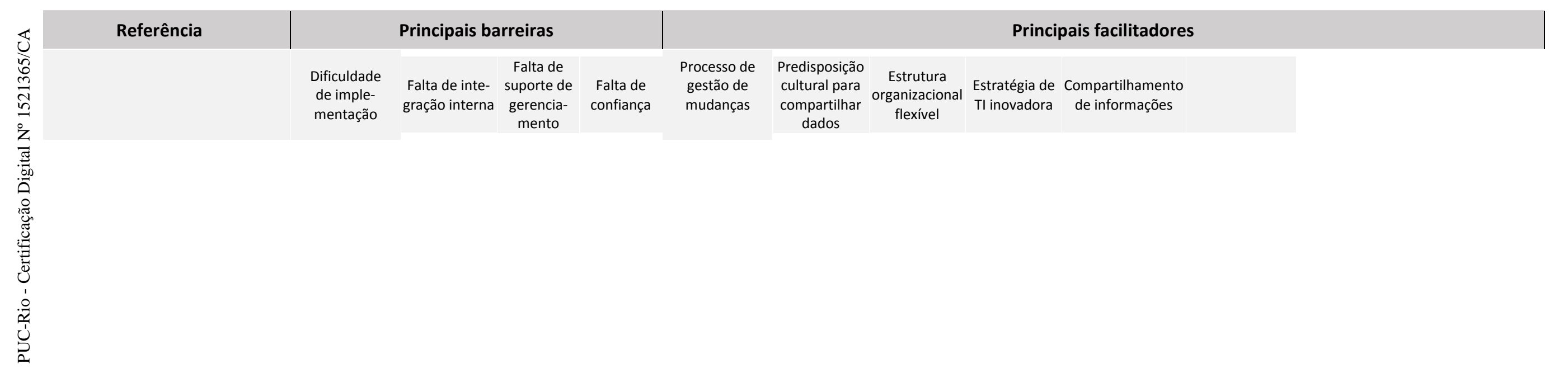




\begin{tabular}{|c|c|c|c|c|c|c|c|c|c|c|c|c|c|}
\hline \multirow[t]{2}{*}{ Referência } & \multicolumn{4}{|c|}{ Principais barreiras } & \multicolumn{9}{|c|}{ Principais facilitadores } \\
\hline & $\begin{array}{l}\text { Dificuldade } \\
\text { de imple- } \\
\text { mentação }\end{array}$ & $\begin{array}{c}\text { Falta de inte- } \\
\text { gração interna }\end{array}$ & $\begin{array}{c}\text { Falta de } \\
\text { suporte de } \\
\text { gerencia- } \\
\text { mento }\end{array}$ & $\begin{array}{l}\text { Falta de } \\
\text { confiança }\end{array}$ & $\begin{array}{l}\text { Processo de } \\
\text { gestão de } \\
\text { mudanças }\end{array}$ & $\begin{array}{c}\text { Predisposição } \\
\text { cultural para } \\
\text { compartilhar } \\
\text { dados }\end{array}$ & $\begin{array}{c}\text { Estrutura } \\
\text { organizacional } \\
\text { flexível }\end{array}$ & $\begin{array}{l}\text { Estratégia de } \\
\text { Tl inovadora }\end{array}$ & $\begin{array}{c}\text { Compartilhamento } \\
\text { de informações }\end{array}$ & Prontidão & $\begin{array}{c}\text { Apoio da alta } \\
\text { gerência }\end{array}$ & \begin{tabular}{|l} 
Tecnologia \\
empregada
\end{tabular} & Confiança \\
\hline Nagashima et al. (2015) & & & & & & & & & $\mathrm{x}$ & & & & \\
\hline Demiray (2016) & & & & & & & & & & & & & \\
\hline Fu (2016) & & $\mathrm{x}$ & $\mathrm{x}$ & $\mathrm{x}$ & $\mathrm{x}$ & $\mathrm{x}$ & $\mathrm{X}$ & $\mathrm{x}$ & $\mathrm{x}$ & $\mathrm{x}$ & $\mathrm{x}$ & $\mathrm{x}$ & $\mathrm{X}$ \\
\hline
\end{tabular}

Fonte: o Autor 